\title{
A Hybrid Computational Framework for Intelligent Inter- continent SARS-CoV-2 Sub-strains Characterization and Prediction
}

Moses E. Ekpenyong ( $\square$ mosesekpenyong@uniuyo.edu.ng )

University of Uyo

Mercy Edoho

University of Uyo

Udoinyang Inyang

University of Uyo

Faith-Michael Uzoka

Mount Royal University

Itemobong S. Ekaidem

University of Uyo

Anietie Moses

University of Uyo

Martins Emeje

National Institute for Pharmaceutical Research and Development (NIPRD)

Youtchou Tatfeng

Niger Delta University

Ifiok Udo

University of Uyo

EnoAbasi Anwana

University of Uyo

Oboso Etim

University of Uyo

Joseph Geoffery

University of Uyo

Emmanuel Dan

University of Uyo

\section{Research Article}

Keywords: Pathogenicity, Identical Genome Diversity, Pattern Correlates Analysis, Machine Learning Methods, Output Classification Targets Intelligent Prediction 
Posted Date: April 12th, 2021

DOI: https://doi.org/10.21203/rs.3.rs-88429/v3

License: (c) (i) This work is licensed under a Creative Commons Attribution 4.0 International License. Read Full License

Version of Record: A version of this preprint was published at Scientific Reports on July 15th, 2021. See the published version at https://doi.org/10.1038/s41598-021-93757-w. 


\title{
A Hybrid Computational Framework for Intelligent Inter-continent SARS- CoV-2 Sub-strains Characterization and Prediction
}

Moses E. Ekpenyong ${ }^{1,2^{*}}$, Mercy E. Edoho ${ }^{1}$, Udoinyang G. Inyang ${ }^{1}$, Faith-Michael Uzoka ${ }^{3}$, Itemobong S. Ekaidem ${ }^{4}$, Anietie E. Moses ${ }^{4}$, Martins Emeje ${ }^{5}$, Youtchou Tatfeng ${ }^{6}$, Ifiok J. Udo ${ }^{1}$, Enoabasi D. Anwana ${ }^{7}$, Oboso Etim ${ }^{8}$, Joseph I. Geoffery $^{1}$, Emmanuel A. Dan ${ }^{1}$.

${ }^{1}$ Department of Computer Science, University of Uyo, Nigeria

${ }^{2}$ Centre for Research and Development, university of Uyo, Nigeria

${ }^{3}$ Department of Mathematics and Computing, Mount Royal University, Canada

${ }^{4}$ College of Health Sciences, University of Uyo, Nigeria

${ }^{5}$ National Institute for Pharmaceutical Research and Development (NIPRD), Nigeria

${ }^{6}$ College of Health Sciences, Niger Delta University, Nigeria

${ }^{7}$ Department of Botany and Ecological Studies, University of Uyo, Nigeria

${ }^{8}$ Department of Biochemistry, University of Uyo, Nigeria

*Correspondence to: mosesekpenyong@uniuyo.edu.ng.

\begin{abstract}
Whereas accelerated attention beclouded early stages of the coronavirus spread, knowledge of actual pathogenicity and origin of possible sub-strains remained unclear. By harvesting the Global initiative on Sharing All Influenza Data (GISAID) database (https://www.gisaid.org/), between December 2019 and January 15, 2021, a total of 8864 human SARS-CoV-2 complete genome sequences processed by gender, across 6 continents ( 88 countries) of the world, Antarctica exempt, were analyzed. We hypothesized that data speaks for itself and can discern true and explainable patterns of the disease. Identical genome diversity and pattern correlates analysis performed using a hybrid of biotechnology and machine learning methods corroborate the emergence of inter- and intra- SARS-CoV-2 sub-strains. Interestingly, some viral sub-strain patterns progressively transformed into new sub-strain clusters indicating varying amino acid and strong nucleotide association derived from same lineage. A novel cognitive approach to knowledge mining from enriched genome datasets and output classification targets, helped intelligent prediction of emerging or new viral sub-strains. Classification results outsmarted state-of-the-art methods and sustained an increase in sub-strains within the various continents with nucleotide mutations dynamically varying between individuals in close association with the virus adaptability to its host/environment. They also offer explanations for the growing concerns and next wave(s) of the virus. Defuzzifying confusable pattern clusters for comparative performance with the proposed cognitive solution is a possible future research direction of this paper.
\end{abstract}

\section{Introduction}

The coronavirus disease pandemic had forced complete shutdown on all economies of the world $^{1,2}$. Since then, its breadth and depth have grown exponentially, causing disruptions that require a hybrid of computational approaches-to discover the changing nature of the virus as it transmits from country to country. While there exist claims that the virus has remained 
unchanged, a growing number of studies have reported the emergence of several sub-strains s $^{3,4}$. The rapid human to human transmission of the pathogenic SARS-CoV-2 to most parts of the world has exhibited differences in disease severity and fatality even within a demographic region of a country. This disparity has been attributed to factors such as gender, age, ethnicity, race, and co-morbidities. However, the dissimilarity in genome sequencing of early viral samples obtained from infected individuals in European, North American, Asian, and Oceanian regions disgorged several studies aimed at analyzing and understanding the evolutionary history and relationships among the different SARS-CoV-2 strains.

SARS-CoV-2 is a $\beta$-coronavirus-an enveloped non-segmented positive-sense RNA virus (subgenus-sarbecovirus, subfamily-Orthocoronavirinae) ${ }^{5}$, which proliferation begun in December 2019 in Wuhan China. It has since been confirmed that two strains of the new coronavirus (the L- and S-strains) are spreading around the world today ${ }^{6}$, and the fact that the Ltype is more prevalent suggests that it is "more aggressive" than the S-type. Greater proportion of research progress on SARS-CoV-2 has taken the biotechnology dimension ${ }^{7,8}$, specifically focusing on species characterization and variants analysis through features extraction. However, Artificial Intelligence (AI) and Machine Learning (ML) methods are expanding biotechnology capacity into the bioinformatics realm, through intelligent genome probing for precise viral classification. So far, AI/ML research on SARS-CoV-2 has permeated four key areas of medicine and healthcare, namely, screening and treatment ${ }^{9,10,11,12}$, contact tracing ${ }^{13}$, prediction and forecasting ${ }^{14,15}$, and drugs and vaccine discovery ${ }^{16,17,18}$.

To understand the origin and structure of SARS-CoV-2, a sequence of the viral genetic material is required. Sequencing viral genomes is performed to identify regions of similarity that may have consequences for functional, structural, or evolutionary associations ${ }^{19}$. Furthermore, it can reveal the possibility of future health risks and vaccine remedies. Phylogenetic tree and genomic tree (also referred to as hierarchical clustering) are common determinants for representing genetic diversity and evolutionary relationships of sequenced genomes. While phylogenetic tree reflects slow evolution within the genome (point mutations), hierarchical clustering describes major genetic re-arrangement events (insertions or deletions). Converting massive amount of complete genome sequences into meaningful biological representations has limited progress of discovering viral sub-strains and detailed transmission routes. Although numerous algorithms/tools have evolved to target specific gene sites/locations for "on-the-fly" online phylogeny representations, incomplete representation and clustering errors abound-as different genome sites undergo different evolutionary changes, resulting in disparate multidimensional patterns at different sites. Attempts at estimating phylogenies by comparing entire genomes have been made by focusing mainly on gene content and gene order comparisons. While early attempts concentrated on morphological characters with the premise that direct genes comparison makes more sense, modern attempts use sequences from homologous genes ${ }^{19}$ but are burdened by the fact that a gene's evolutionary history may differ from the evolutionary history of the organism, as some genes sufficiently conserved across the species of interest may escape detection. Alignment-free genome comparison methods are therefore becoming popular ${ }^{19,20}$ and have evolved to crash the heavy computational requirements of traditional alignment-based methods. Randhawa et al. ${ }^{21}$ for instance proposed an alignment-free approach based on ML, for fast, inexpensive, and taxonomic classification of complete COVID-19 genomes in real time.

Variants of SARS-CoV-2 have emerged with reported new peaks of infection. A variant is a strain when it has a different characteristic. Variants with few mutations belong to the same 
lineages. Lineages are important for showing how a virus spreads through communities or populations. Interestingly, the less virulent strains are disappearing while those showing significant mutant variations prevail. A few documented cases of the spread of the viral substrains are observed based on locations, as follows: In USA, 4 sub-strains and 11 top mutations were discovered from the analysis of 2754 complete SARS-CoV-2 genome sequences, where 2 out of 4 discovered sub-strains were potentially more infectious ${ }^{22}$. These sub0strains and 5 mutants were first detected in China, Singapore, and the United Kingdom ${ }^{23}$. In England, a substrain of replicative advantage was also discovered as variant of SARS-CoV-2, characterized by 9 spike protein mutations consisting of 3 deletions and 6 substitutions ${ }^{24}$. Some of these variants were prevalent in Netherlands, Switzerland, and France. In Southwestern Wisconsin, Southeastern Minnesota, Northeast Iowa, the sequencing of whole viral genomes of COVID-19 positive patients showed the spread of sub-strains to individuals in 13 cities from epicenters of the infection ${ }^{25}$. However, no viral sub-strain was observed in China ${ }^{26}$.

Vaccine types are also being circulated with several conspiracy theories and disbeliefs about the virus existence spreading across the globe. There is fear that emerging sub-strain variants may confer resistance to antibody neutralization, as evolving variants of concern are rapidly growing lineage to SARS-CoV-2 with high replicable mutants that may hinder the efficiency of existing vaccines and expand in response to the increasing after-infection or vaccine-induced seroprevalence ${ }^{24}$. Currently, most COVID-19 vaccines target the vital spike protein. Although mutations may reduce their efficacy, they do not obliterate their effects. Inactivated virus vaccines that target the whole virus have been developed in China, as the immune responses they induce target more than a single part of the spike protein. Inactivated vaccines target an even greater array of viral proteins, inducing several protective immune responses, which instils redundancy in the protective immune responses.

\section{Contribution to Knowledge}

Mining additional knowledge from clinical data would assist complete features extraction, missing information recovery, hidden patterns understanding, and facilitate output targets labeling - for intelligent genome characterization and prediction. Most biotechnology/bioinformatics tools are 'black boxes' and not open to contributions from the research community including reproducible research. Furthermore, extracted features are incomplete to aid meaningful knowledge integration. To support the growing field of medical- and bio- informatics, this paper adopted a novel approach to genome sequence mining. Transitions in nucleotide (dinucleotide) and changes in gene (mutation) information were exploited as input features or predictors, as these features have direct connection to the behavior of the virus. A hierarchical agglomerative clustering method was applied on the extracted features to detect optimal natural clusters for determining the evolutionary group of the various isolates, across countries. Using a self-organizing map (SOM), patterns of unique SARS-CoV-2 genome sequences including the reference genome, were discerned to visually establish which sub-strain group(s) the various genome samples or isolates belong. By decoupling the SOM map through correlation hunting, a cognitive map that associates similar isolate clusters was obtained. The generated patterns and isolate similarity information provided details for enriching the input dataset through a supervised labelling of the classification targets. Statistical analysis validated the variability degree of the SARS-CoV-2 isolates. This research has therefore made substantial contributions to knowledge, as it provides the following: 
(i) Rapid Open Source, Scalable and Replicable Algorithms-This research includes rapid prototype modules that permit community contributions. As opposed to most biotechnology and bioinformatic tools, useful intermediate results are produced - to provide further insights into the prevalence and transmission of COVID-19 and related pandemics. Our research is therefore replicable, as available algorithms and data can be exploited to reproduce and validate the research.

(ii) Realtime Contact Tracing of Undocumented Source of Infection-Tracing infectious disease routes for efficient documentation of infected cases is very crucial in emerging pandemic situations. Unsupervised genome pattern clustering and cognitive knowledge mining information obtained in this research can be used to explain the diversity of SARS-CoV-2, and for understanding which of the viral sub-strain(s) maintain(s) the reference genome pattern or is spreading within a particular country or been acquired from a different country.

(iii) Annotation-free DNA Sequences Processing-an unsupervised approach to mining raw DNA sequences that does not require detailed gene or genome annotation is adopted in this paper, to enable easy extraction of feature vectors.

(iv) Intelligent Genome Characterization-This research enables the accurate characterization of infected patients. By exploiting intelligent techniques, cognitive knowledge that uncovers hidden sub-strains interactions between nucleotide sequences is obtained

(v) Complete SARS-CoV-2 Isolates Processing by Gender-To engage meaningful research of SARS-CoV-2, characterization and prediction by gender is crucial. This resource, which is often missing in the literature was excavated from GSAID and made available in this paper. We present a metadata of the excavated SARS-CoV-2 genomes by gender. Our metadata permits intelligent mining of SARS-CoV-2, as ambiguities in annotation labels inherent in GISAID has been resolved in this paper. Input features and classification target labels of unique isolates based on SOM cluster analysis and cognitive knowledge mining is also available. These resources can be integrated into expert decision support systems for efficient contact tracing and global disease surveillance.

\section{Related Works}

Several studies have dwelled on the characterization of SARS-CoV-2 genome for tracing the evolution, strains, and diversity of the virus. In Tang et. $\mathrm{al}^{6}$, for instance, a population genetic analysis of 103 SARS-CoV-2 genomes was performed. Their analysis revealed two dominant types of SARS-CoV-2 namely the L type $(\sim 70 \%)$ and S type ( $\sim 30 \%)$. In another study, Stefanelli et al. ${ }^{27}$ investigated the phylogeny of 2 patients in Italy; a Chinese tourist from Wuhan and an Italian diagnosed, isolated, and hospitalized in January and February 2020. They found the Italian patient's strain to be different from the tourist's strain, as it clustered with strains from Germany and Mexico, while the Chinese tourist's strain was grouped with strains from Europe and Australia. Similarly, Somasundaram et. $\mathrm{al}^{28}$ systematically explored the phylogenetic and 
viral clade of 28 Indian isolates of SARS-CoV-2. A total of 449 complete genome samples from USA, Europe, China, East Asia, Oceania, Middle East (Kuwait and Saudi Arabia) and India were collected from Global initiative on Sharing All Influenza Data (GISAID:

https://www.gisaid.org/). A phylogenetic analysis by maximum likelihood was achieved using IQ tree. Out of the Indian isolates, 26 samples were equally distributed into 2 clusters (A and B). Cluster A consisted of mostly Oceania/Kuwait and 13 Indian samples, while cluster B contained Europe and some of Middle East/South Asian samples together with another 13 Indian samples. The remaining 2 Indian isolates which neither belonged to cluster A nor cluster B, were present in the cluster with mostly China and East-Asia samples. However, the use of small datasets and the lack of travel history rendered their findings inconclusive

Application of machine learning in the combat of COVID-19 has inspired new discoveries as well as improved methods based on experience of previous/related epidemic. Familiar areas of application center around medical imaging, disease tracing, epidemiology modeling and medicine (analysis of protein structure and drug discovery) and virulent nature of the virus. Whereas the processing of input data for informed decision support is necessary, the types of data exploited in the case of SARS-CoV-2 and related pandemic are mainly demographic and control or clinical data contributed by patients/volunteers around the world. Table 1 presents a summary of works carried out on ML/AI in related areas of application, indicating the objective, number of isolates collected and data source, methods, results/findings, and drawbacks. From the related works, we observe the following: (i) Most of the works explore hybrid tools that combine biotechnology and ML/AI methodologies, which have advanced precision in approach and solution to the pandemic. (ii) While $50 \%$ of the works rely on limited genomic evidence, others are mainly simulation studies. (iii) The fulcrum of most of the works revolve around characterization and forecasting with comparative analysis of SARS-CoV-2 evolution, and relationship between it and (other) related viruses. (iv) All the works are silent on the gender dimension. (v) None of these works to the best of our knowledge has engaged the possibility of SARS-CoV-2 sub-strains discovery.

The abundance of repetitive DNA in human genome assembly has introduced huge gap of multi-megabase heterochromatic regions that challenges standard mapping and assembly algorithms. Consequently, the composition of the sequence and potential functions of these regions have largely remained unexplored. Furthermore, existing genome tools cannot readily engage complete genome analysis to predict complex details and reveal hidden patterns, essential to offer explanations to the increased diversity of viral diseases. This work is therefore motivated by the existing gap between scientific knowledge and clinical application. Despite current advancement in state-of-the-art predictions, application of personalized genomics into clinical practice is yet to flourish. By identifying relevant genetic variants using experiential knowledge we provide inference of the genetic impact of the variants on functional genomic elements.

Table 1. Summary of ML/AI application of SARS-CoV-2 characterization and prediction

\begin{tabular}{|c|c|c|c|c|c|}
\hline Reference & Objective & $\begin{array}{l}\text { Number of isolate } \\
\text { and source }\end{array}$ & Method & Result/finding & Drawback \\
\hline $\begin{array}{l}\text { Randhawa } \\
\text { et al. }{ }^{21}\end{array}$ & $\begin{array}{l}\text { To combine } \\
\text { machine } \\
\text { learning-based } \\
\text { alignment-free } \\
\text { approach with } \\
\text { COVID-19 } \\
\text { genomic }\end{array}$ & $\begin{array}{l}5538 \text { unique viral } \\
\text { genome } \\
\text { sequences, } \\
\text { totaling } 61.8 \\
\text { million bp, } \\
\text { including } 29 \\
\text { COVID-19 virus }\end{array}$ & $\begin{array}{l}\text { Combined supervised } \\
\text { machine learning with } \\
\text { digital signal } \\
\text { processing (MLDSP), } \\
\text { augmented }\end{array}$ & $\begin{array}{l}\text { Results support the bat } \\
\text { origin and classified } \\
\text { the COVID-19 virus as } \\
\text { Sarbecovirus, within } \\
\text { Betacoronavirus. } \\
\text { Their method achieved } \\
\text { high classification }\end{array}$ & $\begin{array}{l}\text { Study only } \\
\text { compared the } \\
\text { relatedness of the } \\
\text { COVID-19 virus } \\
\text { sequences to the } \\
\text { known genera of } \\
\text { Coronaviridae }\end{array}$ \\
\hline
\end{tabular}




\begin{tabular}{|c|c|c|c|c|c|}
\hline Reference & Objective & $\begin{array}{l}\text { Number of isolate } \\
\text { and source }\end{array}$ & Method & Result/finding & Drawback \\
\hline & $\begin{array}{l}\text { signature for } \\
\text { real-time } \\
\text { taxonomic } \\
\text { predictions of } \\
\text { unclassified } \\
\text { new sequences } \\
\text { of COVID-19. }\end{array}$ & $\begin{array}{l}\text { sequences } \\
\text { available on } \\
\text { January } 27,2020 . \\
\text { Sequence data } \\
\text { came from NCBI, } \\
\text { Virus- } \\
\text { Host-DB, and } \\
\text { GISAID. }\end{array}$ & $\begin{array}{l}\text { by decision tree, for } \\
\text { genome analysis. } \\
\text { Spearman's rank } \\
\text { correlation was then } \\
\text { used for result } \\
\text { validation. }\end{array}$ & $\begin{array}{l}\text { accuracy for the } \\
\text { COVID-19 virus } \\
\text { sequences; and can } \\
\text { provide a reliable real- } \\
\text { time option for } \\
\text { taxonomic } \\
\text { classification. }\end{array}$ & $\begin{array}{l}\text { family and known } \\
\text { sub-genera of the } \\
\text { genus } \\
\text { Betacoronavirus. }\end{array}$ \\
\hline $\begin{array}{l}\text { Khanday et } \\
\text { al. } .^{29}\end{array}$ & $\begin{array}{l}\text { To classify } \\
\text { textual clinical } \\
\text { reports on } \\
\text { SARS-related } \\
\text { viruses using } \\
\text { classical and } \\
\text { ensemble } \\
\text { machine } \\
\text { learning } \\
\text { algorithms. }\end{array}$ & $\begin{array}{l}212 \text { patients' data } \\
\text { showing } \\
\text { symptoms of } \\
\text { coronavirus and } \\
\text { other viruses were } \\
\text { collected from } \\
\text { GitHub }^{30}\end{array}$ & $\begin{array}{l}\text { Feature engineering } \\
\text { was performed using } \\
\text { Term frequency/inverse } \\
\text { document frequency } \\
\text { (TF/IDF), Bag of words } \\
\text { (BOW) and report } \\
\text { length. These features } \\
\text { were then learned using } \\
\text { traditional and } \\
\text { ensemble machine } \\
\text { learning classifiers that } \\
\text { classified the text into } \\
\text { four different } \\
\text { categories: COVID, } \\
\text { SARS, ARDS and Both } \\
\text { (COVID, ARDS). }\end{array}$ & $\begin{array}{l}\text { Logistic regression and } \\
\text { Multinomial Naive } \\
\text { Bayes performed better } \\
\text { than other ML } \\
\text { algorithms. }\end{array}$ & $\begin{array}{l}\text { Study relied on } \\
\text { limited amount of } \\
\text { data. }\end{array}$ \\
\hline $\begin{array}{l}\text { Melin et } \\
\text { al. }^{31}\end{array}$ & $\begin{array}{l}\text { To analysis the } \\
\text { spatial } \\
\text { evolution of } \\
\text { coronavirus } \\
\text { pandemic } \\
\text { around the } \\
\text { world. }\end{array}$ & $\begin{array}{l}\text { Publicly available } \\
\text { datasets were } \\
\text { obtained from the } \\
\text { Humanitarian } \\
\text { Data Exchange } \\
(\text { HDX) } \\
\text { countries where } \\
\text { COVID-19 cases } \\
\text { had occurred } \\
\text { between January } \\
\text { 22, } 2020 \text { and May } \\
13,2020 \text {. }\end{array}$ & $\begin{array}{l}\text { The proposed method } \\
\text { used the Kohonen self- } \\
\text { organizing } \\
\text { maps to form clusters } \\
\text { of countries in the } \\
\text { world. The } \\
\text { classification was } \\
\text { achieved using } 4 \\
\text { classes of COVID-19 } \\
\text { severity } \\
\text { cases (Very High, } \\
\text { High, Medium, and } \\
\text { Low) }\end{array}$ & $\begin{array}{l}\text { Interesting conclusions } \\
\text { that may be helpful in } \\
\text { deciding the best } \\
\text { strategies in dealing } \\
\text { with the virus were } \\
\text { drawn from extensive } \\
\text { simulation. }\end{array}$ & $\begin{array}{l}\text { The research was } \\
\text { mainly a } \\
\text { simulation study. }\end{array}$ \\
\hline $\begin{array}{l}\text { Melin et } \\
a l^{33}\end{array}$ & $\begin{array}{l}\text { To develop a } \\
\text { multiple } \\
\text { ensemble neural } \\
\text { network model } \\
\text { with fuzzy } \\
\text { response } \\
\text { aggregation for } \\
\text { the COVID-19 } \\
\text { time series. }\end{array}$ & $\begin{array}{l}\text { Dataset from } \\
\text { confirmed } \\
\text { COVID-19 cases } \\
\text { and death cases, } \\
\text { which consists of } \\
12 \text { states in } \\
\text { Mexico and the } \\
\text { total data of the } \\
\text { country. }\end{array}$ & $\begin{array}{l}\text { A 3-module ensemble } \\
\text { architecture was } \\
\text { deployed, with each } \\
\text { ensemble having its } \\
\text { own fuzzy aggregator, } \\
\text { for final prediction of } \\
\text { the ensemble. }\end{array}$ & $\begin{array}{l}\text { The proposed multiple } \\
\text { ensemble neural } \\
\text { network models with } \\
\text { fuzzy response } \\
\text { integration closely } \\
\text { followed real data and } \\
\text { yielded precise } \\
\text { predictions in the } \\
\text { validation dataset. }\end{array}$ & $\begin{array}{l}\text { The research was } \\
\text { mainly a } \\
\text { simulation study. }\end{array}$ \\
\hline $\begin{array}{l}\text { Castillo } \\
\text { and Melin }\end{array}$ & $\begin{array}{l}\text { To forecast } \\
\text { confirmed } \\
\text { COVID-19 } \\
\text { cases and death } \\
\text { based on the } \\
\text { complexity of } \\
\text { their time series } \\
\text { using a hybrid }\end{array}$ & $\begin{array}{l}\text { Publicly available } \\
\text { datasets of } 10 \\
\text { countries were } \\
\text { obtained from the } \\
\text { Humanitarian } \\
\text { Data Exchange } \\
\text { (HDX) and data } \\
\text { from countries }\end{array}$ & $\begin{array}{l}\text { The datasets were used } \\
\text { to build the fuzzy } \\
\text { model with time series } \\
\text { in a fixed period. Then } \\
\text { the fuzzy fractal model } \\
\text { was tested by } \\
\text { forecasting other times }\end{array}$ & $\begin{array}{l}\text { Simulated forecast } \\
\text { results were close to } \\
\text { the real values, } \\
\text { confirming that the } \\
\text { fuzzy fractal approach } \\
\text { works well in time } \\
\text { series prediction. }\end{array}$ & $\begin{array}{l}\text { The research was } \\
\text { mainly a } \\
\text { simulation study } \\
\text { and limited to } \\
\text { COVID-19 cases. }\end{array}$ \\
\hline
\end{tabular}




\begin{tabular}{|c|c|c|c|c|c|}
\hline Reference & Objective & $\begin{array}{l}\text { Number of isolate } \\
\text { and source }\end{array}$ & Method & Result/finding & Drawback \\
\hline & $\begin{array}{l}\text { fuzzy-fractal } \\
\text { approach. }\end{array}$ & $\begin{array}{l}\text { where COVID-19 } \\
\text { cases have } \\
\text { occurred from } \\
\text { January 22, } 2020 \\
\text { to March 31, } \\
2020 .\end{array}$ & $\begin{array}{l}\text { series in window } \\
\text { periods of } 10 \text { days. }\end{array}$ & & \\
\hline $\begin{array}{l}\text { Lopez- } \\
\text { Rincon et } \\
\text { al. }{ }^{35}\end{array}$ & $\begin{array}{l}\text { Deep learning is } \\
\text { coupled with } \\
\text { explainable } \\
\text { artificial } \\
\text { intelligence } \\
\text { techniques to } \\
\text { discover } \\
\text { representative } \\
\text { genomic } \\
\text { sequences in } \\
\text { SARS-CoV-2. }\end{array}$ & $\begin{array}{l}\text { Data came from } \\
\text { National } \\
\text { Genomics Data } \\
\text { Center (NGDC) } \\
\text { repository, } \\
\text { National Center } \\
\text { for Biotechnology } \\
\text { Information } \\
\text { (NCBI) repository } \\
\text { and the Global } \\
\text { Initiative on } \\
\text { Sharing All } \\
\text { Influenza Data } \\
\text { (GISAID) } \\
\text { repository. }\end{array}$ & $\begin{array}{l}\text { Convolutional neural } \\
\text { network classifier was } \\
\text { first trained on } 553 \\
\text { sequences, separating } \\
\text { the genome of different } \\
\text { virus strains from the } \\
\text { Coronavirus family. } \\
\text { The network's behavior } \\
\text { was then analyzed, to } \\
\text { discover sequences } \\
\text { used to model SARS- } \\
\text { CoV-2 identification. } \\
\text { The sequences were } \\
\text { later validated on the } \\
\text { excavated samples. }\end{array}$ & $\begin{array}{l}12 \text { meaningful } 21-b p s \\
\text { sequences that best } \\
\text { characterized SARS- } \\
\text { CoV-2 were } \\
\text { discovered. For all the } \\
\text { analyzed data, these } \\
\text { sequences appeared } \\
\text { only in SARS-CoV-2 } \\
\text { samples and not in any } \\
\text { other viruses. }\end{array}$ & $\begin{array}{l}\text { The study } \\
\text { concentrated on } \\
\text { only limited set of } \\
\text { viral sequencing } \\
\text { data, targeting } \\
\text { specific genome } \\
\text { sites. }\end{array}$ \\
\hline $\begin{array}{l}\text { Lopez- } \\
\text { Rincon } e t \\
\text { al. }{ }^{36}\end{array}$ & $\begin{array}{l}\text { To propose an } \\
\text { assisted } \\
\text { detection test } \\
\text { that combines } \\
\text { molecular } \\
\text { testing with } \\
\text { deep learning. }\end{array}$ & $\begin{array}{l}\text { Dataset of } 553 \\
\text { complete genome } \\
\text { non-repeated } \\
\text { sequences that } \\
\text { vary from } 1260 \text { to } \\
31029 \text { bps in } \\
\text { length was } \\
\text { collected from } \\
2019 \text { Novel } \\
\text { Coronavirus } \\
\text { Resource } \\
\text { (2019nCoVR) } \\
\text { repository } 37\end{array}$ & $\begin{array}{l}\text { Deep convolutional } \\
\text { neural network using } \\
10 \text {-fold classification } \\
\text { was deployed for } \\
\text { automatic features } \\
\text { creation starting from } \\
\text { the genome sequence } \\
\text { of the virus }\end{array}$ & $\begin{array}{l}\text { The proposed approach } \\
\text { could correctly classify } \\
\text { SARS-CoV-2, } \\
\text { distinguishing it from } \\
\text { other coronavirus } \\
\text { strains, regardless of } \\
\text { missing information } \\
\text { and errors in } \\
\text { sequencing (noise). }\end{array}$ & $\begin{array}{l}\text { Their work } \\
\text { concentrated on } \\
\text { specific genome } \\
\text { sites. }\end{array}$ \\
\hline $\begin{array}{l}\text { Kaden et } \\
\text { al. }^{38}\end{array}$ & $\begin{array}{l}\text { To investigate } \\
\text { SARS-CoV-2 } \\
\text { virus sequences } \\
\text { based on } \\
\text { alignment-free } \\
\text { methods for } \\
\text { RNA sequence } \\
\text { comparison. }\end{array}$ & $\begin{array}{l}\text { Viral sequence } \\
\text { genomes from } \\
\text { GISAID-with } 156 \\
\text { genomes, and } \\
\text { NCBI and } \\
\text { GenBank-with } \\
892 \text { complete } \\
\text { genomes, by April } \\
19,2020 \text {, were } \\
\text { excavated. }\end{array}$ & $\begin{array}{l}\text { A Generalized Matrix } \\
\text { Learning Vector } \\
\text { Quantizer (GMLVQ) } \\
\text { model for labeled } \\
\text { dataset with virus type } \\
\text { information, obtained } \\
\text { by phylogenetic tree } \\
\text { analysis, was } \\
\text { performed using 10- } \\
\text { fold cross validation. } \\
\text { From classification } \\
\text { correlation matrix } \\
\text { delivered by GMLVQ } \\
\text { optimization, features } \\
\text { contributing decisively } \\
\text { to a typed separation } \\
\text { were determined. }\end{array}$ & $\begin{array}{l}\text { The GMLVQ approach } \\
\text { produced lower } \\
\text { complexity and } \\
\text { allowed easy out-of- } \\
\text { training generalization. }\end{array}$ & $\begin{array}{l}\text { Rejected sequences } \\
\text { could only allow } \\
\text { speculations about } \\
\text { new virus types } \\
\text { with respect to } \\
\text { nucleotide base } \\
\text { mutations in the } \\
\text { viral sequences. }\end{array}$ \\
\hline $\begin{array}{l}\text { Sawmya et } \\
\text { al. }^{39}\end{array}$ & $\begin{array}{l}\text { To track SARS- } \\
\text { CoV-2 } \\
\text { evolution }\end{array}$ & $\begin{array}{l}10179 \text { sequences } \\
\text { from } 67 \text { countries } \\
\text { were excavated }\end{array}$ & $\begin{array}{l}\text { ML and Deep learning } \\
\text { models were used to } \\
\text { identify the virulence }\end{array}$ & $\begin{array}{l}\text { As regards virulent } \\
\text { strain prediction, } \\
\text { LightGBM classifier }\end{array}$ & $\begin{array}{l}\text { Their work was } \\
\text { unable to explain } \\
\text { some strong }\end{array}$ \\
\hline
\end{tabular}




\begin{tabular}{|c|c|c|c|c|c|}
\hline Reference & Objective & $\begin{array}{l}\text { Number of isolate } \\
\text { and source }\end{array}$ & Method & Result/finding & Drawback \\
\hline & $\begin{array}{l}\text { among } \\
\text { countries using } \\
\text { phylogenetic } \\
\text { analysis and } \\
\text { perform deep } \\
\text { learning } \\
\text { classification } \\
\text { for } \\
\text { identification of } \\
\text { virulent strains. }\end{array}$ & $\begin{array}{l}\text { from GISAID as } \\
\text { of April 24, } 2020 .\end{array}$ & $\begin{array}{l}\text { of the strains. From the } \\
\text { classification pipeline, } \\
\text { important features were } \\
\text { identified as sites of } \\
\text { interest (SOI) in the } \\
\text { virus strains for further } \\
\text { analysis. }\end{array}$ & $\begin{array}{l}\text { was superior to deep } \\
\text { learning classifiers. As } \\
\text { regards mutation } \\
\text { prediction, CNN- } \\
\text { LSTM and CNN- } \\
\text { bidirectional LSTM } \\
\text { gave near similar } \\
\text { performance for } \\
\text { different SoI of the } \\
\text { genome. }\end{array}$ & $\begin{array}{l}\text { relationships } \\
\text { between countries, } \\
\text { as inferred by the } \\
\text { phylogenetic tree. }\end{array}$ \\
\hline $\begin{array}{l}\text { Sun and } \\
\text { Wang }\end{array}$ & $\begin{array}{l}\text { To develop } \\
\text { mathematical } \\
\text { model for } \\
\text { characterizing } \\
\text { imported and } \\
\text { asymptomatic } \\
\text { patients. }\end{array}$ & $\begin{array}{l}\text { Study relied on } \\
\text { demographic data } \\
\text { on COVID-19 } \\
\text { epidemic in } \\
\text { Heilongjiang } \\
\text { province from } \\
\text { January 23 to } \\
\text { March 25, 2020. }\end{array}$ & $\begin{array}{l}\text { An ordinary differential } \\
\text { equation model was } \\
\text { trained to fit the } \\
\text { epidemic data and the } \\
\text { simulation extended to } \\
\text { characterize an } \\
\text { infected/imported case } \\
\text { as well as } \\
\text { asymptomatic patients. }\end{array}$ & $\begin{array}{l}\text { Imported case was } \\
\text { responsible for the } \\
\text { newly confirmed } \\
\text { COVID-19 infections } \\
\text { in the province. } \\
\text { Stochastic simulations } \\
\text { showed significant } \\
\text { increase in local } \\
\text { contacts and outbreak } \\
\text { of COVID-19. } \\
\text { Reported number of } \\
\text { asymptomatic patients } \\
\text { was markedly lower } \\
\text { than the model } \\
\text { predictions, implying } \\
\text { large unidentified } \\
\text { asymptomatic pool. }\end{array}$ & $\begin{array}{l}\text { The research was } \\
\text { mainly a } \\
\text { simulation study } \\
\text { and limited to } \\
\text { COVID-19 cases. }\end{array}$ \\
\hline $\begin{array}{l}\text { Dey and } \\
\text { Mukhopad } \\
\text { hyay }^{41}\end{array}$ & $\begin{array}{l}\text { To build } \\
\text { machine } \\
\text { learning models } \\
\text { that predict } \\
\text { protein-protein } \\
\text { interactions } \\
\text { (PPIs) between } \\
\text { the virus and } \\
\text { human proteins. }\end{array}$ & $\begin{array}{l}\text { SARS-CoV-2 } \\
\text { human PPI } \\
\text { database }{ }^{42} \\
\text { containing } 332 \\
\text { unique } \\
\text { interactions } \\
\text { between } 332 \\
\text { human proteins } \\
\text { and four structural } \\
\text { and as well as } 20 \\
\text { accessory } \\
\text { coronavirus } \\
\text { proteins. }\end{array}$ & $\begin{array}{l}\text { Classification models } \\
\text { were prepared based on } \\
\text { different sequence- } \\
\text { based features of } \\
\text { human proteins like } \\
\text { amino acid } \\
\text { composition, pseudo } \\
\text { amino acid } \\
\text { composition, and } \\
\text { conjoint triad. }\end{array}$ & $\begin{array}{l}\text { The ensemble voting } \\
\text { classifier using } \\
\text { SVM }^{\text {Radial }} \\
\text { SVM }^{\text {Polynomial }} \text {, and } \\
\text { Random Forest } \\
\text { technique, gave greater } \\
\text { accuracy, precision, } \\
\text { specificity, recall, and } \\
\text { F1 score compared to } \\
\text { other models. }\end{array}$ & $\begin{array}{l}\text { Their classifier } \\
\text { yielded } 70 \% \\
\text { accuracy due to } \\
\text { limited } \\
\text { experimental data. }\end{array}$ \\
\hline $\begin{array}{l}\text { Dlamini et } \\
\text { al. }^{43}\end{array}$ & $\begin{array}{l}\text { To analyze } \\
\text { intrinsic } \\
\text { dinucleotide } \\
\text { genomic } \\
\text { signatures for } \\
\text { whole genome } \\
\text { sequence data } \\
\text { of } 8 \text { pathogenic } \\
\text { species, } \\
\text { including } \\
\text { SARS-CoV-2. }\end{array}$ & $\begin{array}{l}\text { About } 33000 \\
\text { Fully assembled, } \\
\text { whole genome } \\
\text { sequence in } \\
\text { FASTA format } \\
\text { were retrieved } \\
\text { from GISAID, for } \\
8 \text { pathogenic } \\
\text { species. }\end{array}$ & $\begin{array}{l}\text { The genome sequences } \\
\text { were transformed into } \\
\text { dinucleotide relative } \\
\text { frequencies and } \\
\text { classified using } \\
\text { extreme gradient } \\
\text { boosting (XGBoost) } \\
\text { model. }\end{array}$ & $\begin{array}{l}\text { Their result was able to } \\
\text { discriminate between } \\
\text { distantly related } \\
\text { species such as viruses } \\
\text { and bacteria, closely } \\
\text { related species such as } \\
\text { SARS-CoV-2 and } \\
\text { MERS-CoV, as well as } \\
\text { samples of the same } \\
\text { species that originate } \\
\text { from different regions. }\end{array}$ & $\begin{array}{l}\text { Classes with small } \\
\text { sample size (e.g., } \\
\text { Africa), yielded } \\
\text { high } \\
\text { misclassification } \\
\text { rate. }\end{array}$ \\
\hline
\end{tabular}




\section{Results}

The general workflow describing the proposed hybrid computational framework is presented in Fig. 1, and the sequence of steps implementing the workflow is given on Supplementary Table $\mathrm{S} 1$. Each genome sequence was mapped or transformed into an equivalent genomic signal (a discrete numeric sequence) using the following encoding of the individual nucleotide (i.e., $\mathrm{A}=1$; $\mathrm{C}=2 ; \mathrm{G}=3 ; \mathrm{T}=4$ ). As base input, we maintained nucleotide pairs above $29000 \mathrm{bp}$ (the input vector), indicating approximate (maximum) length of DNA sequences of the raw SARS-CoV-2 genome. Next, all repeated sequences were removed using a Microsoft Excel macro that deletes duplicate columns. The Excel macro implementing this process is found on Supplementary Table S2. A similarity threshold of 0.90 was then imposed to further trim near similar genomes, resulting in unique sequences of isolates distributed per continent containing 88 countries (male $=71$ countries; female $=66$ countries), by gender (SupplData8.xlsx), as follows (Africa: $\mathrm{M}=371, \mathrm{~F}=477$; Asia: $\mathrm{M}=514, \mathrm{~F}=510$; Europe: $\mathrm{M}=311$, F=283; North America: $\mathrm{M}=294, \mathrm{~F}=199$; South America: $M=185, F=153$; Oceania: $M=9, F=6$ ). A vector representation for pairwise Euclidean distance computation among the vectors in the form of a distance matrix was achieved using a SOM program developed in MATLAB. As the distance matrix is extremely highdimensional, suitable representative sequences of the isolate clusters, decoupled into a cognitive map for efficient labeling the classification targets were obtained. A k-fold cross-validation was finally performed by dividing the data into $\mathrm{k}$ parts. At each iteration $\mathrm{i}$, the ith fold was used for testing, while the other folds were used for training. 


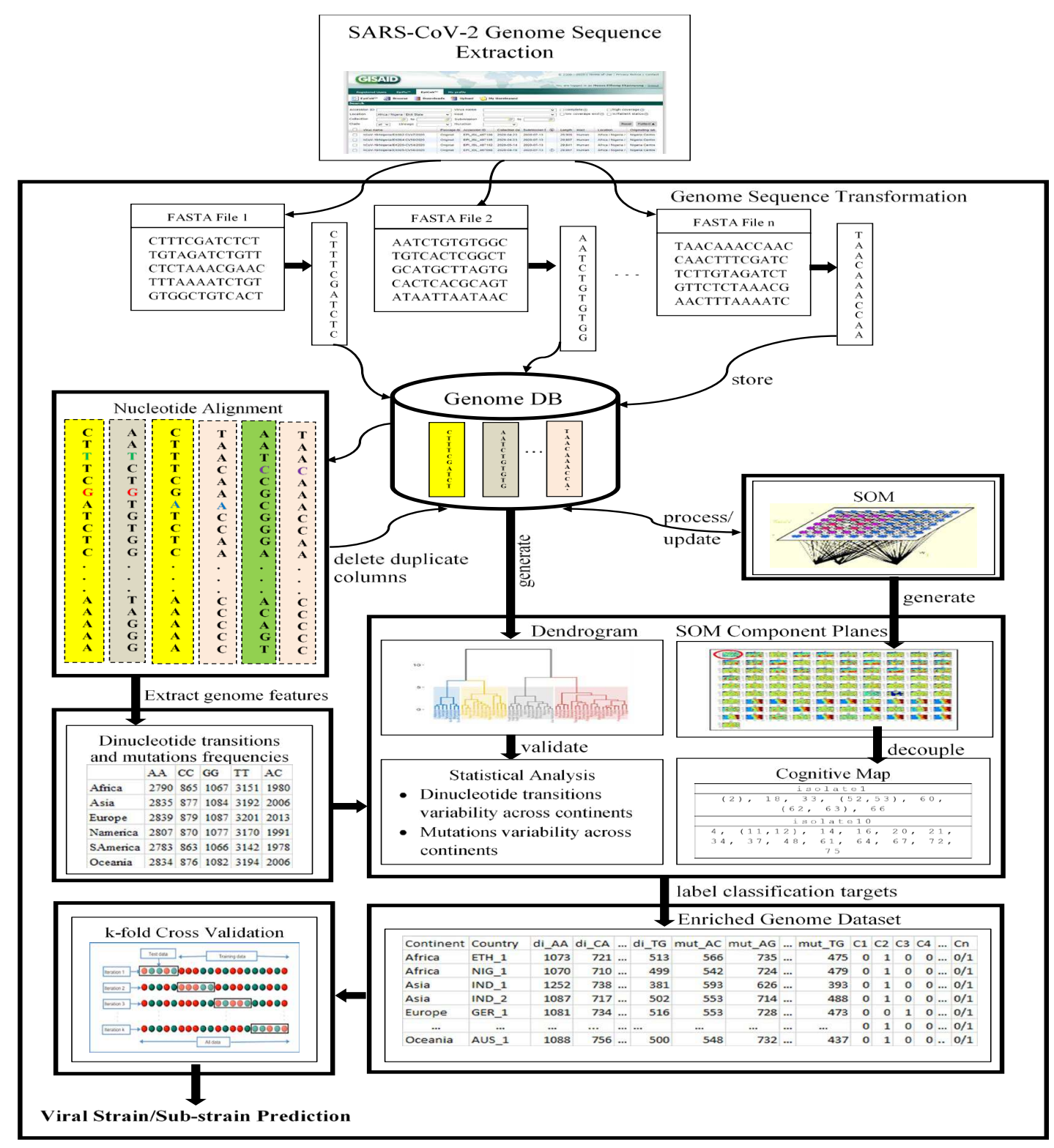

Fig. 1. Workflow describing the proposed hybrid approach. The workflow begins with the excavation of FASTA files of human SARS-CoV-2 genome sequences from GISAID. These files were stripped and processed into a genome database (DB) as multiple columns of nucleotide sequence. AI/ML techniques were then applied to extract knowledge from the genome datasets as follows: Using ML techniques, compute dis(similarities) scores between the various pairs of genome sequences and obtain a genomic tree of highly dis(similar) isolates grouped in the form of a dendrogram/phylogenetic tree. Determine the optimal number of natural clusters-to provide additional knowledge for supervised learning. Separate the viral sub-strains using SOM component planes-for possible transmission pathway/pattern visualization. Perform nucleotide alignment of the entire genome sequences (owing to varying sequence lengths of the different genome isolates, a cutoff at the last nucleotide of the genome isolate or the reference genome serves as the maximum pair for comparison), remove duplicate columns while imposing a similarity threshold-to yield unique genome sequences. Extract genome features by computing dinucleotide transitions and mutation frequencies. Generate cognitive map-for intelligent sub-strains prediction. Label classification targets of extracted features using derived SOM clusters and cognitive map. Learn and predict new/emerging sub-strains using ANN with k-fold validation method. 


\section{Base Variant Analysis}

Dinucleotide transitions and nucleotide mutations were computed for male and female isolates and averaged across the various continents namely Africa (Data S1: SupplData1.xlsx), Asia (Data S2: SupplData2.xlsx), Europe (Data S3: SupplData3.xlsx), North America (Data S4: SupplData4.xlsx), South America (Data S5: SupplData5.xlsx), and Oceania (Data S6: SupplData6.xslx). We discuss in this section an analysis of the average base transitions and mutations, and how they influence the overall behavior of the datasets.

Dinucleotide Transitions: Average dinucleotide transitions of SARS-CoV-2 genomes computed across various continents are presented in Fig. 2. These transitions are represented as quadrilaterals dissected along its diagonals. Wang et al. ${ }^{44}$ found that the SARS-CoV-2 reference genome has $29.94 \%$ of A, $32.08 \%$ of T, $19.61 \%$ of G and $18.37 \%$ of C. Hence, the expected dinucleotide transitions proportion is the product of the two nucleotide bases. For instance, the CG dinucleotide in the viral genome is $3.60 \%$ (i.e., $19.61 \% \times 18.37 \%$ ). Therefore, we arrive at the following computations for the respective dinucleotides/features in this study: AA $=8.96 \%$; $\mathrm{CC}=3.37 \%$; $\mathrm{GG}=3.84 \%$; $\mathrm{TT}=10.29 \% ; \mathrm{AC}=5.50 \% ; \mathrm{AG}=5.87 \%$; $\mathrm{AT}=9.60 \% ; \mathrm{CG}=3.60 \%$; $\mathrm{CT}=5.87 \%$; $\mathrm{GT}=6.29 \% ; \mathrm{TG}=6.29 \%$; $\mathrm{TC}=5.87 \% ; \mathrm{TA}=9.60 \% ; \mathrm{GC}=3.60 \% ; \mathrm{GA}=5.87 \%$; and $\mathrm{CA}=5.50 \%$. Comparison of our results therefore corroborates Wang et al. ${ }^{44}$ on CG dinucleotide reduction of SARS-CoV-2, as the CG transitions for both male (M) and female (F) isolates across the various continents present lowest dinucleotide transitions compared to the rest of the transitions. Furthermore, slightly different variations exist between the male and female transitions, which may not be unconnected with genome sequencing errors and the presence of new viral sub-strain(s).

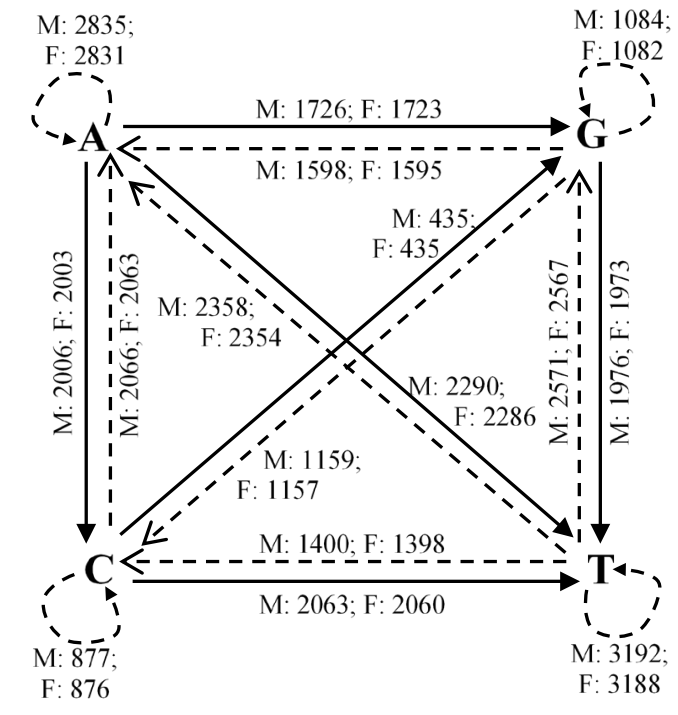

(a) African isolates

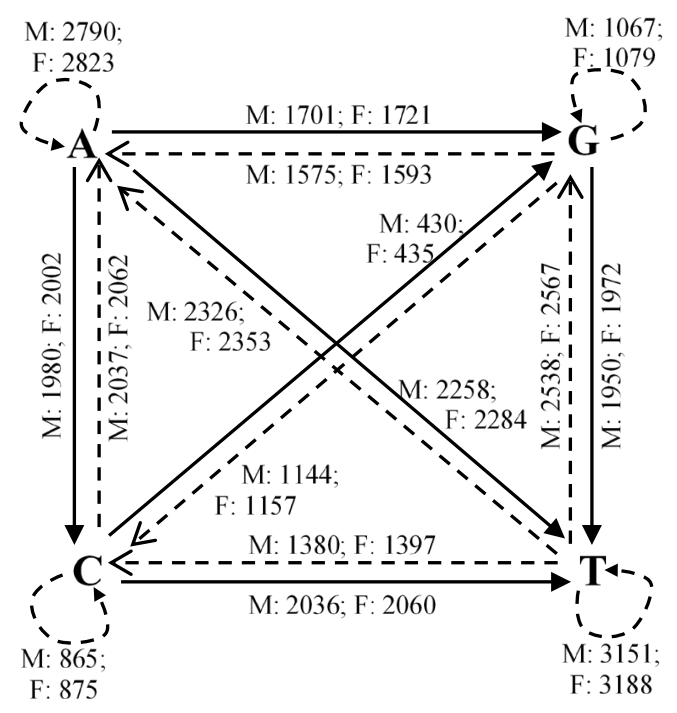

(b) Asian isolates 


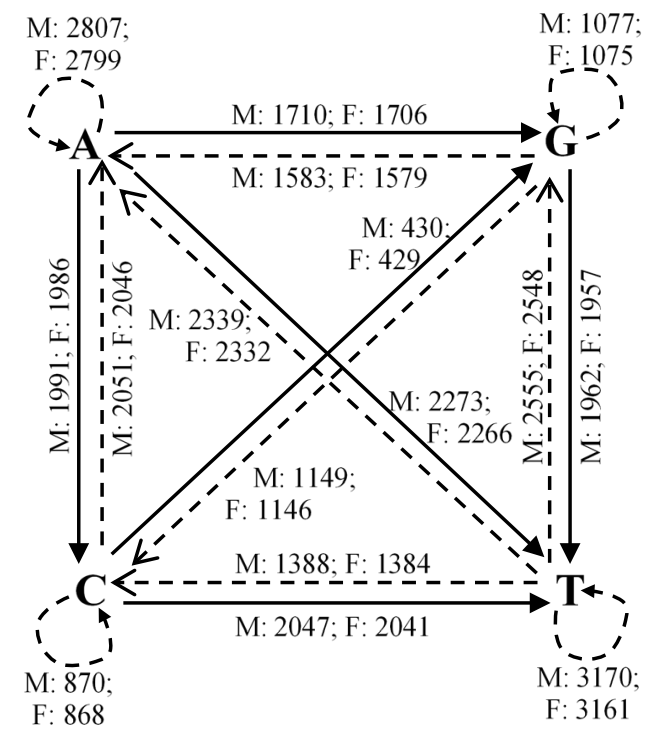

(c) European isolates

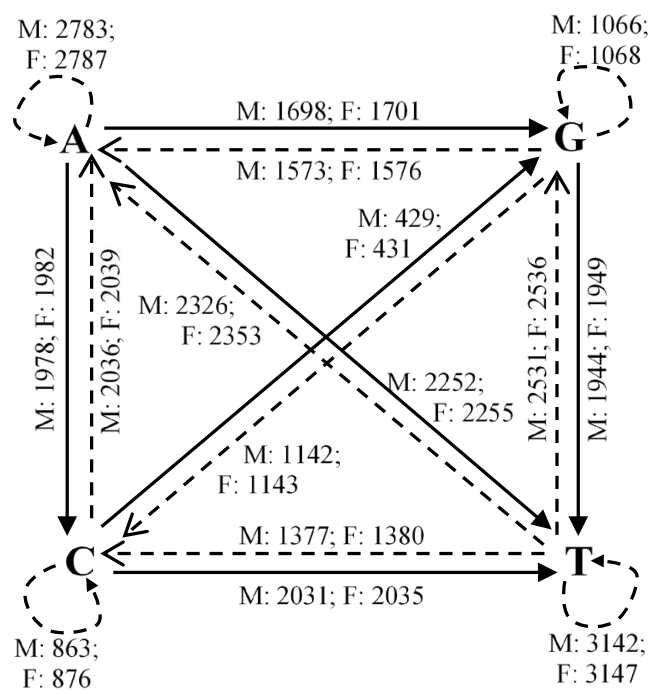

(e) South American isolates

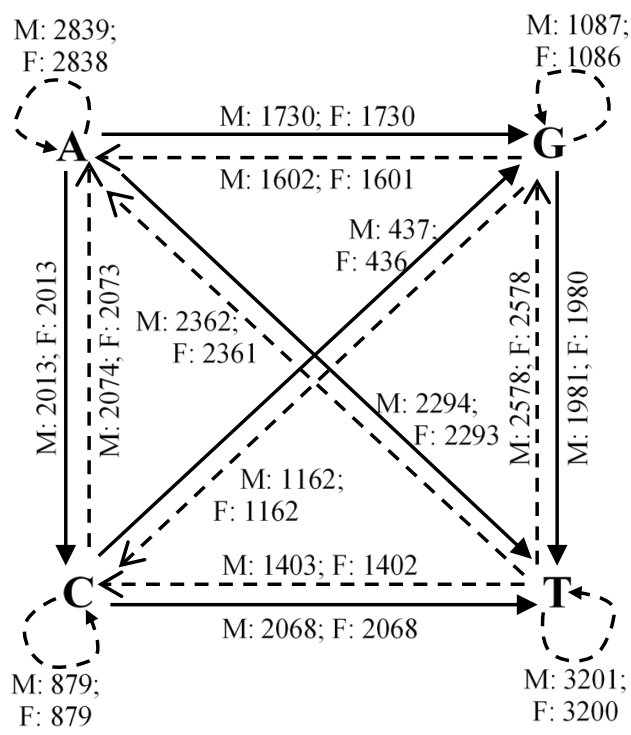

(d) North American isolates

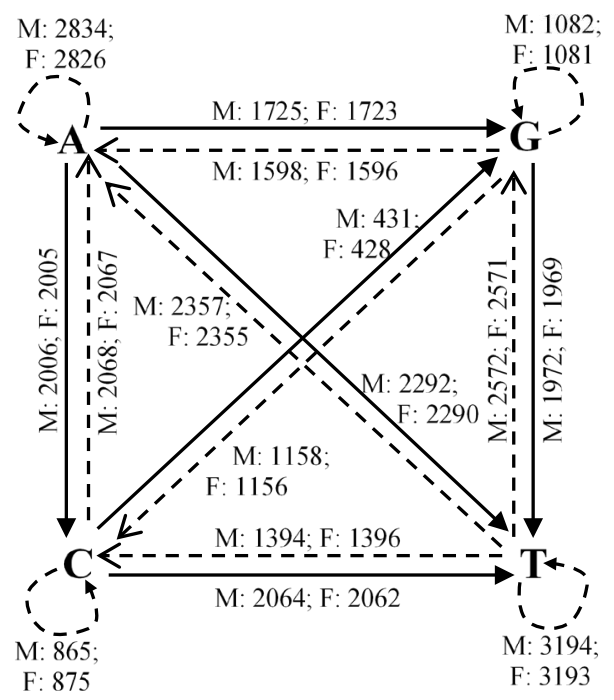

(f) Oceanian isolates

Fig. 2. Base pair transitions in SARS-CoV-2 genomes for male and female isolates. Thick arrows indicate transition, while dotted arrows represent transversion. Looped (dotted) arrows represent same base transition. Inscriptions on/near the arrows represent transition/transversion frequencies for male and female isolates.

Average dinucleotide transitions variant: Observed transitions variants between male and female isolates $(\mathrm{M}-\mathrm{F})$ computed from Fig 2, across the various continents are shown in Table 2. Positive numbers indicate male frequency dominance while negative numbers indicate female frequency dominance. Table 2 reveals that female isolates from Africa greatly dominated the dinucleotide transitions space compared to male isolates. This wide difference may not be unconnected with sequencing errors observed in the raw genomes for African isolates. Other continents however show negligible variations. 
Table 2. Observed average dinucleotide transitions variants between male and female isolates

\begin{tabular}{lrrrrrrrrrrrrrrrr}
\hline Continent & AA & CC & GG & TT & AC & AG & AT & CG & CT & GT & TG & TC & TA & GC & GA & CA \\
\hline Africa & -32 & -10 & -12 & -38 & -23 & -20 & -26 & -5 & -24 & -23 & -29 & -17 & -27 & -13 & -18 & -24 \\
Asia & 4 & 1 & 2 & 4 & 2 & 3 & 3 & 0 & 3 & 3 & 4 & 2 & 4 & 2 & 2 & 2 \\
Europe & 2 & 0 & 0 & 1 & 1 & 1 & 1 & 0 & 1 & 1 & 1 & 1 & 1 & 0 & 0 & 1 \\
North America & 9 & 2 & 2 & 10 & 5 & 5 & 7 & 1 & 6 & 5 & 6 & 4 & 7 & 3 & 5 & 5 \\
South America & -3 & -2 & -2 & -5 & -4 & -3 & -3 & -1 & -4 & -5 & -5 & -3 & -4 & -2 & -3 & -3 \\
Oceania & 7 & 1 & 2 & 1 & 1 & 2 & 2 & 3 & 2 & 3 & 1 & 4 & 2 & 2 & 1 & 1 \\
\hline
\end{tabular}

Nucleotide Mutations: Mutations in base pairs are important for understanding the pathogenicity of SARS-CoV-2. These computations were compiled after direct pairwise comparisons with the reference genome, averaged across the various continents, to produce Fig. 3. As expected, changes in base pairs were observed after pairwise comparisons. Also, genome sequences with very negligeable changes or (no significant mutations) from the reference genome were noticed across the various continents for male and female isolates (see Table 3). Overall, total insignificant mutants of 587, representing $14.98 \%$ of the total number of isolates was observed for male patients, while female patients showed 258 insignificant mutants, representing $9.06 \%$ of the total number of isolates.

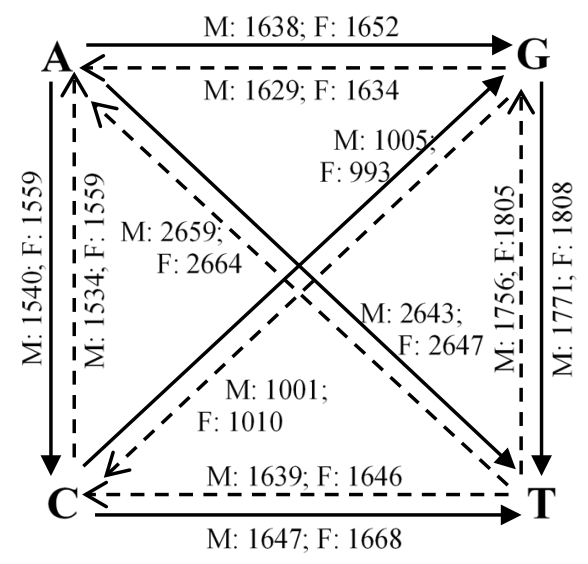

(a) Africa

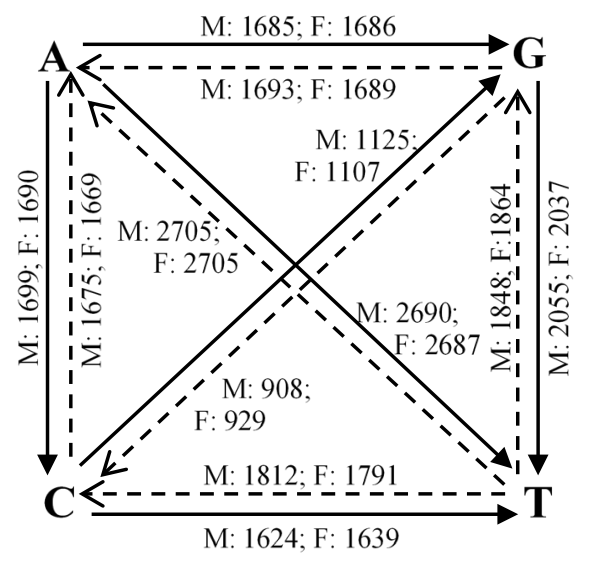

(c) Europe

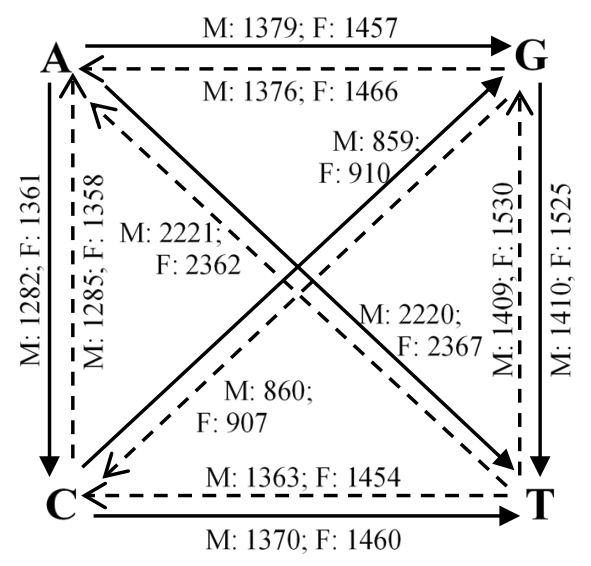

(b) Asia

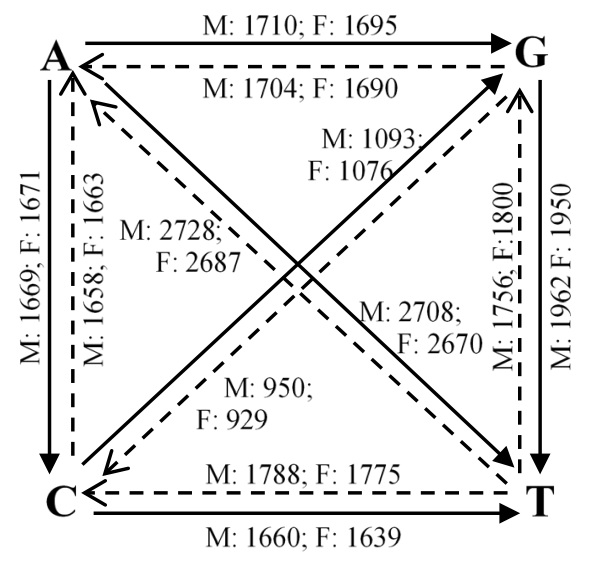

(d) North America 


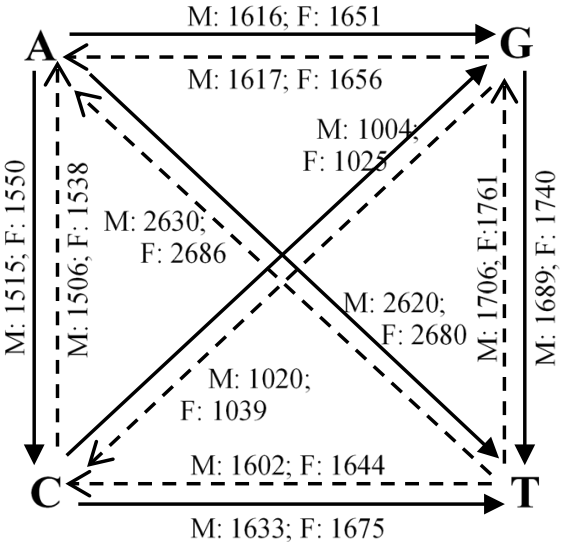

(e) South America

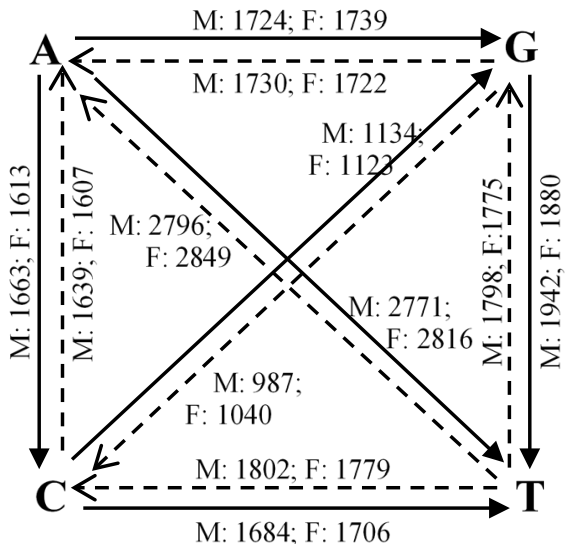

(f) Oceania

Fig. 3. Base pair changes in SARS-CoV-2 genomes for male and female isolates. Thick arrows indicate transitions, while dotted arrows represent transversions. Inscriptions on/near the arrows represent transition frequencies for male and female isolates.

Table 3. Isolates with insignificant mutants across continents

\begin{tabular}{|c|c|c|c|c|c|c|c|}
\hline \multirow[b]{2}{*}{ Continent } & \multirow[b]{2}{*}{ Country } & \multicolumn{3}{|c|}{ Male } & \multicolumn{3}{|c|}{ Female } \\
\hline & & $\begin{array}{l}\text { No. of } \\
\text { insignificant } \\
\text { mutants }\end{array}$ & $\begin{array}{l}\text { Total } \\
\text { isolates }\end{array}$ & $\%$ & $\begin{array}{l}\text { No. of } \\
\text { insignificant } \\
\text { mutants }\end{array}$ & $\begin{array}{l}\text { Total } \\
\text { isolates }\end{array}$ & $\%$ \\
\hline \multirow{2}{*}{ Africa } & South Africa & 27 & 503 & 5.37 & 56 & 1004 & 5.58 \\
\hline & Tunisia & 4 & 19 & 2.11 & 0 & 0 & - \\
\hline \multirow{14}{*}{ Asia } & Singapore & 10 & 487 & 2.05 & 6 & 53 & 1.13 \\
\hline & China & 47 & 189 & 24.86 & 47 & 131 & 35.88 \\
\hline & Sri Lanka & 2 & 23 & 8.70 & 0 & 0 & - \\
\hline & Bangladesh & 8 & 22 & 36.36 & 0 & 0 & - \\
\hline & India & 5 & 1041 & 0.48 & 2 & 557 & 0.36 \\
\hline & Kazakstan & 5 & 14 & 35.71 & 9 & 10 & 90 \\
\hline & Indonesia & 10 & 64 & 15.63 & 4 & 27 & 14.81 \\
\hline & Turkey & 2 & 80 & 2.50 & 0 & 0 & - \\
\hline & Taiwan & 24 & 34 & 70.59 & 20 & 30 & 66.67 \\
\hline & Philippines & 1 & 6 & 16.67 & 0 & 0 & - \\
\hline & Israel & - & - & - & 1 & 15 & 6.67 \\
\hline & Saudi Arabia & 384 & 408 & 94.12 & 77 & 91 & 86.83 \\
\hline & Oman & 1 & 81 & 1.23 & 0 & 0 & - \\
\hline & $\begin{array}{l}\text { United Arab } \\
\text { Emirates }\end{array}$ & 22 & 73 & 30.14 & 9 & 38 & 23.68 \\
\hline \multirow{5}{*}{ Europe } & Romania & 1 & 18 & 5.56 & 0 & 0 & - \\
\hline & Spain & 3 & 148 & 2.03 & 4 & 117 & 3.42 \\
\hline & Italy & 6 & 309 & 1.94 & 5 & 253 & 1.98 \\
\hline & Russia & 1 & 42 & 2.38 & 2 & 83 & 2.41 \\
\hline & France & 1 & 78 & 1.28 & 1 & 53 & 1.89 \\
\hline \multirow[b]{2}{*}{ North America } & Mexico & 2 & 66 & 3.30 & 2 & 44 & 4.55 \\
\hline & $\begin{array}{l}\text { Dominican } \\
\text { Republic }\end{array}$ & - & - & - & 1 & 5 & 0.20 \\
\hline \multirow{4}{*}{ South America } & Chile & 1 & 1 & 100 & 0 & 0 & - \\
\hline & Colombia & 3 & 133 & 2.26 & 2 & 77 & 2.60 \\
\hline & Ecuador & 4 & 21 & 19.07 & 0 & 0 & - \\
\hline & Brazil & 13 & 58 & 22.41 & 10 & 261 & 3.83 \\
\hline
\end{tabular}




\begin{tabular}{|c|c|c|c|c|c|c|c|}
\hline \multirow{3}{*}{ Continent } & \multirow[b]{2}{*}{ Country } & \multicolumn{3}{|c|}{ Male } & \multicolumn{3}{|c|}{ Female } \\
\hline & & $\begin{array}{l}\text { No. of } \\
\text { insignificant } \\
\text { mutants }\end{array}$ & $\begin{array}{l}\text { Total } \\
\text { isolates }\end{array}$ & $\%$ & $\begin{array}{l}\text { No. of } \\
\text { insignificant } \\
\text { mutants }\end{array}$ & $\begin{array}{l}\text { Total } \\
\text { isolates }\end{array}$ & $\%$ \\
\hline & Total: & 587 & 3918 & 14.98 & 258 & 2849 & 9.06 \\
\hline
\end{tabular}

Average nucleotide mutations variant: In an analysis of SARS-CoV-2 mutations in the United States, CT mutant variants were found to have strong gender dependence ${ }^{22}$. Observed mutation variants between male and female isolates $(\mathrm{M}-\mathrm{F})$ computed from Fig 3, across the various continents are shown in Table 4. Positive numbers indicate male frequency dominance while negative numbers indicate female frequency dominance. Table 4 reveals that female isolates from Asia greatly dominate the nucleotide mutations compared to male isolates. This trend is consistently followed by female isolates from South America with dominant transitions compared to male isolates. However, other mutation statistics have mixed dominant values with varying degree of dominance. The result indicates that nucleotide mutations (not only the CT mutant) dynamically vary between individuals and are more associated with the virus adaptability to its host/environment.

Table 4. Observed mutant variants between male and female isolates

\begin{tabular}{lrrrrrrrrrrrr}
\hline Continent & AC & AG & AT & CG & CT & GT & TG & TC & TA & GC & GA & CA \\
\hline Africa & -19 & -14 & -3 & 12 & -21 & -37 & -48 & -8 & -5 & -8 & -5 & -26 \\
Asia & -79 & -78 & -147 & -52 & -91 & -115 & -121 & -91 & -141 & -47 & -90 & -73 \\
Europe & 9 & -1 & 3 & 18 & -15 & 18 & -16 & 21 & 0 & -21 & 4 & 6 \\
North America & -2 & 15 & 38 & 17 & 21 & 12 & 14 & 13 & 41 & 21 & 14 & -4 \\
South America & -35 & -35 & -59 & -20 & -42 & -51 & -55 & -41 & -56 & -19 & -39 & -32 \\
Oceania & 50 & -15 & -45 & 11 & -23 & 62 & 23 & 23 & -53 & -54 & 9 & 32 \\
\hline
\end{tabular}

\section{Hierarchical Clustering Analysis (Agglomerative Nesting: AGNES)}

Li et. $\mathrm{al}^{45}$ investigated the angiotensin-converting enzyme 2 (ACE2)-the receptor agent for the SARS-CoV-2 virus-a known contributor to viral infections susceptibility and/or resistance ${ }^{46}$. ACE2 generates small proteins by cutting up larger protein angiotensinogen, in turn affecting the nucleotide/protein. They compared ACE2 expression levels across 31 normal human tissues between males and females and between younger and older persons using two-sided student's ttest. By examining the expression patterns, they found that protein expression levels were similarly expressed between males and females or between younger and older persons in experimented tissues. Furthermore, men showed worse prognosis than women. Their findings however lacked experimental and clinical data validation. Using clinical evidence, we provide results of hierarchical clustering analysis to examine the arrangement of the nucleotide (protein) sequences/clusters across the entire genome through mutant accumulation, for male and female patients. Three distance measures were experimented, the ward, complete and single methods. Results show that the ward method has the highest agglomerative coefficient of (male $=0.9746$; female $=0.9683$ ), indicating more compact clusters; closely followed by complete (male $=0.9579$; female $=0.9523)$; average $($ male $=0.9423$; female $=0.9445)$; and single $($ male $=0.8710$; female $=0.9058$ ) methods. Using the unique isolates, the HCA or AGNES plots (see Fig. 2 of methods section) presents 2 natural clusters A and B, suggesting inevitable viral strains mutant accumulation (group A), while few mild divergent strains (group B) with specific mutations are geographically different. Hence, for the male isolates (Fig. 2a), 68 isolates belonged to cluster A 
while 3 isolates belonged to cluster B. For the female isolates (Fig. 2c), 63 isolates belonged to cluster A while 3 isolates belonged to cluster B.

To determine if differences exist in the genome sequences between genders, an independent t-test was imposed on the AGNES dis(similarity) scores. Results showed that male patients had statistically insignificantly longer genome sequences $(0.9726 \pm 0.0377)$ compared to female patients $(0.9673 \pm 0.0344), t(3280)=1.710, p=0.0871$. However, there was no statistically significant difference in mean similarity between the nucleotide (protein) structures of the two groups at $95 \%$ confidence interval, hence, no significant genetic variations were observed. Our result therefore corroborates the findings in $\mathrm{Li} \mathrm{et} \mathrm{al.}{ }^{44}$ and validates the claim that no significant genetic variation exists in human SARS-CoV-2 genomes for both groups.

\section{Genome Pattern Analysis}

Component planes visualization reveals the distribution of single feature values on a SOM map. The component planes permit an investigation of continents that share similar sub-strain(s) of SARS-CoV-2 and which sub-strain(s) permeate the different regions. To account for the variability of SOM neighborhood structure at every SOM run, the reference genome was included as part of the experiment datasets during each training phase. Hence, 4 reference genome pattern possibilities were generated to establish the very topology suitable for the trained datasets. Our topologies possess random (but controllable) discontinuities that permit more flexible self-organization with high-dimensional data, thus, preserving the map structure as much as possible. The training was carried out by gender, per continent. To ensure clear visualization of the generated maps, most of the gender-specific runs were split into 2 runs. This method was adopted to reduce the computational burden accompanying the huge datasets in this study. A total of 18 SOM maps were generated (see Figs. 4-8). We observed single-, double- and multiple-source transmissions. Overall, 7 pattern clusters were discovered as documented in Table 5. Cluster 1 represents the reference genome. Clusters 2, 3, 4, 5 and 6 are inter-continent pattern clusters or sub-strain(s). Cluster 7 indicates discovered intra-country pattern clusters or sub-strains. Wang's et al..$^{22}$ analysis suggests the presence of four sub-strains in the United States. Our results therefore sustain an increase in sub-strains within the various continents and offer explanations for the growing concerns and next wave(s) of the virus. 


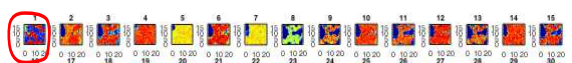

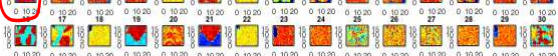
渭 1

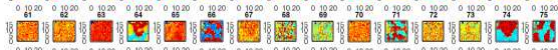

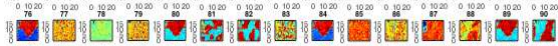
特 1. 18

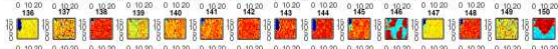

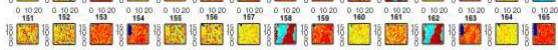

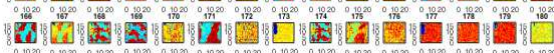

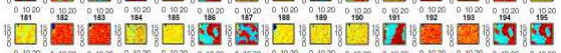

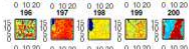

(a) Male

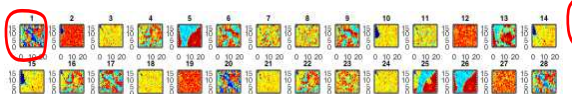

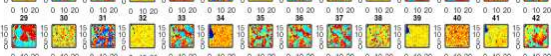

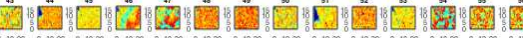
洫

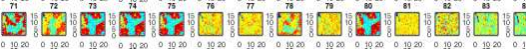

国 田

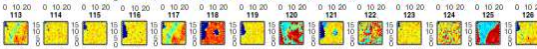

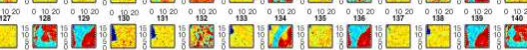

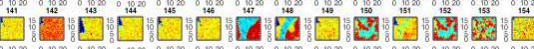

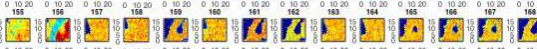

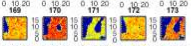

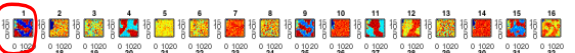

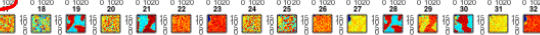

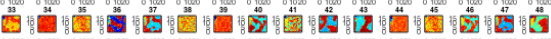
.5.

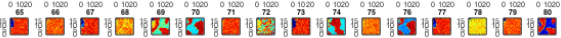

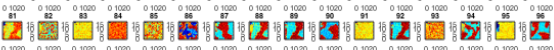
ํำ

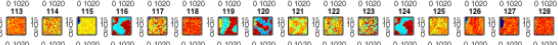
ㅂ. 语

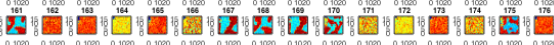

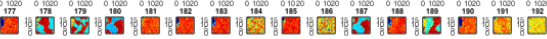

\section{活}

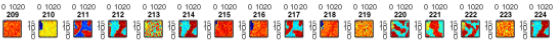

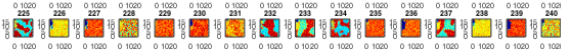
(3) 96), Nigeria (97-107), Senegal (108-156), Rwanda (157-173). Female - (b) Map 1: Ghana (2), South Africa (3-240). Map 2: South Africa (2-186), Gambia (187), Algeria (188), Egypt (189-194), Tunisia (195-203), Madagascar (204), Nigeria (205-208), Senegal (209-237), Rwanda (238-239).

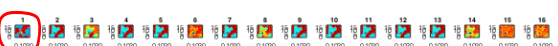

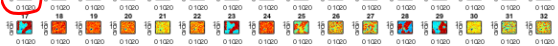

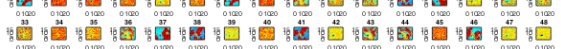

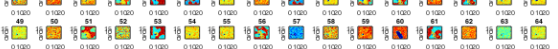

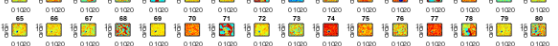

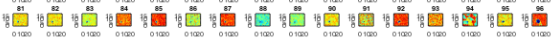

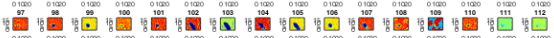

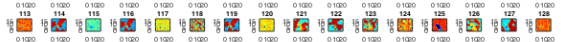

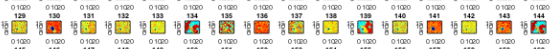

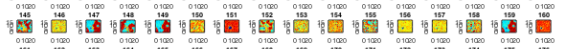

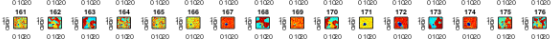

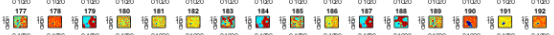

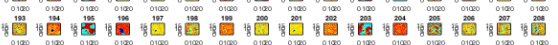

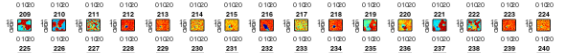

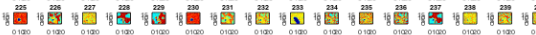

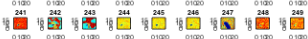

(a) Male

(8.

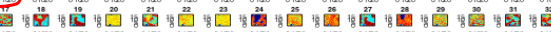

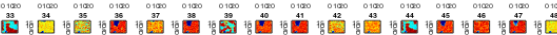
$\begin{array}{lll} & \\ 0\end{array}$

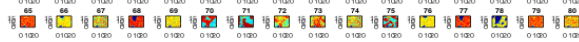

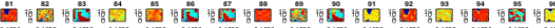

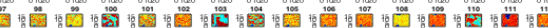

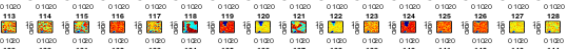

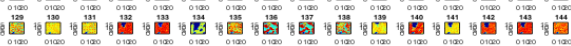

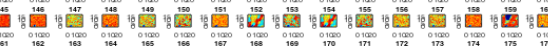

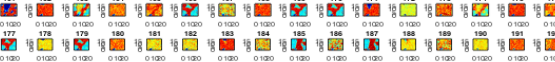

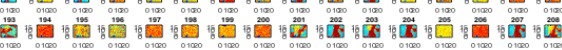

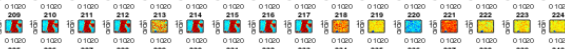

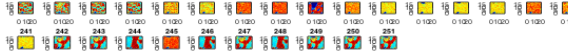

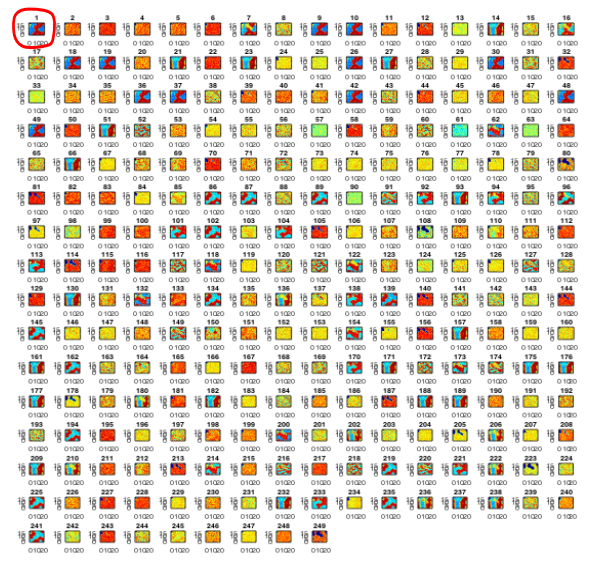

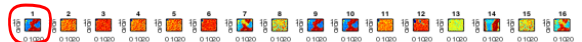

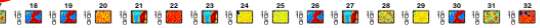

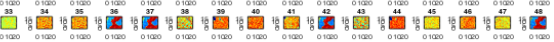

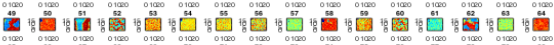

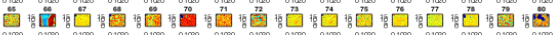

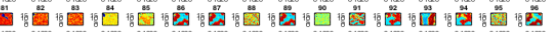

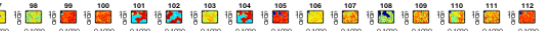

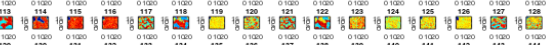

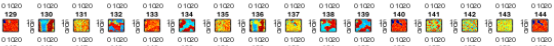

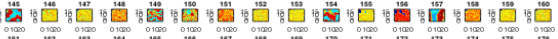

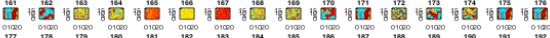

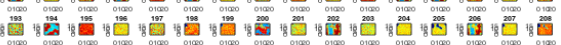

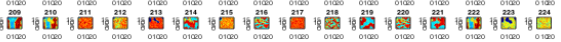

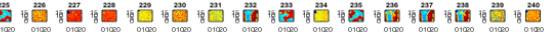

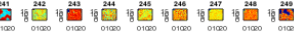

(b) Female

Fig. 5. SOM component planes visualization for Asian isolates. Component planes 1 (encircled) represent the SARS-CoV-2 reference genome. The male and female isolates have 2 SOM maps each with country and (component plane map position(s)) distributed as follows: Male - (a) Map 1: Singapore (2-18), Iraq 
(19), China (20-71), Kuwait (72-74), Malaysia (75-94), Sri Lanka (95-109), Bangladesh (110-119), India (120-249). Map 2: India (1-145), South Korea (146149), Kazakhstan (150), Indonesia (151-164), Turkey (165-180), Iran (181-184), Taiwan (185-191), Vietnam (192-200), Israel (201), Saudi Arabia (202-221), Mongolia (222-224), Oman (225-231), Lebanon (232-240), United Arab Emirates (241-251). Female - (b) Map 1: Singapore (205), Iraq (6), China )7-54),

Malaysia (55-79), Sri Lanka (80-85), Bangladesh (86-90), India (91-249). Map 2: India (2-129), South Korea (130-131), Kazakhstan (132-136), Indonesia (137149), Turkey (150-159), Iran (160-162), Taiwan (163-176), Vietnam (177-193), Israel (194-197), Philippines (198-199), Saudi Arabia (200-217), Pakistan (218219), Oman (220-227), Lebanon (228-233), United Arab Emirates (234-247), Bahrain (248).

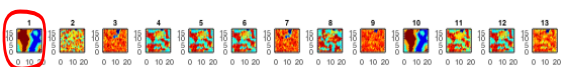

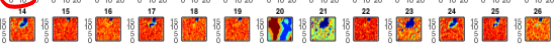

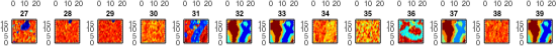

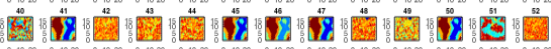

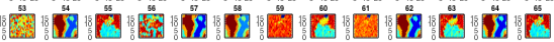

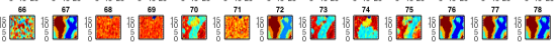

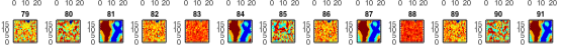

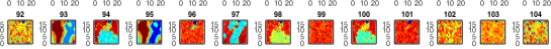

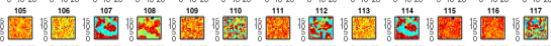

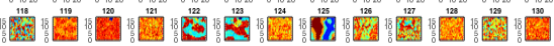

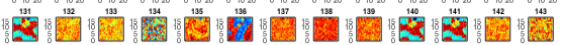

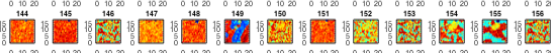 III I I I}

(a) Male

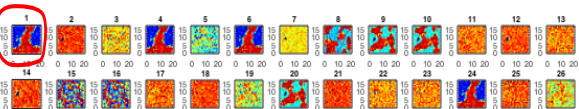

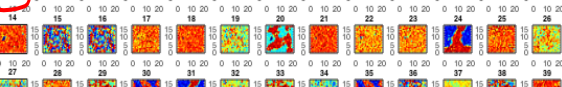

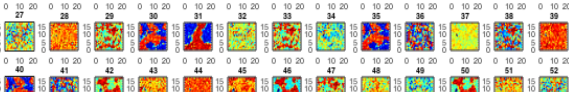

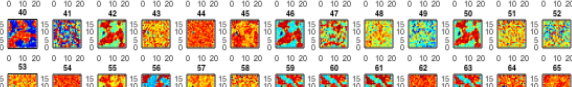

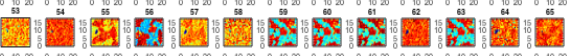

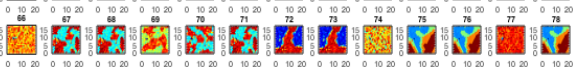

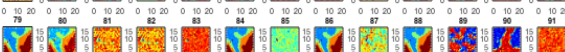

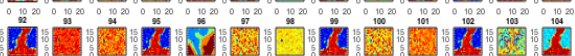

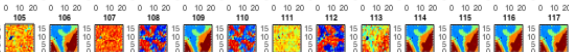

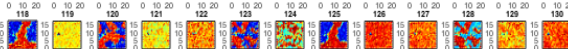

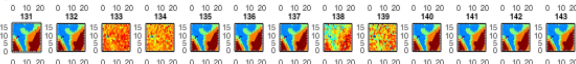

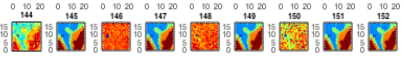

Fig. 6. SOM component planes visualization for European isolates. Component planes 1 (encircled) represent the SARS-CoV-2 reference genome. The male and female isolates have 2 SOM maps each with country and (component plane map position(s)) distributed as follows: Male - (a) Map 1: Switzerland (2), Faroe Island (3-7), Belgium (8-9), Poland (10-23), Greece (14-29), Romania (30-43), Spain (44-102), Georgia (103-105), Italy (106-161). Map 2: Italy (2-59), Russia (60-73), France (74-112), Slovakia (113), Hungary (114-118), Cyprus (119), Ukraine (120-125), Sweden (126), Austria (127), Croatia (128-129), Bosnia and Herzegovina (130), Czech Republic (131-152). Female - (b) Map 1: Switzerland (2), Faroe Islands (3-6), Belgium (7-8), Greece (9-19), Germany (20-26), Romania (27-47), Spain (48-95), Georgia (96), Italy (97-161). Map 2: Italy (2-28), Russia (29-55). France (56-87), Slovakia (88-90), Moldovia (91-93), Hungary (94-100), Ukraine (101-104), Austria (105), Finland (106), Bosnia and Herzegovina (107), Czech Republic (107-123). 


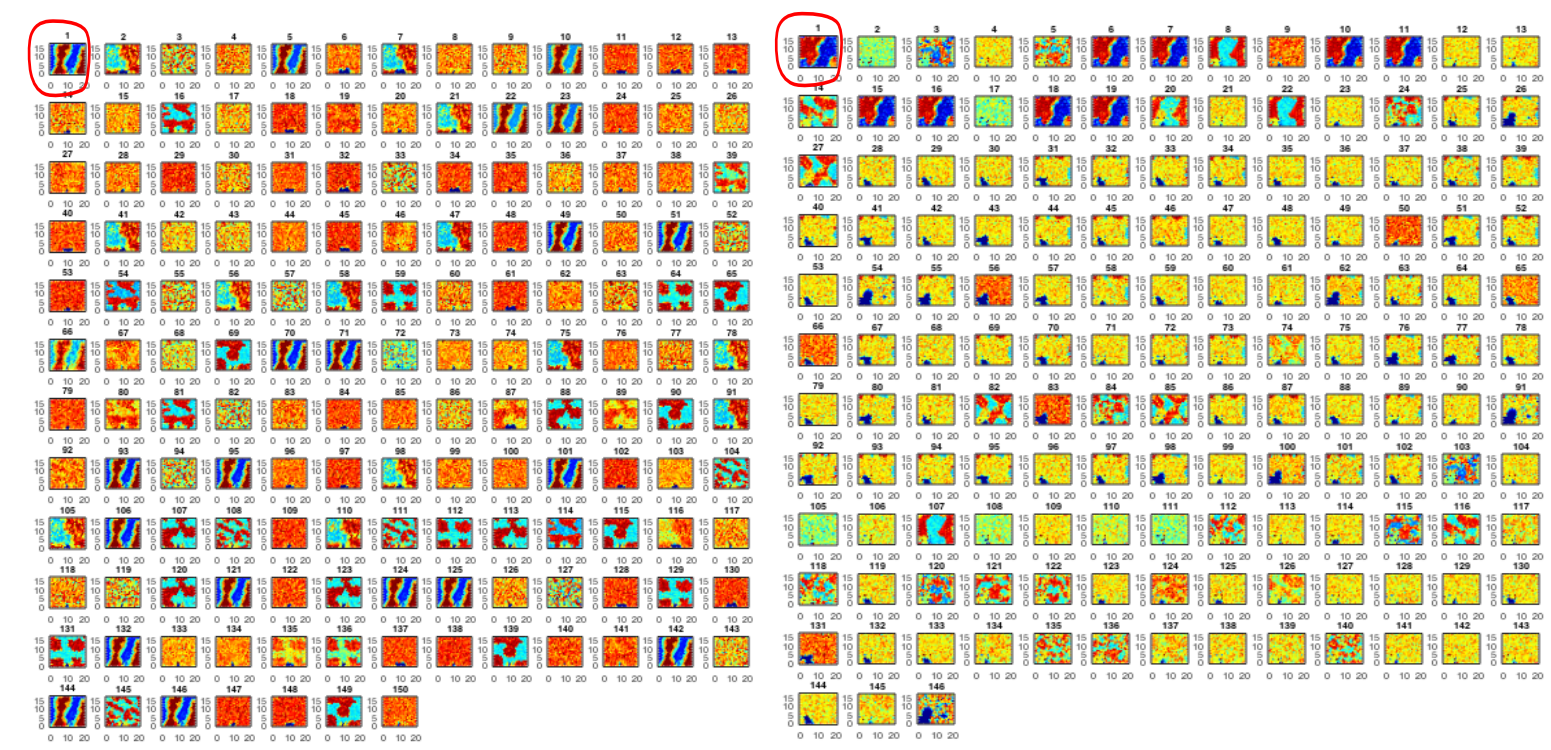

(a) Male

Fisualization for North American isolates. Component planes 1 (encircled) represent the SARS-CoV-2 reference genome.

The male isolates have 2 SOM maps while the female isolates have 1 map, each with country and (component plane map position(s)) distributed as follows: Male

- (a) Map 1: Mexico (2-46), USA (47-150). Map 2: USA (2-23), Panama (25-102), Saint Martin (103-105), Guadeloupe (106-109), Canada (110-112), Costa

Rica (113-145), Dominican Republic (146). Female - (b) Map 1: Mexico (2-34), USA (35-106), Panama (107-165), Saint Martin (166-168), Guadeloupe (169-

176), Canada (177-182), Costa Rica (183-196), Dominican Republic (197-200).

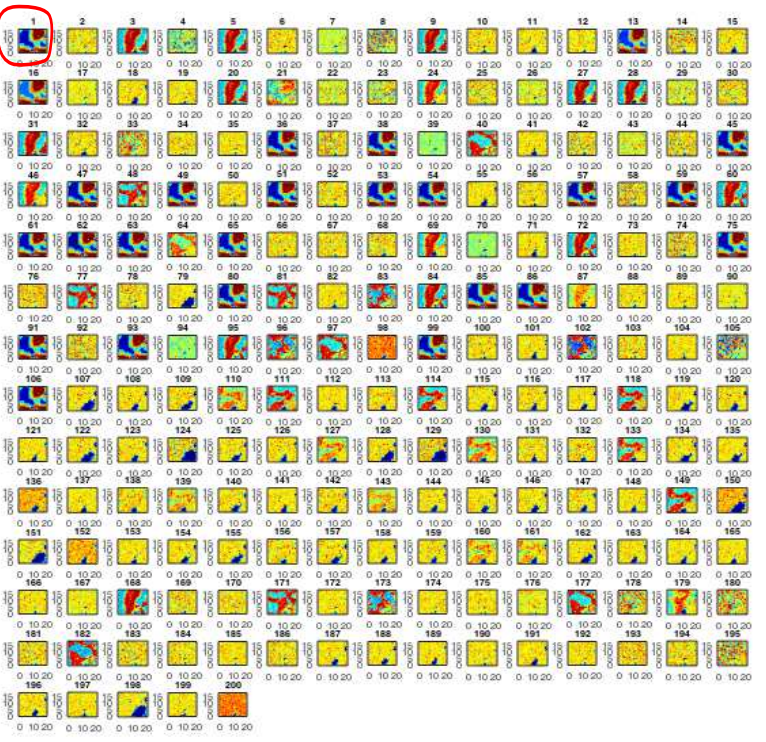

(b) Female 


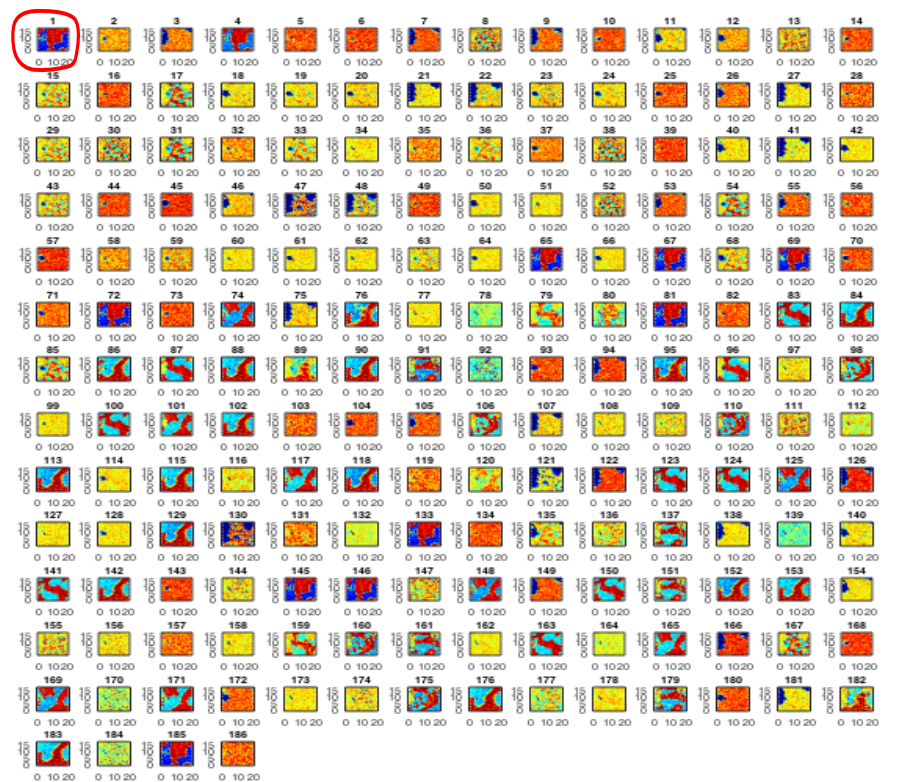

(a) Male

Fig. 8. SOM component planes visualization for South American and Ocea

reference genome. For South American isolates, the male isolates (a) and female isolates (b) have 1 SOM map each. For Oceanian isolates, the male and female isolates (c) are condensed into 1 map, each with country and (component plane map position(s)) distributed as follows: Male - (a) Map 1: Venezuela (2-3), Chile (4), Argentina (5), Colombia (6-62), Ecuador (63-72), Peru (73), Brazil (74-186).

Female - (b) Venezuela (2), Argentina (3), Colombia (4-47), Ecuador (48-50), Brazil (51-154). Male and female - (c) Map 1: Male - Australia (2-7), Guam (89), New Zealand (10). Female - Australia (11-15), New Zealand (16).

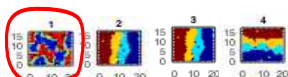 $=-\mathbf{M}$ 15in U}

(c) Male and female

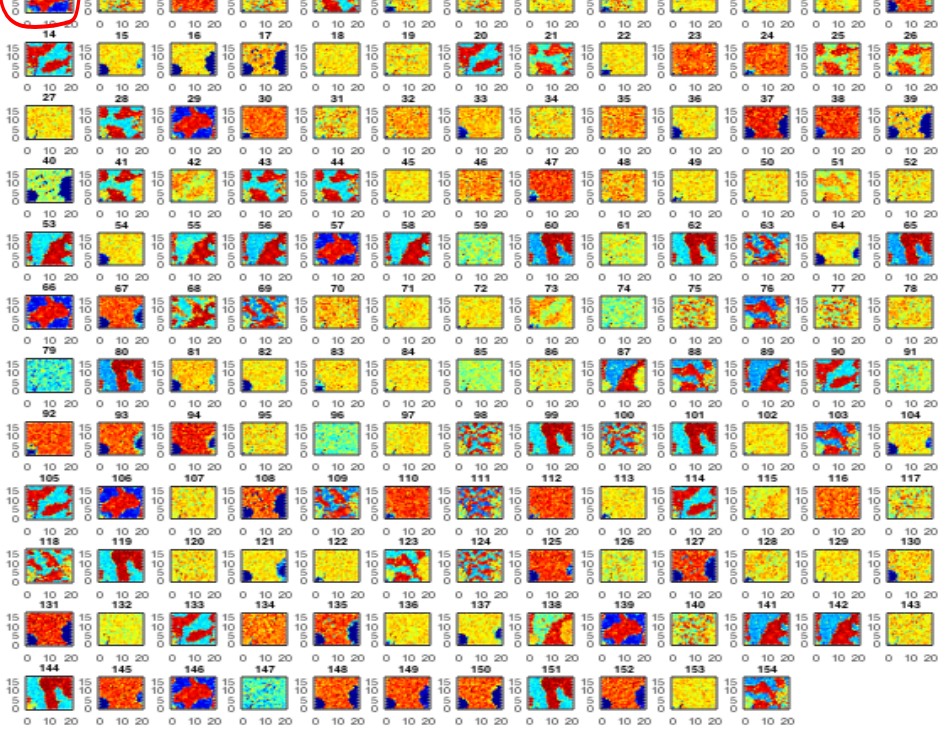

(b) Female 
A distribution of discovered clusters ( 7 in this case) by gender, across the various continents under study, is presented on Table 5. Notice that cluster 7 has the highest proportion of data points, indicating increased intra-country transmissions; save North America, where cluster 3 has the highest proportion of data points, an indication of increased inter-country transmissions. A further analysis across the continents reveals that the African, Asian, and South American isolates clustered around sub-strains G1, G2 and G5 (where G represents a generic sub-strain) with number of isolates and cluster proportions for male and female patients distributed as follows:

- Africa - G1: $186(\mathrm{M}=20.22 \%, \mathrm{~F}=23.27 \%), \mathrm{G} 2: 185(\mathrm{M}=23.18 \%, \mathrm{~F}=20.75 \%)$, and $\mathrm{G} 5: 89$ $(\mathrm{M}=6.74 \%, \mathrm{~F}=13.34 \%)$. The least sub-strains proportions come from Reference: 31 $(\mathrm{M}=3.77 \%, \mathrm{~F}=3.56 \%)$ and $\mathrm{G} 4: 0(\mathrm{M}=0 \%, \mathrm{~F}=0 \%)$.

- Asia - G1: $255(\mathrm{M}=27.31 \%, \mathrm{~F}=24.04 \%), \mathrm{G} 2: 168(\mathrm{M}=17.47 \%, \mathrm{~F}=16.36 \%)$, and $\mathrm{G} 5: 150$ $(\mathrm{M}=16.47 \%, \mathrm{~F}=13.74 \%)$. The least sub-strains proportions come from cluster 4: 27 $(\mathrm{M}=1.61 \%, \mathrm{~F}=3.84 \%)$ and $\mathrm{G} 4(\mathrm{M}=0.40 \%, \mathrm{~F}=0.20 \%)$.

- South America - G1: 75 (M=24.86\%, F=18.95\%), G2: $91(\mathrm{M}=23.24 \%, \mathrm{~F}=31.37 \%)$ and 6: $20(\mathrm{M}=3.78 \%, \mathrm{~F}=8.50 \%)$. The least sub-strains proportions come from cluster 4: 15 $(\mathrm{M}=4.32 \%, \mathrm{~F}=4.58 \%)$ and $\mathrm{G} 4: 2(\mathrm{M}=0 \%, \mathrm{~F}=1.31 \%)$.

European and North American isolates clustered around the Reference genome, the G1 and G2 sub-strains, with number of isolates and cluster proportions for male and female patients distributed as follows:

- Europe - cluster 1: $80(\mathrm{M}=13.18 \%, \mathrm{~F}=13.78 \%)$, cluster 2: $185(\mathrm{M}=34.73 \%, \mathrm{~F}=27.21 \%)$ and cluster 3: $45(\mathrm{M}=4.18 \%, \mathrm{~F}=11.31 \%)$. The least sub-strains proportions come from cluster 4: $17(\mathrm{M}=2.57, \mathrm{~F}=3.18 \%)$ and cluster 5: $12(\mathrm{M}=0.64, \mathrm{~F}=3.53 \%)$.

- North America - cluster 1: $50(\mathrm{M}=9.18 \%, \mathrm{~F}=11.56 \%)$, cluster 2: $79(\mathrm{M}=25.17 \%$, $\mathrm{F}=2.51 \%)$ and cluster 3: $113(\mathrm{M}=35.03 \%, \mathrm{~F}=55.28 \%)$. The least sub-strains proportions come from cluster 4: $15(\mathrm{M}=2.38 \%, \mathrm{~F}=4.08 \%)$ and cluster 5: $0(\mathrm{M}=0 \%, \mathrm{~F}=0 \%)$.

Due to paucity of data, the Oceanian isolates have data for only cluster $1: 2(\mathrm{M}=24.86 \%$, $\mathrm{F}=18.95 \%$ ). Table 6 summarizes the clusters distribution, by gender across the various continents.

Table 5. Cluster distribution by gender across continents

\begin{tabular}{|c|c|c|c|c|c|c|c|c|c|c|c|c|c|c|c|c|}
\hline \multirow[t]{2}{*}{ Continent } & \multirow[t]{2}{*}{ Gender } & \multicolumn{2}{|c|}{$\begin{array}{l}\text { Cluster } 1 \\
\text { (Reference } \\
\text { genome) }\end{array}$} & \multicolumn{2}{|c|}{$\begin{array}{c}\text { Cluster } 2 \\
\text { (inter-country } \\
\text { sub-strain G1) }\end{array}$} & \multicolumn{2}{|c|}{$\begin{array}{c}\text { Cluster } 3 \\
\text { (inter-country } \\
\text { sub-strain G2) }\end{array}$} & \multicolumn{2}{|c|}{$\begin{array}{c}\text { Cluster } 4 \\
\text { (inter-country } \\
\text { sub-strain G3) }\end{array}$} & \multicolumn{2}{|c|}{$\begin{array}{c}\text { Cluster } 5 \\
\text { (inter-country } \\
\text { sub-strain G4) }\end{array}$} & \multicolumn{2}{|c|}{$\begin{array}{c}\text { Cluster } 6 \\
\text { (inter country } \\
\text { sub-strain G5) }\end{array}$} & \multicolumn{2}{|c|}{$\begin{array}{c}\text { Cluster } 7 \\
\text { (intra-country } \\
\text { sub-strain) } \\
\end{array}$} & \multirow{2}{*}{$\begin{array}{l}\text { Total } \\
\% \\
\end{array}$} \\
\hline & & No. & $\%$ & No. & $\%$ & No. & $\%$ & No. & $\%$ & No. & $\%$ & No. & $\%$ & No. & $\%$ & \\
\hline \multirow{2}{*}{ Africa } & Male & 14 & 3.77 & 75 & 20.22 & 86 & 23.18 & 10 & 2.70 & 0 & 0 & 25 & 6.74 & 161 & 43.40 & 100 \\
\hline & Female & 17 & 3.56 & 111 & 23.27 & 99 & 20.75 & 10 & 2.10 & 0 & 0 & 64 & 13.42 & 176 & 36.90 & 100 \\
\hline \multirow{2}{*}{ Asia } & Male & 26 & 5.22 & 136 & 27.31 & 87 & 17.47 & 8 & 1.61 & 2 & 0.40 & 82 & 16.47 & 157 & 31.53 & 100 \\
\hline & Female & 40 & 8.08 & 119 & 24.04 & 81 & 16.36 & 19 & 3.84 & 1 & 0.20 & 68 & 13.74 & 167 & 33.74 & 100 \\
\hline \multirow{2}{*}{ Europe } & Male & 41 & 13.18 & 108 & 34.73 & 13 & 4.18 & 8 & 2.57 & 2 & 0.64 & 20 & 6.43 & 119 & 38.26 & 100 \\
\hline & Female & 39 & 13.78 & 77 & 27.21 & 32 & 11.31 & 9 & 3.18 & 10 & 3.53 & 8 & 2.83 & 108 & 38.16 & 100 \\
\hline \multirow{2}{*}{$\begin{array}{l}\text { North } \\
\text { America }\end{array}$} & Male & 27 & 9.18 & 74 & 25.17 & 103 & 35.03 & 7 & 2.38 & 0 & 0 & 18 & 6.12 & 65 & 22.11 & 100 \\
\hline & Female & 23 & 11.56 & 5 & 2.51 & 110 & 55.28 & 8 & 4.02 & 0 & 0 & 8 & 4.02 & 45 & 22.61 & 100 \\
\hline \multirow{2}{*}{$\begin{array}{l}\text { South } \\
\text { America }\end{array}$} & Male & 10 & 5.41 & 46 & 24.86 & 43 & 23.24 & 8 & 4.32 & 0 & 0 & 7 & 3.78 & 71 & 38.38 & 100 \\
\hline & Female & 6 & 3.92 & 29 & 18.95 & 48 & 31.37 & 7 & 4.58 & 2 & 1.31 & 13 & 8.50 & 48 & 31.37 & 100 \\
\hline \multirow{2}{*}{ Oceania } & Male & 3 & 33.33 & 0 & 0 & 0 & 0 & 0 & 0 & 0 & 0 & 0 & 0 & 6 & 66.67 & 100 \\
\hline & Female & 1 & 16.67 & 0 & 0 & 0 & 0 & 0 & 0 & 0 & 0 & 0 & 0 & 5 & 83.33 & 100 \\
\hline
\end{tabular}




\section{Cognitive Knowledge Generation}

While mutations are expected, there is need to initiate robust surveillance mechanism for continuous monitoring of the public health implications and rapid response to new strains of COVID-19. To intelligently predict the viral sub-strains for both genders, novel cognitive map that preserves chains of similar isolates were generated from SOM component planes using the Python programming language. The extracted clusters are necessary for supervised labeling of the classification targets. By disassembling the SOM correlation hunting matrix space, we attribute these associations to disparate classes of discovered viral sub-strains. The outcome is a cognitive map of 7 clusters simulating the discovered SOM patterns and countries/isolates linked to these patterns for male and female patients (see Supplementary Table S3). Each sub-strain cluster holds similar isolates that belong to a related pattern bounded by certain degree of association or correlation range, established by the SOM, and captures all isolates discovered within this range. We also captured from the SOM component planes any progression in patterns showing sub-strain(s) development leading to well separated cluster image(s). The cognitive knowledge can help the contact tracing of cases in emerging disease situations as well as establish how the reference genome has evolved over time. This additional knowledge also permits further characterization of the viral sub-strains, as our results allow unique SARS-CoV-2 base pairs sequence identification (which do not appear in other viral sub-strains) but could be useful as baselines for designing new primers that permit further insights and examination by experts.

\section{ANN performance Evaluation}

The k-fold cross validation method is known to estimate the robustness of the model on new data and was used to drive the validation phase of the NN. As the model is fit on training data, we obtain more realistic estimates of how well the model prediction will work on new cases. The experimental setup performed twenty (20) runs of stratified k-fold cross validation ${ }^{47}$ on the male and female datasets using the Neural Network (NN) model. The number of groups was split into (k) such that each data sample spanned 3, 5, 10 and 15 yielding 60, 100, 200 and 300 calls respectively on the training and testing mode of each dataset. This was done to ensure that the best possible value of $\mathrm{k}$ was chosen alongside the NN model. The performance of the NN model on the datasets was finally evaluated using the Classification Accuracy, Root Mean Squared Error (RMSE), Mean Absolute Error, Precision, Recall and Area Under the Curve (AUC). Results obtained on Table 6 and Table 7 confirm the suitability of ANNs in predicting COVID 19 subs-trains for male and female patients, respectively. Furthermore, the metric specific result from each dataset compared using paired t-test, depict no statistically significant difference between the male and female features with $p$ values $>0.05$ on each metric at $95 \%$ confidence level. The deployed model is helpful for classifying new datasets and for building expert support system for efficient SARS-CoV-2 sub-strains discrimination.

\begin{tabular}{ccccccr}
\multicolumn{6}{l}{ Table } & 6 Mean values and standard deviation of model performances on the male dataset \\
\hline $\mathrm{k}$ & Classification & RMSE & MAE & Precision & recall & AUC \\
& Accuracy & & & & & \\
\hline 3 & $98.5900 \pm 0.7600$ & $0.0500 \pm 0.0200$ & $0.0100 \pm 0.00$ & $0.9900 \pm 0.0300$ & $0.9700 \pm 0.0400$ & $1.00 \pm 0.00$ \\
5 & $98.5900 \pm 0.7600$ & $0.0500 \pm 0.0200$ & $0.0100 \pm 0.00$ & $0.9900 \pm 0.0300$ & $0.9700 \pm 0.0400$ & $1.00 \pm 0.00$ \\
10 & $98.5900 \pm 0.7600$ & $0.0500 \pm 0.0200$ & $0.0100 \pm 0.00$ & $0.9900 \pm 0.0300$ & $0.9700 \pm 0.0400$ & $1.00 \pm 0.00$ \\
15 & $98.5900 \pm 0.7600$ & $0.0500 \pm 0.0200$ & $0.0100 \pm 0.00$ & $0.9900 \pm 0.0300$ & $0.9700 \pm 0.0400$ & $1.00 \pm 0.00$ \\
\hline
\end{tabular}


Table 7. Mean values and standard deviation of model performances on the female dataset

\begin{tabular}{rlcrcrr}
\hline $\mathrm{k}$ & $\begin{array}{l}\text { Classification } \\
\text { Accuracy (\%) }\end{array}$ & \multicolumn{1}{c}{ RMSE } & \multicolumn{1}{c}{ MAE } & Precision & Recall & AUC \\
\hline 3 & $98.5900 \pm 0.7600$ & $0.0500 \pm 0.0100$ & $0.00 \pm 0.00$ & $0.9900 \pm 0.0100$ & $1.00 \pm 0.01$ & $1.00 \pm 0.00$ \\
5 & $98.6100 \pm 0.7000$ & $0.0500 \pm 0.0100$ & $0.0100 \pm 0.00$ & $0.9900 \pm 0.0300$ & $1.00 \pm 0.01$ & $1.00 \pm 0.00$ \\
10 & $98.6100 \pm 0.7000$ & $0.0500 \pm 0.0100$ & $0.00 \pm 0.00$ & $0.9900 \pm 0.0100$ & $1.00 \pm 0.01$ & $1.00 \pm 0.00$ \\
15 & $98.6100 \pm 0.7000$ & $0.0500 \pm 0.0100$ & $0.00 \pm 0.00$ & $0.9900 \pm 0.0100$ & $1.00 \pm 0.01$ & $1.00 \pm 0.00$ \\
\hline
\end{tabular}

On Table 8, a summary of important performance metrics extracted from the literature for ANN with or without cross validation method, is presented to enable a comparison of our approach with state-of-the-art. We observe that the proposed approach performed better with very high classification accuracy, precision, and recall rates, indicating good generalization and correct prediction. Furthermore, increase in number of validation folds $(\mathrm{k})$ did not improve the performance of the system, indicating a stable neural network.

Table 8. Summary of performance metrics from previous works

\begin{tabular}{|c|c|c|c|c|c|c|c|}
\hline Reference & $\begin{array}{l}\text { k-fold } \\
\text { method }\end{array}$ & $\begin{array}{l}\text { Classification } \\
\text { Accuracy (\%) }\end{array}$ & RMSE & Precision & Recall & F1-Score \% & $\begin{array}{c}\text { AUC } \\
\%\end{array}$ \\
\hline [41] & - & 72.3300 & - & 0.7241 & 0.7167 & 0.72030 & - \\
\hline [43] & - & $\begin{array}{l}\text { From Asia }(67.0000) \text {. } \\
\text { Otherwise }(86.0000)\end{array}$ & - & - & - & - & - \\
\hline [33] & - & - & 0.08019 & - & - & - & - \\
\hline [38] & 10 -fold & 76.9000 & - & - & - & - & - \\
\hline [29] & - & 96.2000 & - & 0.9400 & 0.9600 & 0.95000 & - \\
\hline [21] & 10 -fold & 93.5000 & - & - & - & - & - \\
\hline [36] & 10 -fold & 90.0000 & - & - & - & - & 0.9200 \\
\hline
\end{tabular}

\section{Discussion}

In clinical diagnostics, image processing and computer vision are revolutionizing image-based diagnosis. Similarly, in the field of genetics, genomic research is poised to improve care through genotypes definition of other organisms. AI-based and Big Data analytics have also offered promising applications through processing of large and complex genome datasets. The future of individualized medicine has however imposed limitations, challenges and biases during implementation and stiffened successful deployment of AI in medical applications, particularly those utilizing human genetics and genome datasets. Although addressing underrepresented data in training datasets can resolve bias, while model retraining can assist in improving performance, confusable symptoms relative to the disease have posed a major bottleneck for future applications. This work has created a foundation for future studies on emerging infectious diseases by investigating the variation and functions of SARS-CoV-2 genomes for possible discovery of patterns exhibited by human isolates. The case of symptomatic and asymptomatic patients presents inconsistencies and is inconclusive in this paper. This aspect of infectious disease therefore demands more research efforts on prompt detection of asymptomatic cases. 


\section{References}

1. Mitchell, E. P. Corona Virus: Global Pandemic Causing World-Wide Shutdown. Journal of the National Medical Association. 112(2): 113-114. (2020).

https://doi.org/10.1016/j.jnma.2020.03.015.

2. Bedford, J., Enria, D., Giesecke, J., Heymann, D.L., Ihekweazu, C., Kobinger, G., Lane, H.C., Memish, Z., Oh, M.D., Schuchat, A. and Ungchusak, K. COVID-19: towards controlling of a pandemic. The Lancet, 395(10229), 1015-1018. (2020). https://doi.org/10.1016/S0140-6736(20)30673-5.

3. Chen, J., Wang, R., Wang, M., \& Wei, G. W. Mutations strengthened SARS-CoV-2 infectivity. arXiv preprint arXiv:2005.14669. (2020). https://arxiv.org/abs/2005.14669

4. Koyama, T., Weeraratne, D., Snowdon, J. L., \& Parida, L. Emergence of drift variants that may affect COVID-19 vaccine development and antibody treatment. Pathogens, 9(5), 324: 17. (2020). https://doi.org/10.3390/pathogens 9050324 .

5. Zhu, N., Zhang, D., Wang, W., Li, X., Yang, B., Song, J., Zhao, X., Huang, B., Shi, W., Lu, R. and Niu, P. A novel coronavirus from patients with pneumonia in China, 2019. New England Journal of Medicine. 382(8):727-733. (2020).

https://doi.org/10.1056/NEJMoa2001017

6. Tang X, Wu C, Li X, Song Y, Yao X, Wu X, et al. On the origin and continuing evolution of SARS-CoV-2. Natl Sci Rev. 7: 1012-1023. (2020). https://doi.org/10.1093/nsr/nwaa036

7. Wiechers, I. R., Perin, N. C. \& Cook-Deegan, R. The emergence of commercial genomics: analysis of the rise of a biotechnology subsector during the Human Genome Project, 1990 to 2004. Genome Med 5, 83: 1-9. (2013). https://doi.org/10.1186/gm487

8. Giani, A. M., Gallo, G. R., Gianfranceschi, L., \& Formenti, G. Long walk to genomics: History and current approaches to genome sequencing and assembly. Computational and Structural Biotechnology Journal, 18, 9-19. (2020). https://doi.org/10.1016/j.csbj.2019.11.002.

9. Ardakani A.A., Kanafi A.R., Acharya U.R., Khadem N., Mohammadi A. Application of deep learning technique to manage COVID-19 in routine clinical practice using CT images: results of 10 convolutional neural networks. Comput Biol Med. 121. 103795. (2020). https://doi.org/10.1016/j.compbiomed.2020.103795.

10. Ozturk T., Talo M., Yildirim E.A., Baloglu U.B., Yildirim O., Rajendra Acharya U. Automated detection of COVID-19 cases using deep neural networks with X-ray images. Comput Biol Med. 121. 103792. (2020). https://doi.org/10.1016/j.compbiomed.2020.103792.

11. Sun L., Liu G., Song F., Shi N., Liu F., Li S., Li P., Zhang W., Jiang X., Zhang Y., Sun L., Chen X., Shi Y. Combination of four clinical indicators predicts the severe/critical symptom of patients infected COVID-19. J Clin Virol. 104431. (2020).

https://doi.org/10.1016/j.jcv.2020.104431.

12. Wu, J., Zhang, P., Zhang, L., Meng, W., Li, J., Tong, C., Li, Y., Cai, J., Yang, Z., JZhu, J., Zhao, M., Huang, H., Xie, X. and Li, S. (2020). Rapid and accurate identification of COVID19 infection through machine learning based on clinical available blood test results. medRxiv Preprint. https//doi.org/10.1101/2020.04.02.20051136. 
13. MIT: Covid Tracing Tracker - a flood of coronavirus apps are tracking us. Now it's time to keep track of them. https://www.technologyreview.com/2020/05/07/1000961/launchingmittr-covid-tracing-tracker/ (accessed 20 August, 2020).

14. Ribeiro M. H. D. M., da Silva R. G., Mariani V. C., Coelho L. D. S. (2020). Short-term forecasting COVID-19 cumulative confirmed cases: perspectives for Brazil. Chaos, Solitons Fractals. 109853. https://doi.org/10.1016/j.chaos.2020.109853.

15. Yan L., Zhang H.-T., Goncalves J., Xiao Y., Wang M., Guo Y., Sun C., Tang X., Jing L., Zhang M., Huang X., Xiao Y., Cao H., Chen Y., Ren T., Wang F., Xiao Y., Huang S., Tan X., Huang N., Jiao B., Cheng C., Zhang Y., Luo A., Mombaerts L., Jin J., Cao Z., Li S., Xu H., Yuan Y. An interpretable mortality prediction model for COVID-19 patients. Nat Mach Intell. 1-6. (2020). https://doi.org/10.1038/s42256-020-0180-7.

16. Ke Y.-Y., Peng T.-T., Yeh T.-K., Huang W.-Z., Chang S.-E., Wu S.-H., Hung H.-C., Hsu T.A., Lee S.-J., Song J.-S., Lin W.-H., Chiang T.-J., Lin J.-H., Sytwu H.-K., Chen C.-T. Artificial intelligence approach fighting COVID-19 with repurposing drugs. Biomed J. (2020). https://doi.org/10.1016/j.bj.2020.05.001.

17. Beck B. R., Shin B., Choi Y., Park S., Kang K. Predicting commercially available antiviral drugs that may act on the novel coronavirus (SARS-CoV-2) through a drug-target interaction deep learning model. Comput Struct Biotechnol J.;18: 784-790. (2020). https://doi.org/10.1016/j.csbj.2020.03.025.

18. Ekins S., Mottin M., Ramos P.R.P.S., Sousa B.K.P., Neves B.J., Foil D.H., Zorn K.M., Braga R.C., Coffee M., Southan C., Puhl C.A., Andrade C.H. Déjà vu: stimulating open drug discovery for SARS-CoV-2. Drug Discov Today. 25(5): 928-941. (2020). https://doi.org/10.1016/j.drudis.2020.03.019.

19. Zielezinski A, Vinga S, Almeida J, Karlowski WM. Alignment-free sequence comparison: benefits, applications, and tools. Genome Biology. 18(1):186. 1-17. https://doi.org/10.1186/s13059-017-1319-7.

20. Vinga S, Almeida J. Alignment-free sequence comparison-a review. Bioinformatics. 19(4):513-23. https://doi.org/10.1093/bioinformatics/btg005.

21. Randhawa GS, Soltysiak MPM, El Roz H, de Souza CPE, Hill KA, Kari L. Machine learning using intrinsic genomic signatures for rapid classification of novel pathogens: COVID19 case study. Plos One. 15(4). e0232391: 1-24. https://doi.org/10.1371/journal.pone.0232391.

22. Wang, R., Chen, J., Gao, K., Hozumi, Y., Yin, C., \& Wei, G. W. (2021). Analysis of SARSCoV-2 mutations in the United States suggests presence of four substrains and novel variants. Communications biology, 4(1), 1-14. https://doi.org/10.1038/s42003-021-01754-6.

23. Wang, R., Chen, J., Gao, K., Hozumi, Y., Yin, C., \& Wei, G. W. (2020). Characterizing SARS-CoV-2 mutations in the United States. arXiv preprint arXiv:2007.12692.

24. Grabowski, F., Kochanczyk, M., \& Lipniacki, T. (2021). L18F substrain of SARS-CoV-2 VOC-202012/01 is rapidly spreading in England. medRxiv. https://doi.org/10.1101/2021.02.07.21251262 
25. Richmond, C. S., Sabin, A. P., Jobe, D. A., Lovrich, S. D., \& Kenny, P. A. (2020). Interregional SARS-CoV-2 spread from a single introduction outbreak in a meat-packing plant in northeast Iowa. MedRxiv. https://doi.org/10.1101/2020.06.08.20125534

26. Koyama, T., Weeraratne, D., Snowdon, J. L., \& Parida, L. (2020). Emergence of drift variants that may affect COVID-19 vaccine development and antibody treatment. Pathogens, 9(5), 324. https://doi.org/10.3390/pathogens9050324.

27. Stefanelli, P., Faggioni, G., Presti, A.L., Fiore, S., Marchi, A., Benedetti, E., Fabiani, C., Anselmo, A., Ciammaruconi, A., Fortunato, A. and De Santis, R. V. Whole genome and phylogenetic analysis of two SARS-CoV-2 strains isolated in Italy in January and February 2020: additional clues on multiple introductions and further circulation in Europe. Eurosurveillance, 25(13), 2000305. (2020). https://doi.org/10.2807/15607917.ES.2020.25.13.2000305

28. Somasundaram, K., Mondal, M., \& Lawarde, A. Genomics of Indian SARS-CoV-2: Implications in genetic diversity, possible origin and spread of virus. medRxiv. (2020). https://doi.org/10.1101/2020.04.25.20079475

29. Khanday, A. M. U. D., Rabani, S. T., Khan, Q. R., Rouf, N., \& Din, M. M. U. Machine learning based approaches for detecting COVID-19 using clinical text data. International Journal of Information Technology, 1-9. (2020). https://doi.org/10.1007/s41870-020-004959.

30. https://github.com/Akibkhanday/Meta-data-of-Coronavirus.

31. Melin, P., Monica, J. C., Sanchez, D., \& Castillo, O. Analysis of Spatial Spread Relationships of Coronavirus (COVID-19) Pandemic in the World using Self Organizing Maps. Chaos, Solitons \& Fractals, 1-7. (2020). https://doi.org/10.1016/j.chaos.2020.109917.

32. The Humanitarian Data Exchange (HDX), [Online] (2020). Available: https://data.humdata.org/dataset/novel-coronavirus-2019-ncov-cases.

33. Melin, P., Monica, J. C., Sanchez, D., \& Castillo, O. (2020b). Multiple ensemble neural network models with fuzzy response aggregation for predicting COVID-19 time series: the case of Mexico. Healthcare 8 (181): 1-13. https://doi.org/10.3390/healthcare 8020181.

34. Castillo, O., \& Melin, P. (2020). Forecasting of COVID-19 time series for countries in the world based on a hybrid approach combining the fractal dimension and fuzzy logic. Chaos, Solitons \& Fractals, 140, 110242. https://doi.org/10.1016/j.chaos.2020.110242

35. Lopez-Rincon, A., Tonda, A., Mendoza-Maldonado, L., Mulders, D. G., Molenkamp, R., Perez-Romero, C. A., Claassen, E., Garssen, J \& Kraneveld, A. D. (2020a). Classification and Specific Primer Design for Accurate Detection of SARS-CoV-2 Using Deep Learning. bioRxiv. https://doi.org/10.1101/2020.03.13.990242

36. Lopez-Rincon, A., Tonda, A., Mendoza-Maldonado, L., Claassen, E., Garssen, J., \& Kraneveld, A. D. Accurate identification of sars-cov-2 from viral genome sequences using deep learning. bioRxiv. (2020b). https://doi.org/10.1101/2020.03.13.990242.

37. Beijing Institute of Genomics, Chinese Academy of Science, China National Center for Bioinformation \& National Genomics Data Center. https://bigd.big.ac.cn/ncov/?lang=en. 
38. Kaden, M., Bohnsack, K. S., Weber, M., Kudla, M., Gutowska, K., Blazewicz, J. \& V Villmann, T. (2020). Analysis of SARS-CoV-2 RNA-Sequences by Interpretable Machine Learning Models. bioRxiv. https://www.biorxiv.org/content/10.1101/2020.05.15.097741v1

39. Sawmya, S., Saha, A., Tasnim, S., Anjum, N., Toufikuzzaman, M., Rafid, A. H. M., Rahman, M.S. \& Rahman, M.S. (2020). Analyzing hCov genome sequences: Applying Machine Intelligence and beyond. bioRxiv. https://doi.org/10.1101/2020.06.03.131987

40. Sun, T., \& Wang, Y. (2020). Modeling COVID-19 Epidemic in Heilongjiang Province, China. Chaos, Solitons \& Fractals, 109949.

41. Dey, L., Chakraborty, S., \& Mukhopadhyay, A. (2020). Machine learning techniques for sequence-based prediction of viral-host interactions between SARS-CoV-2 and human proteins. Biomedical journal. 43(5): 438-450. https://doi.org/10.1016/j.bj.2020.08.003

42. Gordon, D. E., Jang, G. M., Bouhaddou, M., Xu, J., Obernier, K., White, K. M., O’Meara, M. J., Rezelj, V. V., Guo, J. Z., Swaney, D. L. and Tummino, T. A. (2020). A SARS-CoV-2 protein interaction map reveals targets for drug repurposing. Nature, 1-13. https://doi.org/10.1016/j.bj.2020.08.003

43. Dlamini, G. S., Müller, S. J., Meraba, R. L., Young, R. A., Mashiyane, J., Chiwewe, T., \& Mapiye, D. S. (2020). Classification of COVID-19 and Other Pathogenic Sequences: A Dinucleotide Frequency and Machine Learning Approach. IEEE Access, 8, 195263-195273. https://doi.org/10.1109/ACCESS.2020.3031387

44. Wang, Y., Mao, J. M., Wang, G. D., Luo, Z. P., Yang, L., Yao, Q. \& Chen, K. P. Human SARS-CoV-2 has evolved to reduce CG dinucleotide in its open reading frames. Sci Rep 10, 12331 (2020). https://doi.org/10.1038/s41598-020-69342-y.

45. Li, M. Y., Li, L., Zhang, Y., \& Wang, X. S. Expression of the SARS-CoV-2 cell receptor gene ACE2 in a wide variety of human tissues. Infectious diseases of poverty, 9, 1-7. (2020). https://doi.org/10.1186/s40249-020-00662-X.

46. Hussain, M., Jabeen, N., Raza, F., Shabbir, S., Baig, A. A., Amanullah, A., \& Aziz, B. Structural variations in human ACE2 may influence its binding with SARS-CoV-2 spike protein. Journal of medical virology. 92:1580-1586. (2020). https://doi.org/10.1002/jmv.25832

47. Krstajic, D., Buturovic, L.J., Leahy, D.E. et al. Cross-validation pitfalls when selecting and assessing regression and classification models. J Cheminform 6, 10 (2014). https://doi.org/10.1186/1758-2946-6-10

\section{Authors Contributions:}

All authors contributed equally to the final draft of this paper.

M.E.* conceptualized the research idea, contributed to the research methods, preparation of figures, framework/tools design, implementation and interpretation of the results.

M.E.1 provided literature materials, performed critical review as well as data validation. 
U.I. contributed to the research methodology, framework/tools design, preparation of figures, implementation, and interpretation of results.

F-M.U. structurally edited the original draft and contributed to the software design component and implementation.

I.E. contributed to the biotechnology and bioinformatics components of the paper, as well as the research methods.

A.M. was involved in formal analysis of the study data, research methods and implementation.

M.E.2 structurally edited the original draft, involved in research data validation and interpretation of results.

Y.T. contributed to the biotechnology/bioinformatics components of the paper and editing of the original draft.

I.U. was involved in critical review of literature and research data validation.

E.A. was involved in the critical review as well as a formal analysis of the study data.

O.E. contributed to the study background, research methods and biotechnology components of the paper.

G.J. was involved in the data curation, collection/excavation, and processing of the human SARS-CoV-2 genomes.

E.D. was involved in data curation, collection/excavation, and processing of the human SARSCoV-2 genomes.

Competing Interest: There are no competing interests. 


\section{Methods \\ Data Source and Genome Sequences Selection}

Publicly available datasets of coronavirus cases around the globe deposited between December 2019 and January 15, 2021 were excavated from GISAID (https://gisaid.org - a database of SARS-CoV-2 partial and complete genome compilations distributed by clinicians and researchers, the world over). A total of 8864 isolates (5130 male samples, and 3734 female samples) from different countries of the world were collected and processed, across 6 continents, Antarctica exempt (as no deposit of SARS-CoV-2 data was found as at the time of excavation). Complete genome lengths of above $29000 \mathrm{bp}$ with $<1 \%$ undefined or ambiguous bases ('N's) were excavated from 88 different countries (male $=71$ countries; female $=77$ countries) distributed across the following continents: Africa (Data S1: SupplData1.xlsx), Asia (Data S2: SupplData2.xlsx), Europe (Data S3: SupplData3.xlsx), North America (Data S4: SupplData4.xlsx), South America (Data S5: SupplData5.xlsx), and Oceania (Data S6: SupplData6.xslx). Table 1 documents the continent, isolate distribution by country, isolate distribution by gender, and total isolates excavated. Metadata on the extracted genome sequences consisting of the following columns (Isolate Code: Country+isolate number, Country, Accession Number, Gender, Age, Status, Specimen source and Additional Information) were also documented (see Data S7: SupplData7.xlsx). The Additional Information column holds both location and host information such as transmission history, treatment history, date sample was taken, etc. FASTA files of the genome isolates can be located at GISAID using the Accession Number. Specimen sources include swabs (nasal, oral, throat, nasal and oral); fluids (bronchoalveolar lavage, saliva, sputum, stool) and unknown. We observed that the GSAID database was inconsistent in rendering the patient status, as numerous incoherent annotations introduced inherent redundancy. To assist efficient documentation and processing of data, a taxonomy re-classifying the patient status is given in Fig. 1. This taxonomy subsumes the incoherent annotations (annotations in square text boxes) into unique specifications (annotations in oval shapes), for intelligent data mining ${ }^{48}$. Age range of 1 month and 107 years were collected.

The presence of ambiguous nucleotides may potentially mask the genomic signature encoded within nucleotide frequencies. Although sequencing errors in the form of ambiguous nucleotides (e.g., strings of letter "N") were noticed in the datasets, the affected nucleotide positions were ignored during preprocessing, such that the nucleotide positions maintained their current position and did not shift. A total genome sequence size of $(8864 \times 29000-8864 \times 30165)$ bps $=$ $(257,056,000-267,382,560)$ bps was excavated, processed, and stored in comma separated value $(\mathrm{CSV})$ file.

Table 1. Distribution of excavated isolates

\begin{tabular}{|c|c|c|c|c|}
\hline Continent & Country & Male & Female & Total \\
\hline Africa & $\begin{array}{l}\text { Algeria (3), Cameroon (1), DRC (8), Egypt (35), Gambia } \\
\text { (13), Ghana (15), Madagascar (3), Morocco (6), Mozambique } \\
\text { (7), Nigeria (18), Rwanda (27), Senegal (135), South Africa } \\
\text { (1507), Tunisia (26) }\end{array}$ & 701 & 1103 & 1804 \\
\hline Europe & $\begin{array}{l}\text { Andorra (1), Austria (18), Belgium (11), Bosnia and } \\
\text { Herzegovina (4), Bulgaria (1), Croatia (15), Cyprus (8), } \\
\text { Czech Republic (173), Denmark (3), Faroe Islands (14), } \\
\text { Finland (2), France (131), Georgia (4), Germany (12), Greece } \\
\text { (30), Hungary (80), Italy (561), Moldova (3), Norway (1), } \\
\text { Poland (7), Portugal (2), Romania (52), Russia (125), }\end{array}$ & 802 & 743 & 1545 \\
\hline
\end{tabular}




\begin{tabular}{|c|c|c|c|c|}
\hline Continent & Country & Male & Female & Total \\
\hline & $\begin{array}{l}\text { Slovakia (4), Spain (256), Sweden (3), Switzerland (2), } \\
\text { Ukraine (13). }\end{array}$ & & & \\
\hline Asia & $\begin{array}{l}\text { Bahrain (1), Bangladesh (29), Cambodia (1), China (319), } \\
\text { India (1598), Indonesia (91), Iran (11), Iraq (2), Israel (38), } \\
\text { Kazakhstan (24), Kuwait (3), Lebanon (18), Malaysia (89), } \\
\text { Mongolia (6), Myanmar (1), Nepal (1), Oman (58), Pakistan } \\
\text { (4), Philippines (12), Saudi Arabia (500), Singapore (540), } \\
\text { South Korea (18), Sri Lanka (29), Taiwan (64), Thailand (2), } \\
\text { Turkey (134), United Arab Emirates (111), Vietnam (74). }\end{array}$ & 2618 & 1160 & 3778 \\
\hline South America & $\begin{array}{l}\text { Argentina (2), Brazil (519), Chile (1), Colombia (186), } \\
\text { Ecuador (28), Peru (2), Venezuela (3). }\end{array}$ & 394 & 347 & 741 \\
\hline North America & $\begin{array}{l}\text { Canada (27), Costa Rica (58), Dominican Republic (6), } \\
\text { Guadeloupe (17), Mexico (110), Panama (253), Saint Martin } \\
\text { (8), USA (499). }\end{array}$ & 603 & 375 & 978 \\
\hline \multirow[t]{2}{*}{ Oceania } & Guam (2), New Zealand (2), Australia (14). & 12 & 6 & 18 \\
\hline & $\begin{array}{l}\text { Total: Number of countries excavated per continent: Africa } \\
\text { (14), Europe (28), Asia (28), South America (7), North } \\
\text { America (8), Oceana (3). }\end{array}$ & 5130 & 3734 & 8864 \\
\hline
\end{tabular}




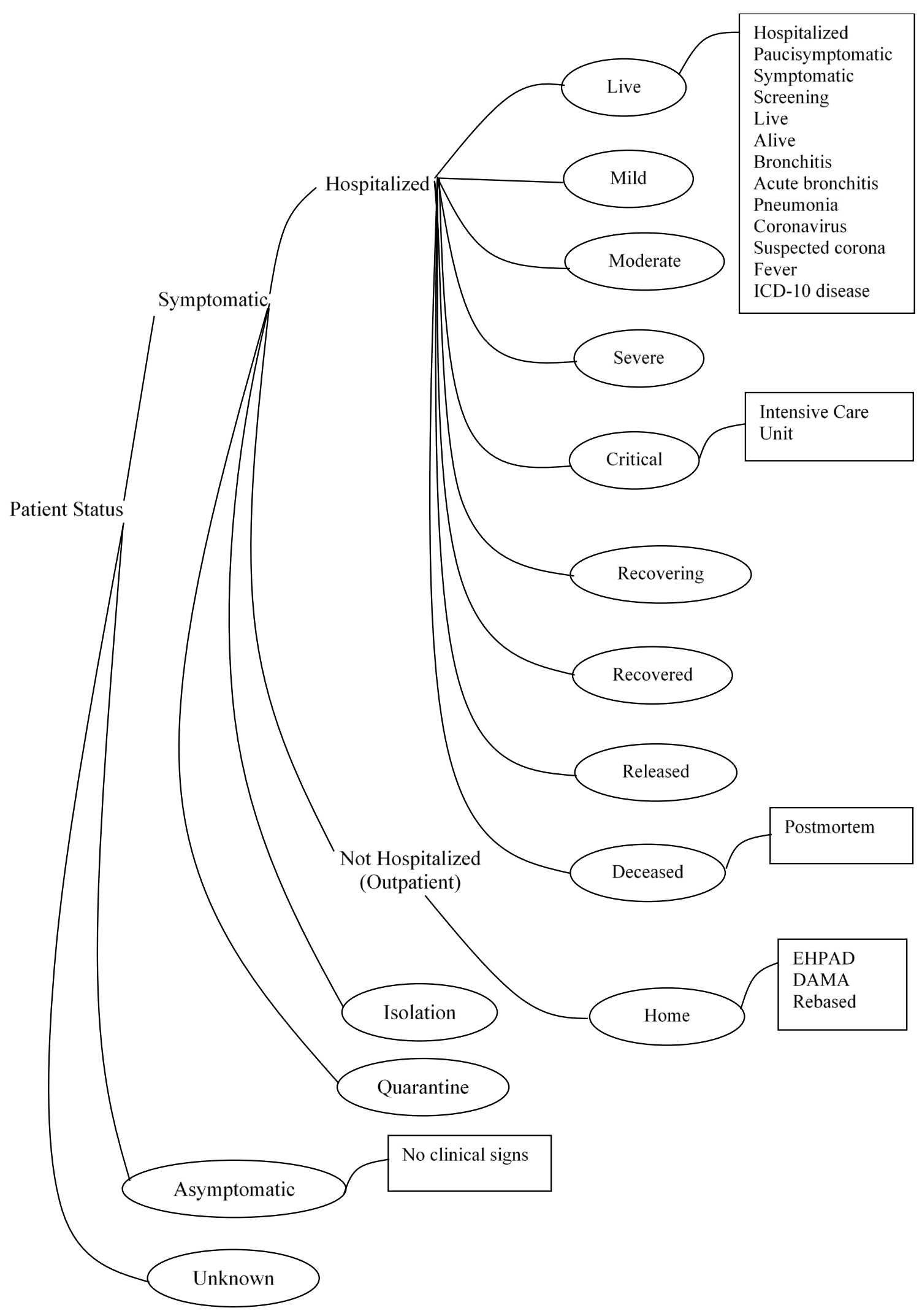

Fig. 1. Reclassified GISAID COVID-19 patient status taxonomy 
Table 2 documents patient status statistics for symptomatic and asymptomatic cases. As observed, there are more hospitalized cases (7580) compared to non-hospitalized cases (391), with more male patients, hospitalized $(\mathrm{M}=4318, \mathrm{~F}=3262)$. Furthermore, more males died of COVID-19 than females $(M=541, \mathrm{~F}=248)$. Asymptomatic cases however represent $(37 / 5130$; $0.72 \%)$ and $(41 / 3734 ; 1.10 \%)$ of the total male and female isolates, respectively.

Table 2. Symptomatic and asymptomatic statistics

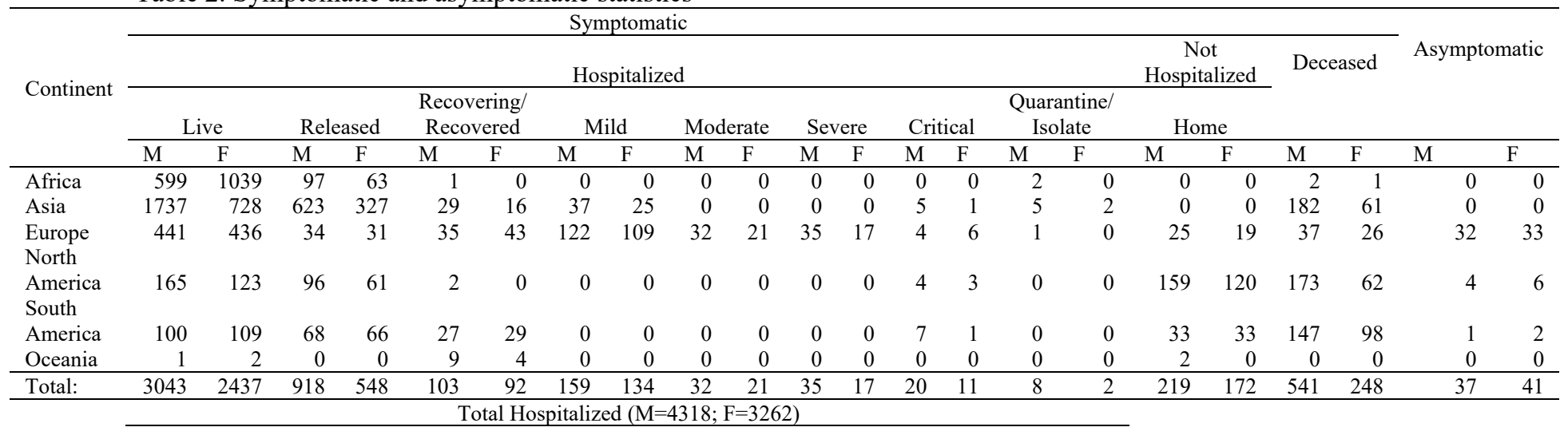

\section{Configuration of Computing Device}

A HP laptop 15-bs1xx with up to 1TB storage running on Windows 10 Pro Version 10.018326 Build 18362 was used for processing the excavated genome sequences, algorithms/programs, and other ancillary data. The system had an installed memory (RAM) of 16 GB with the following processor configuration: $1.60 \mathrm{GHz}, 1801 \mathrm{MHz}, 4 \mathrm{Core}(\mathrm{s})$ and 8 logical processors. Although our system performed satisfactorily and produced the desired results, higher system configurations would improve the computational speedup.

\section{Hierarchical Agglomerative Clustering (HAC)}

The dataset is configured with observations (nucleotides) represented in rows, while columns are variables (genome sequences ordered by countries). The number of columns corresponds to selected countries while the sequences have varying lengths. The data table is further converted into as.matrix format where all values of raster layers objects have columns for each layer and rows for each cells with numeric (continuous) values. In order to make the variables comparable through the elimination of arbitrary variable units, they are transformed (standardized) such that they have mean of zero and standard deviation of unity ${ }^{49}$, using equation (1).

$$
x(s)=x_{i}-\frac{\operatorname{mean}(x)}{s d(x)}
$$

where $s d(x)$ represents the standard deviation of the feature values.

The procedure for implementing the HAC are as follows: Compute all the pairwise similarities (distances) between observations in the dataset and represent the result as a matrix. The resultant matrix is square and symmetric with diagonal members defined as unity-the measure of similarity between an element and itself. The matrix elements are computed by iterating over each element and calculating its (dis)similarity to every other element. Suppose $A$ is a similarity matrix of size $N \times N$, and $B$, a set of $N$ elements. $A_{i j}$ is the similarity between elements $B_{i}$ and $B_{j}$ using a specified criterion (Euclidean distance, squared Euclidean distance, manhattan distance, maximum distance, Mahalanobis distance, cosine similarity). The selected 
criterion however depends on the nature of the experimental datasets. This paper adopts the standardized Euclidian distance criterion, as this measure is widely used and has shown good performance in the modeling variances in biological sequences.

\section{HAC Visualization}

After computing the distance between every pair of observation point, the result is stored in a distance matrix. Then, (i) every point is put in its own cluster (i.e., the initial number of clusters corresponds to the number of variables); (ii) the closest pairs of points are merged based on the distances from the distance matrix as the number of clusters reduces by 1 ; (iii) the distance between the new cluster and the previous ones is recomputed and stored in a new distance matrix; (iv) steps (ii) and (iii) are repeated until all the clusters are merged into one single cluster.

The distance separating the clusters is specified via linkage methods ${ }^{48}$ which includes, complete, average, single, and ward. Complete linkage computes the similarities and uses the maximum distance between clusters for merging while calculating cluster distances and adopting minimum inter-cluster distance merging. Average linkage calculates the average distance between groups of genome sequence before merging; while the total within-cluster variance is minimized with ward's method and the pair of clusters with minimum between-cluster distance are merged. We rely on all the four techniques for assessment and adopt the distance measure with the highest agglomerative coefficient for cluster formation. The resultant cluster solution is finally visualized as a tree structure called a dendrogram (or phylogenetic) tree. As the tree is traversed upwards, observations that are similar to each other are combined into branches, which are themselves fused at a higher height. The height of the fusion, provided on the vertical axis, indicates the (dis)similarity between two observations. The higher the height of the fusion, the less similar the observations are. Fig. 2. show cluster plots and genomic plots generated using the ward minimum variance criterion.

\section{Optimal Natural Clusters Selection}

While there are natural structural entities in some datasets that provide information on the number of clusters or classes, others including the dataset containing genome sequences are structured without boundaries. Cluster validation (an unsupervised methodology aimed at unravelling the actual count of clusters that best describes a dataset without any priori class knowledge) is therefore essential. This paper adopts three widely used criteria to validate the number of clusters in the genome sequence dataset namely, silhouette, elbow ${ }^{50}$, and gap-statistics with the aim of minimizing the total intra-cluster variation (total within-cluster sum of square) as given in equation (2).

$$
\operatorname{minimize}\left(\sum_{i=1}^{k} w\left(c_{k}\right)\right)
$$

where $c_{k}$ is the kth cluster, and, $w\left(c_{k}\right)$ is the within-cluster variation. The total within-cluster sum of squares (wss) measures the compactness of the clustering solution. The following steps are applied to achieve the optimal clusters: (i) Compute clustering algorithm (e.g., k-means clustering) for different values of $k$; by varying $k$ from 1 to 10 clusters, for instance. (ii) For each $k$, calculate wss. (iii) plot the curve of wss according to the number of clusters $k$. (iv) the location of a bend (knee) in the plot is generally considered as an indicator of the appropriate number of clusters.

Silhouette criterion is used to validate the clustering solution using pair-wise difference between the within-cluster distances, and by maximizing the value of this index to arrive at the optimal cluster number ${ }^{51}$. Elbow criterion plots the variance resulting from plotting the explained 
variation as a function of the number of clusters and picking the elbow of the curve as the number of clusters to use. Gap-statistics compares the total intra-cluster variation for different values of $k$ with their expected values under null reference distribution of the data. The reference dataset is generated using Monte Carlo simulations of the sampling process. The silhouette, elbow and gap-statistics methods rely on k-mean algorithm ${ }^{52}$. In this paper, the k-means algorithm is implemented in $\mathrm{R}$ script consisting of $\mathrm{R}$ functions for the silhouette, elbow, and gapstatistics implementation. The decision on the choice of the optimal number of clusters is based on the results of the three methods. The clustering solution is visualized using the fviz_cluster function in R programming language for the grouping and extraction of genome sequences and finally represented in tree format using dendrogram.

\section{Genome Features Extraction}

Dinucleotide Transition Frequency: The SARS-CoV-2 reference genome ${ }^{53}$ (Severe acute respiratory syndrome coronavirus- 2 isolate Wuhan-Hu-1, complete genome) obtained from the NCBI: www.ncbi.nlm.nih.gov) contains 4 conventional DNA nucleotide bases, A, C, G, T. Hence, there are $4^{2}=16$ unique dinucleotide pairs that can be constructed from these bases, namely:

$$
\omega=\{\mathrm{AA}, \mathrm{AC}, \mathrm{AG}, \mathrm{AT}, \mathrm{CA}, \mathrm{CC}, \mathrm{CG}, \mathrm{CT}, \mathrm{GA}, \mathrm{GC}, \mathrm{GG}, \mathrm{GT}, \mathrm{TA}, \mathrm{TC}, \mathrm{TG}, \mathrm{TT}\}
$$

If we denote the frequency of the ith dinucleotide as $d_{i}$, then, a genomic sequence with 16dimensional feature vector in the form of equation (5) are possible,

$$
f_{\omega}=\left\{\mathrm{d}_{\mathrm{AA}}, \mathrm{d}_{\mathrm{AC}}, \mathrm{d}_{\mathrm{AG}}, \ldots, \mathrm{d}_{\mathrm{TT}}\right\}
$$

The frequencies of the dinucleotide transitions are obtained by accumulating each dinucleotide along the extracted genome sequences. We ignore ambiguous nucleotides absent in the reference genome. Suppose we have $n$ total genome length. By allowing a single sliding iteration window there exists $n-1$ bubble counts. Hence, the dinucleotide frequencies of $d_{i}$ can be obtained by counting all nucleotides that correspond to $i$.

Nucleotide Mutation Frequency: Several techniques for biological sequence alignment (multiple or pairwise) have flourished the literature ${ }^{54}$ and are continually being refined, but most of these techniques suffer from the lack of accuracy and partial interpretations. A direct pairwise alignment of each nucleotide with the reference genome was achieved by computing the recurrence of mutated nucleotides down the sequence line. For this study, the sequence of established SARS-CoV-2 reference genome (NC_045512; 29903 bp) sequenced in December 2019 was used. Suppose $n$ represents the total length of a genome; By permitting a single sliding iteration window, a mutation may be any of the following pair:

$$
\mathrm{m}=\{\mathrm{AC}, \mathrm{AG}, \mathrm{AT}, \mathrm{CA}, \mathrm{CG}, \mathrm{CT}, \mathrm{GA}, \mathrm{GC}, \mathrm{GT}, \mathrm{TA}, \mathrm{TC}, \mathrm{TG}\}
$$

If we denote the frequency of the ith nucleotide pair as $p_{i}$, then, genomic sequence pairs with 12dimensional feature vector in the form of equation (9) are possible,

$$
\mathrm{f}_{\mathrm{m}}=\left\{\mathrm{p}_{\mathrm{AC}}, \mathrm{p}_{\mathrm{AG}}, \mathrm{p}_{\mathrm{AT}}, \ldots, \mathrm{p}_{\mathrm{TG}}\right\}
$$

\section{Unsupervised Genome Clustering}

Several mathematical techniques have been deployed for identifying underlying patterns in complex data. These techniques, which cluster data points differently in multidimensional space are important to discover fundamental patterns of gene expression inherent in data. The clustering technique adopted in this paper is the self-organizing map (SOM) and has been used 
extensively in the field of bioinformatics, for visual inspection of biological processes, genes pattern expressions-as maps of (input) component planes analysis. SOM is a neural-network that projects data into a low-dimensional space ${ }^{55}$, by accepting a set of input data and then mapping the data onto neurons of a 2D grid (see Fig. 3). The SOM algorithm locates a winning neuron, its adjusting weights, and neighboring neurons. Using an unsupervised, competitive learning process, SOMs produce a low-dimensional, discretized representation of the input space of training samples, known as the feature map. During training, weights of the winning neuron and neurons in a predefined neighborhood are adjusted towards the input vector using equation (3),

$$
w_{i d}^{t+1}=w_{i d}^{t}+r f(i, q)\left(x_{d}-w_{i d}^{t}\right) ; 1 \leq d \leq D .
$$

where $r$ is the learning rate and $f(i, q)$ is the neighborhood function, with value 1 at the winning neuron $q$; and decreases as the distance between $i$ and $q$ increases. At the end, the principal features of the input data are retained, hence, making SOM a dimension reduction technique. The batch unsupervised weight/bias algorithm of MATLAB (trainbu) with mean squared error (MSE) performance evaluation, was adopted to drive the proposed SOM. This algorithm trains a network with weight and bias learning rules using batch updates. The training was carried out in two phases: a rough training with large (initial) neighborhood radius and large (initial) learning rate, followed by a finetuned training phase with smaller radius and learning rate. The rough training phase can span any number of iterations depending on the capacity of the processing device. In this paper, we kept the number of iterations at 200 with initial and final neighborhood radius of 5 and 2, respectively, in addition to a learning rate in the range of 0.5 and 0.1 . The fine training phase also had a maximum of 200 epochs, and a fixed learning rate of 0.2. Selection of best centroids of the genome feature within each cluster was based on the Euclidean distance criterion. The algorithm configures output vectors into a topological presentation of the original multi-dimensional data, producing a SOM in which individuals with similar features are mapped to the same map unit or nearby units, thereby creating smooth transition of related genome sequences to unrelated genome sequences over the entire map.

Pattern Correlates Generation: Comparing component planes help detect similar patterns in identical positions indicating correlation between the respective components. Local correlations can also occur if two parameter planes are similar in some regions. Both linear and non-linear correlations including local or partial correlations between variables are possible. We achieve the correlation hunting ${ }^{56}$ automatically, by decoupling the SOM correlations, to explore patterns among the pairwise genome samples for distinct identification of transmission pathways or routes. The extracted correlation matrices are pairwise relations of the viral sub-strains' transmissions.

Cognitive Knowledge Extraction: Knowledge mining has served huge benefits for quick learning from big data. We apply Natural Language Processing of the genome datasets to extract knowledge of similar strains of the virus. A simple iteration technique is imposed on the SOM isolates $(i=1,2,3, \ldots, n)$, where $n$ is the maximum number of isolates, as follows: For each isolate pattern, compile similar patterns with the rest of the isolates (i.e., $i+1, i+2, \ldots, n$ ). Concatenate compiled isolate(s) into a list $\left(j_{1}, j_{2}, \ldots, j_{m}\right)$ where $j$ is an element of the list. Dump the compiled list into $\operatorname{Cog} \operatorname{Map}\left(k_{i} \in j_{1}, j_{2}, \ldots, j_{m}\right)$.

Neural Network Design: Artificial Neural Networks (ANNs) are networks inspired by the neurological structure of the human brain. They are complex computer code written with simple, 
highly interconnected processing elements inspired by human biological brain structure for simulating the human brain and processing data/information models. Although five core ANN areas have been explored, namely: Multi-Layer Perceptron, Radial Basis Network, Recurrent Neural Networks, Generative Adversarial Networks, and Convolutional Neural Networks; this paper adopts the Multi-Layer Perceptron model (MLP)-a class of feedforward ANNs, with at least three layers of nodes: an input layer, a hidden layer, and an output layer (Fig. 4). Except for the input nodes, each node is a neuron that uses a nonlinear activation function. MLP utilizes a supervised learning technique called backpropagation ${ }^{57}$ for training. The output classes (C1-C7) were derived from the sub-strains discovered from learning the SOM.

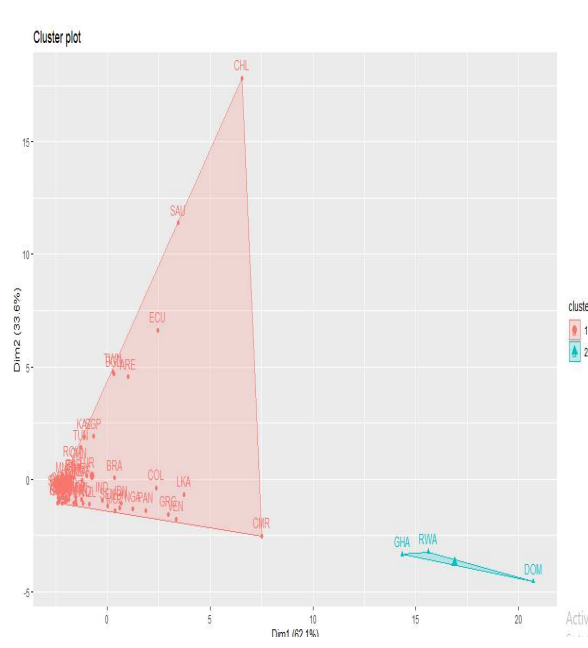

(a) Cluster plot-male

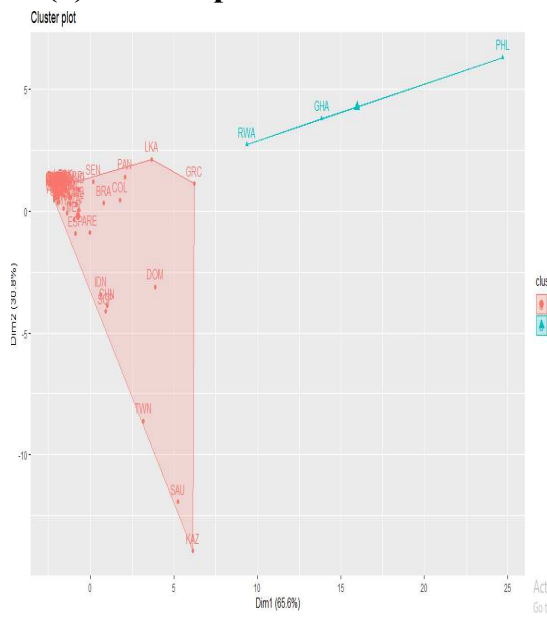

(c) Cluster plot-female

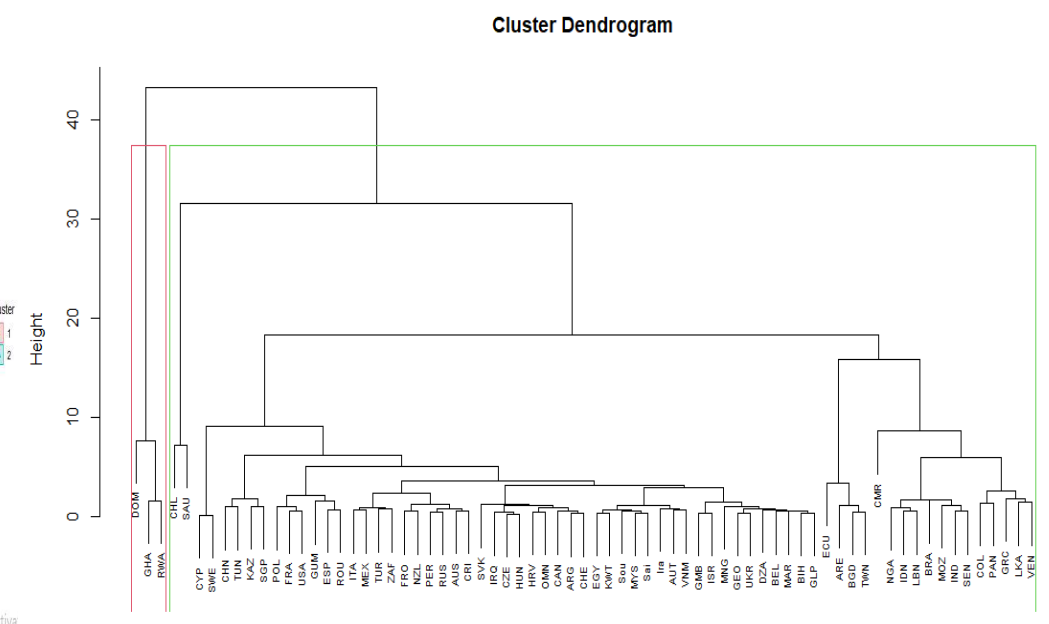

(b) Genomic tree-male

Cluster Dendrogram

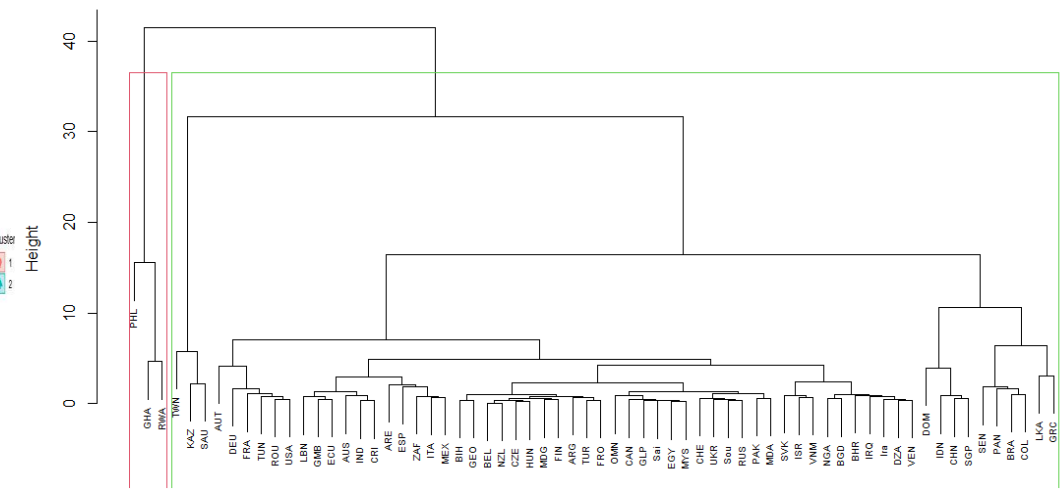

(d) Genomic tree-female

Fig 2. Cluster plots and genomic trees. Notice 2 distinct groups (or clusters) A and B separated between closely similar and dissimilar isolates, with the A group having heavy isolates concentration than the B group. For males (Fig. 2b), group A consists of 68 isolates with 7 sub-groups as follows: 1 (CHL, SAU); 2 (CHN, TUN, KAZ, SGP, POL, FRA, USA, GUM, ESP, ROU); 3 (ITA, MEX, TUR, ZAF, FRO, NZL, PER, RUS, AUS, CRI); 4 (SVK, IRQ, CZE, HUN, HRV, OMN, CAN, ARG, CHE, EGY, KWT, SOU, MYS, SAI, Iran, AUT, VNM, GMB, ISR, MNG, GEO, UKR, DZA, BEL, MAR, BIH, GLP); 5 (ECU, ARE, BGD, TWN); 6 (CMR, NGA, IDN, LBN, BRA, MOZ, IND, SEN, COL, PAN, GRC, LKA, VEN). Group B consists of 1 sub-group as follows: 1 (DOM, GHA, RWA). For Females (Fig. 2d), group A consists of 63 isolates with 6 sub-groups as follows: 1 (TWN, KAZ, SAU); 2 (AUT, DEU, FRA, TUN, ROU, USA); 3 (LBN, GMB, ECU, AUS, IND, CRI, ARE, ESP, ZAF, ITA, MEX); 4 (BIH, GEO, BEL, NZL, CZE, HUN, MDG, FIN, ARG, TUR, FRO, OMN, CAN, GLP, SAI, EGY, MYS, CHE, UKR, SOU, RUS, PAK, 
MDA, SVK, ISR, VNM, NGA, BGD, BHR, IRQ, Iran, DZA, VEN); 5 (DOM, IDN, CHN, SGP); 6 (SEN, PAN, BRA, COL, LKA, GRC).

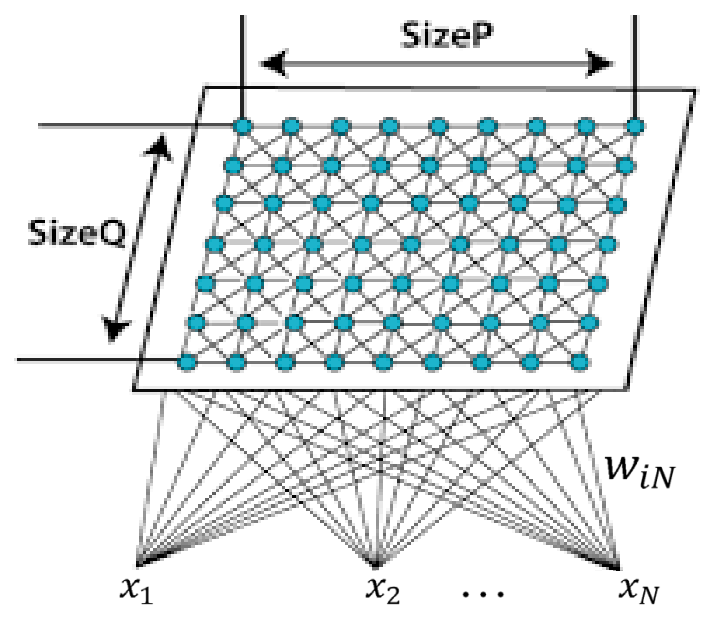

Fig. 3. SOM showing the map topology and interactions between nodes. Each neuron is assigned a vector of weights $\left(w=w_{i 1}, w_{i 2}, . . w_{i N}\right)$ with dimension similar to the input vector $i(i=1,2, \ldots, L)$; where $L$ is the total number of neurons in the network. The input nodes have $p$ features, and the output nodes, $q$ prototypes, with each prototype connected to all features. The weight vector of the connections consumes the prototype of each neuron and has same dimension as the input vector. SOMs differ from other artificial neural networks as they apply competitive learning, against error correction learning such as backpropagation, and the fact that they preserve the topological properties of the input space using a neighborhood function.

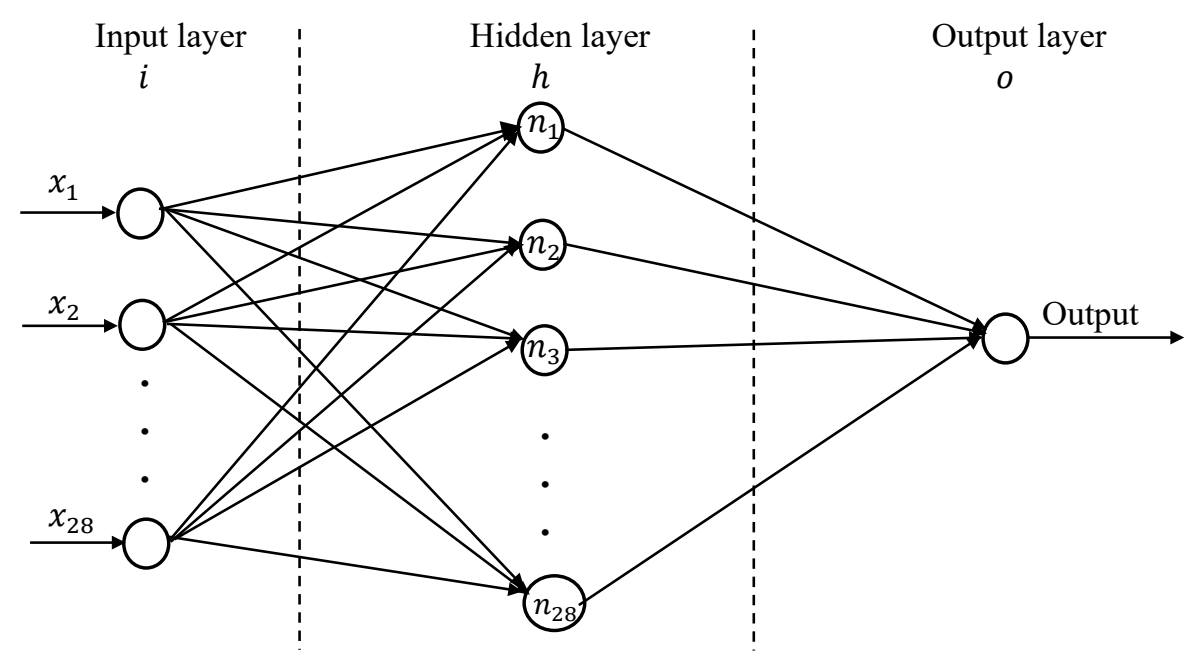

Fig. 4. ANN architecture. A 3-layered network, with one output layer and one hidden layer. The input layer consumes the knowledge-enriched genome datasets comprising of extracted patterns of SOM learning of the respective genome isolates and additional knowledge sieved from analysis of the genome sequences (i.e., number of natural clusters discovered from the genomic tree, discovered SOM sub-strain clusters, and link sequences derived from cognitive maps of the various isolates) 


\section{References}

48. Edoho, M. E., Ekpenyong, M. E., Momodu, A. B., \& Joseph, G. Mining the Human Metabolome for Precision Oncology Research. In Proceedings of the 4th International Conference on Medical and Health Informatics, 8-17. (2020).

https://dl.acm.org/doi/10.1145/3418094.3418123

49. Inyang, U. G., Eyoh, I. J., Robinson, S. A., \& Udo, E. N. Visual Association Analytics Approach to Predictive Modelling of Students' Academic Performance. International Journal of Modern Education \& Computer Science, 11(12), 1-13. (2019). https://doi.org/10.5815/ijmecs.2019.12.01

50. Inyang, U. G., Akpan, E. E., \& Akinyokun, O. C. A Hybrid Machine Learning Approach for Flood Risk Assessment and Classification. International Journal of Computational Intelligence and Applications, 19(2), 1-20. (2020). https://doi.org/10.1142/S1469026820500121

51. Inyang, U. G., \& Joshua, E. E. Fuzzy clustering of students' data repository for at-risks students' identification and monitoring. Computer and Information Science, 6(4), 37-50. (2013). https://doi.org/doi:10.5539/cis.v6n4p37

52. Ekpenyong, M. E., \& Inyang, U. G. Unsupervised mining of under-resourced speech corpora for tone features classification. In 2016 International Joint Conference on Neural Networks (IJCNN) (pp. 2374-2381). IEEE. (2016). https://doi.org/10.1109/IJCNN.2016.7727494

53. Wu, F., Zhao, S., Yu, B., Chen, Y. M., Wang, W., Song, Z. G., Hu, Y., Tao, Z. W., Tian, J. H., Pei, Y. Y. and Yuan, M. L. Severe acute respiratory syndrome coronavirus 2 isolate Wuhan-Hu-1, complete genome. Nature. 579 (7798): 265-269 (2020).

54. Abascal, F., Zardoya, R., \& Telford, M. J. TranslatorX: multiple alignment of nucleotide sequences guided by amino acid translations. Nucleic acids research, 38(suppl_2), W7-W13. (2010). https://doi.org/10.1093/nar/gkq291.

55. Kangas, J., Kohonen, T., \& Laaksonen, J. Variants of self-organizing maps. IEEE transactions on neural networks, 1(1), 93-99. (1990). https://doi.org/10.1109/72.80208.

56. Vesanto, J. and Ahola, J. Hunting for Correlations in Data Using the Self-Organizing Map. Proceeding of the International ICSC Congress on Computational Intelligence Methods and Applications, pp. 279-285. (1999). 


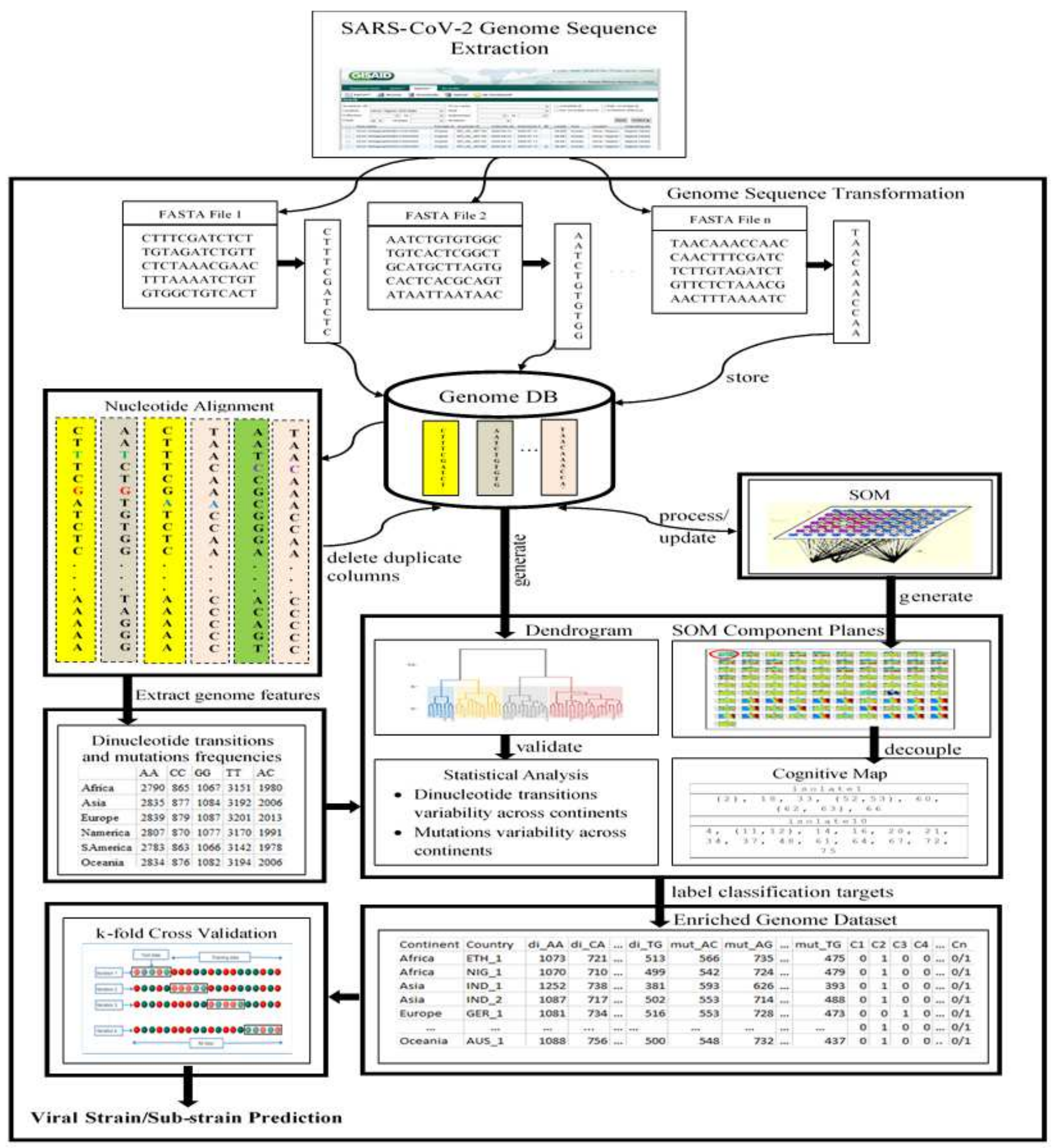

Figure 1

Workflow describing the proposed hybrid approach. The workflow begins with the excavation of FASTA files of human SARS-CoV-2 genome sequences from GISAID. These files were stripped and processed into a genome database (DB) as multiple columns of nucleotide sequence. Al/ML techniques were then 
applied to extract knowledge from the genome datasets as follows: Using ML techniques, compute dis(similarities) scores between the various pairs of genome sequences and obtain a genomic tree of highly dis(similar) isolates grouped in the form of a dendrogram/phylogenetic tree. Determine the optimal number of natural clusters-to provide additional knowledge for supervised learning. Separate the viral sub-strains using SOM component planes-for possible transmission pathway/pattern visualization. Perform nucleotide alignment of the entire genome sequences (owing to varying sequence lengths of the different genome isolates, a cutoff at the last nucleotide of the genome isolate or the reference genome serves as the maximum pair for comparison), remove duplicate columns while imposing a similarity threshold-to yield unique genome sequences. Extract genome features by computing dinucleotide transitions and mutation frequencies. Generate cognitive map-for intelligent sub-strains prediction. Label classification targets of extracted features using derived SOM clusters and cognitive map. Learn and predict new/emerging sub-strains using ANN with k-fold validation method. 


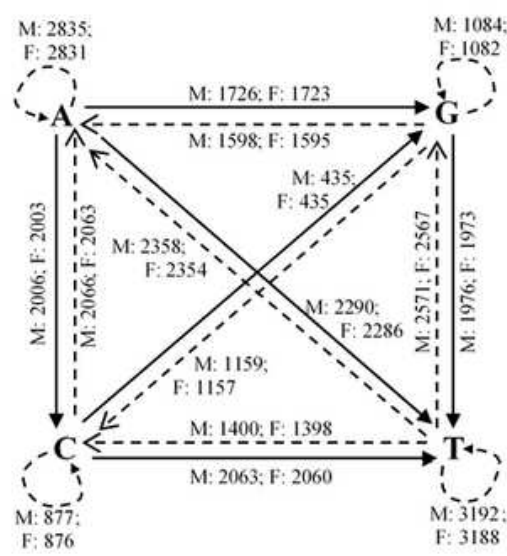

(a) African isolates

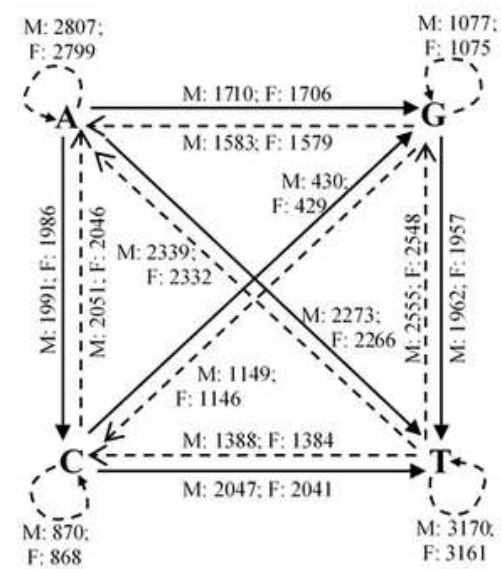

(c) European isolates

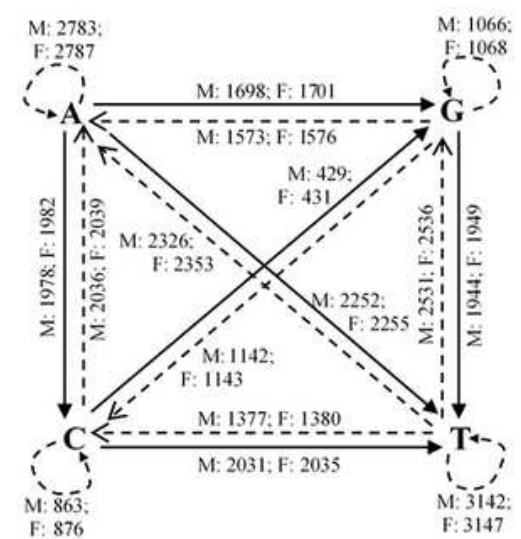

(e) South American isolates

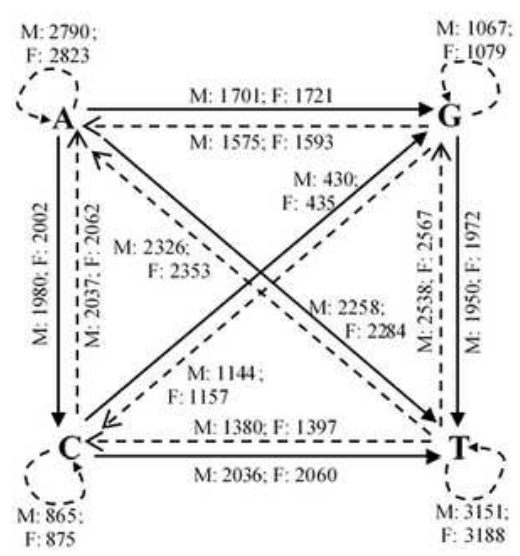

(b) Asian isolates

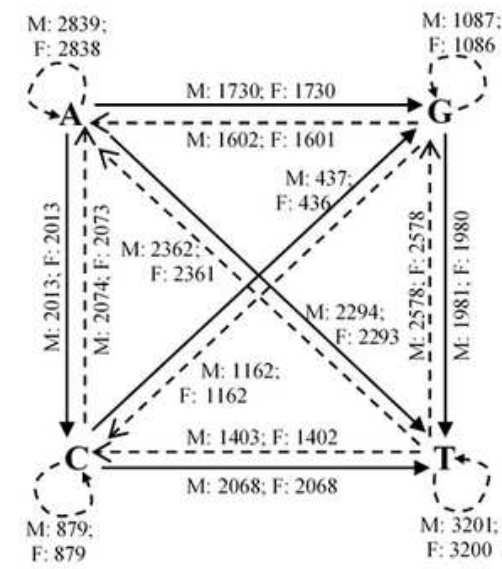

(d) North American isolates

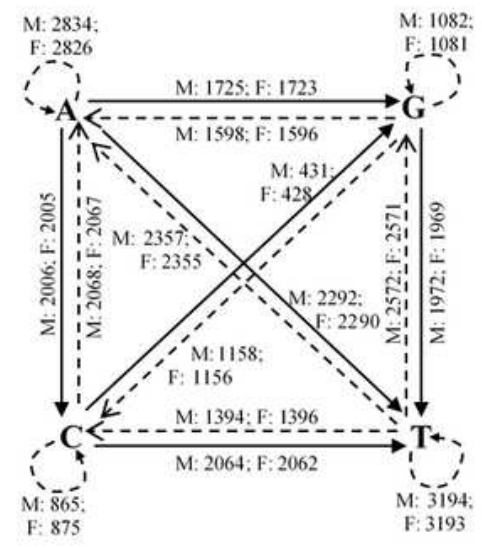

(f) Oceanian isolates

\section{Figure 2}

Base pair transitions in SARS-CoV-2 genomes for male and female isolates. Thick arrows indicate transition, while dotted arrows represent transversion. Looped (dotted) arrows represent same base transition. Inscriptions on/near the arrows represent transition/transversion frequencies for male and female isolates. 


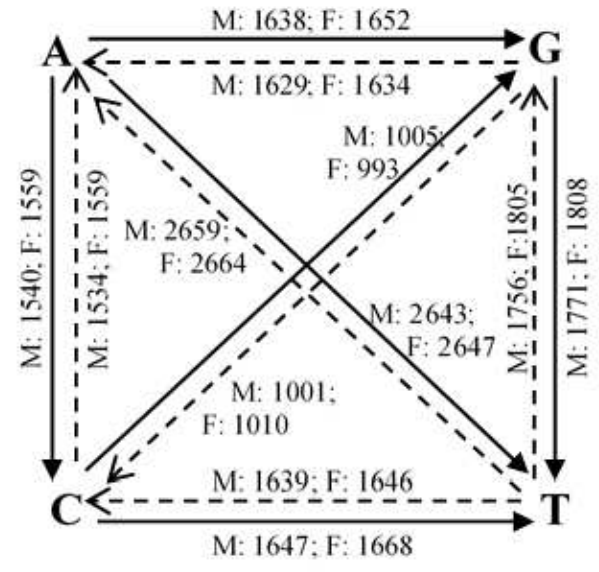

(a) Africa

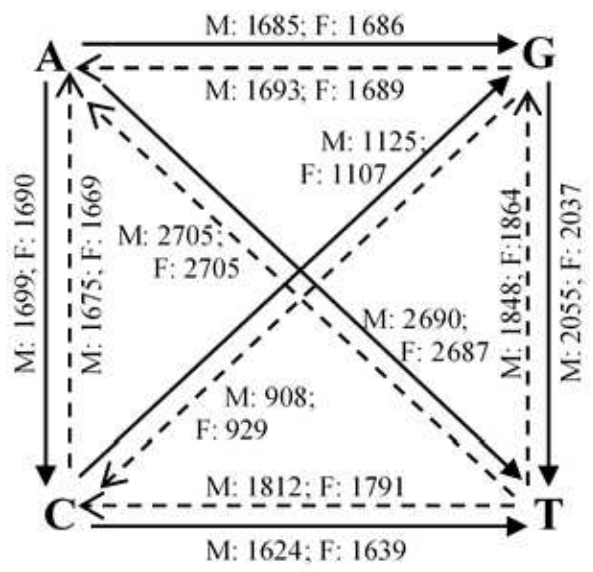

(c) Europe

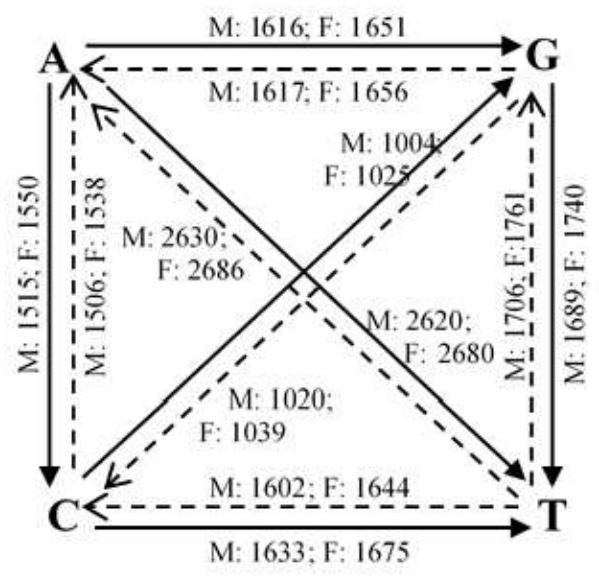

(e) South America

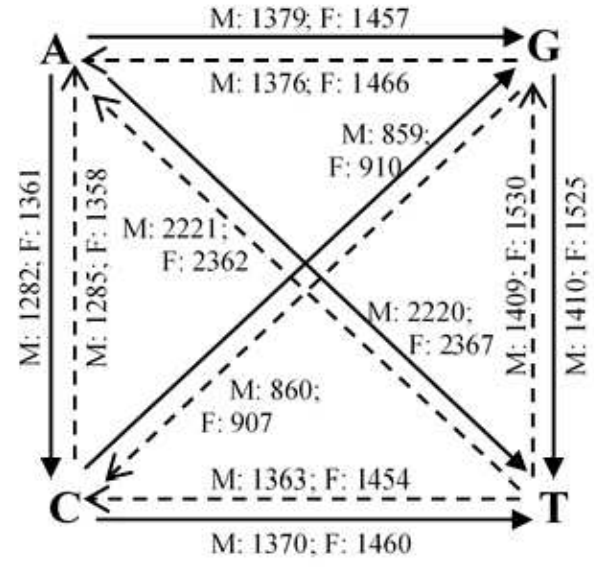

(b) Asia

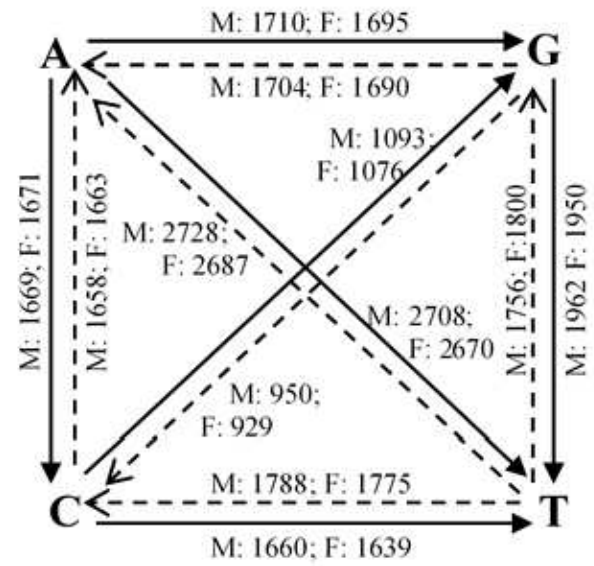

(d) North America

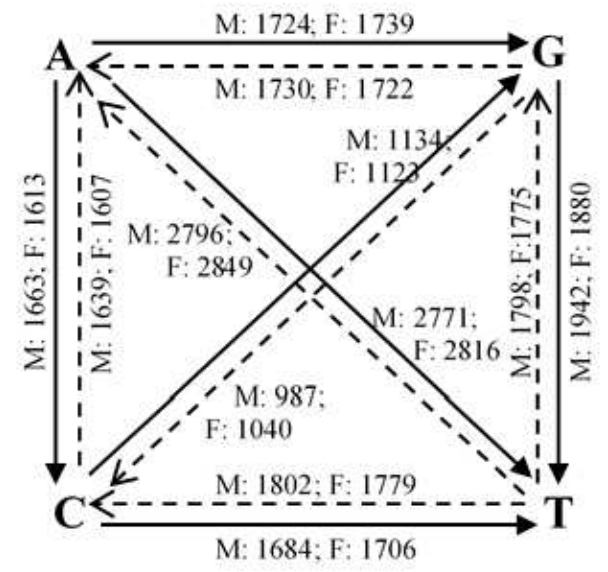

(f) Oceania

\section{Figure 3}

Base pair changes in SARS-CoV-2 genomes for male and female isolates. Thick arrows indicate transitions, while dotted arrows represent transversions. Inscriptions on/near the arrows represent transition frequencies for male and female isolates. 


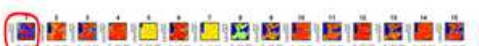

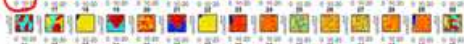

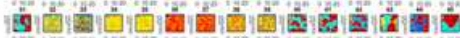

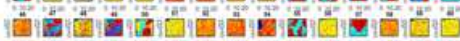

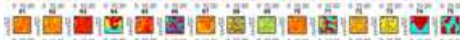

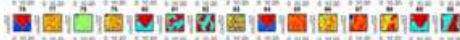

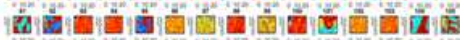

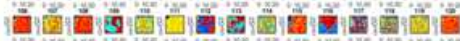

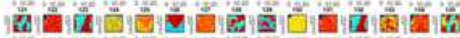

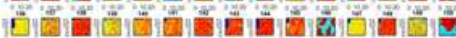

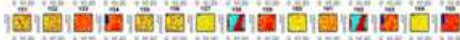
3

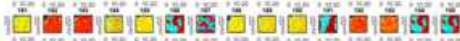
1ํㅜㅂำำ

(a) Male

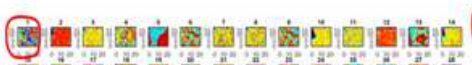

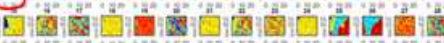

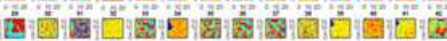

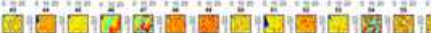

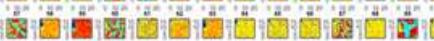

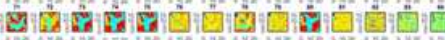

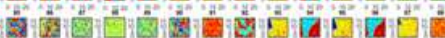

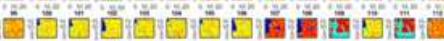

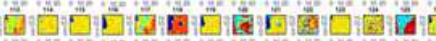

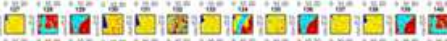

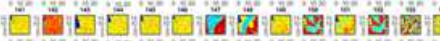

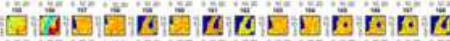

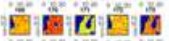

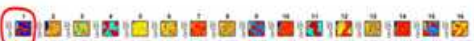

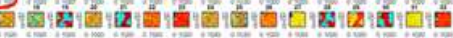

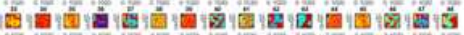

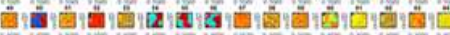

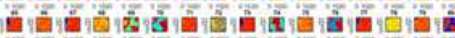

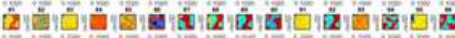

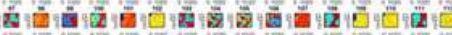

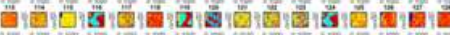

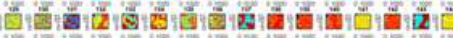

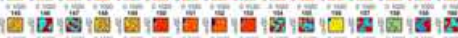

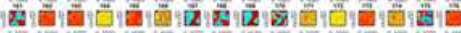

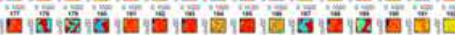

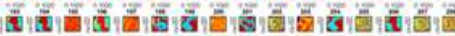

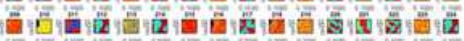

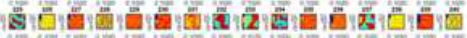

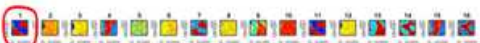

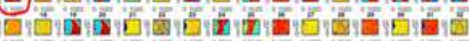

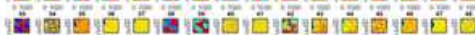

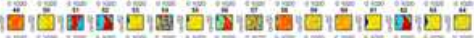

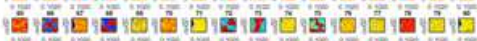

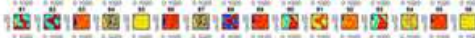

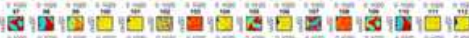

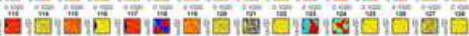

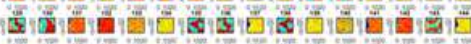

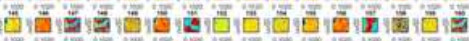

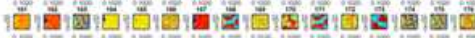

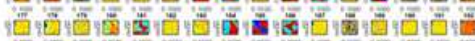

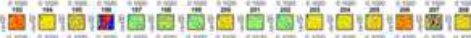

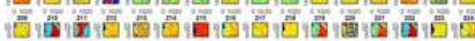

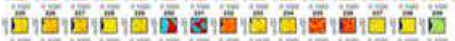

\section{Figure 4}

SOM component planes visualization for African isolates. Component planes 1 (encircled) represent the SARS-CoV-2 reference genome. The male and female isolates have 2 SOM maps each with country and (component plane map position(s)) distributed as follows: Male - (a) Map 1: Cameroon (2), Ghana (315), South Africa (16-200). Map 2: South Africa (2-63), Gambia (64-66), Algeria (67), Egypt (68-81), Tunisia (82-90), Morocco (91-92), Mozambique (93-96), Nigeria (97-107), Senegal (108-156), Rwanda (157-173). Female - (b) Map 1: Ghana (2), South Africa (3-240). Map 2: South Africa (2-186), Gambia (187), Algeria (188), Egypt (189-194), Tunisia (195-203), Madagascar (204), Nigeria (205-208), Senegal (209-237), Rwanda (238-239).

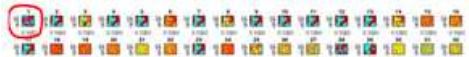

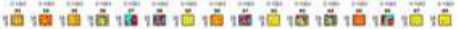

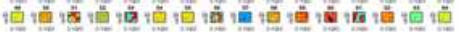

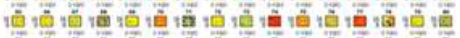

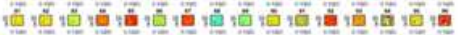

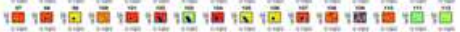

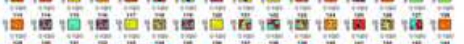

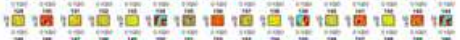

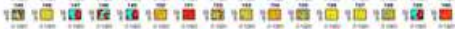

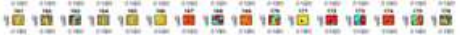

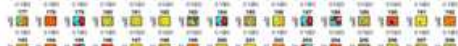

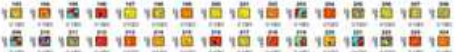

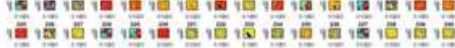

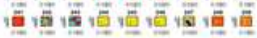

(a) Male

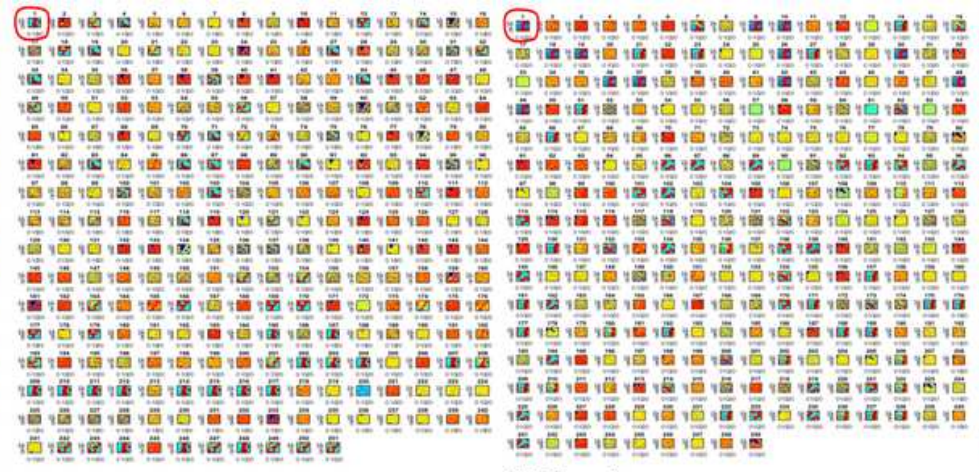

(b) Female

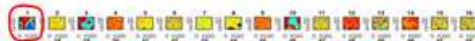

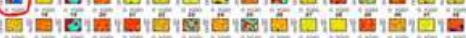

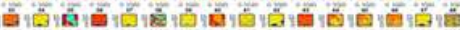

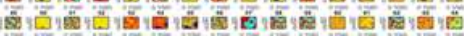

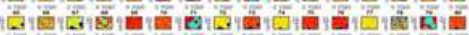

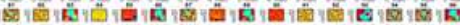

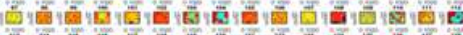

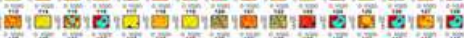

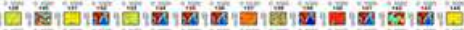

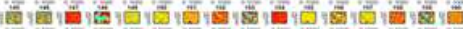

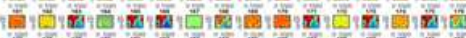
ง

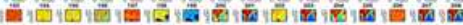

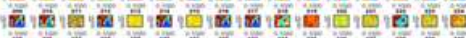

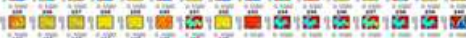

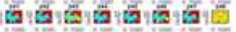

\section{Figure 5}

SOM component planes visualization for Asian isolates. Component planes 1 (encircled) represent the SARS-CoV-2 reference genome. The male and female isolates have 2 SOM maps each with country and (component plane map position(s)) distributed as follows: Male - (a) Map 1: Singapore (2-18), Iraq (19), China (20-71), Kuwait (72-74), Malaysia (75-94), Sri Lanka (95-109), Bangladesh (110-119), India (120249). Map 2: India (1-145), South Korea (146-149), Kazakhstan (150), Indonesia (151-164), Turkey (165180), Iran (181-184), Taiwan (185-191), Vietnam (192-200), Israel (201), Saudi Arabia (202-221), Mongolia (222-224), Oman (225-231), Lebanon (232-240), United Arab Emirates (241-251). Female - (b) Map 1: Singapore (205), Iraq (6), China )7-54), Malaysia (55-79), Sri Lanka (80-85), Bangladesh (86-90), India (91-249). Map 2: India (2-129), South Korea (130-131), Kazakhstan (132-136), Indonesia (137-149), 
Turkey (150-159), Iran (160-162), Taiwan (163-176), Vietnam (177-193), Israel (194-197), Philippines (198199), Saudi Arabia (200-217), Pakistan (218-219), Oman (220-227), Lebanon (228-233), United Arab Emirates (234-247), Bahrain (248).

\begin{abstract}
(7).

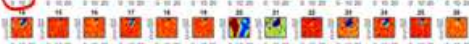

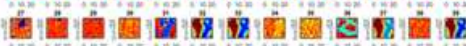

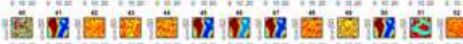

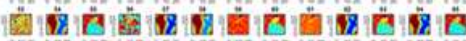

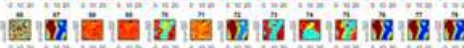

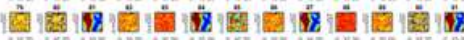

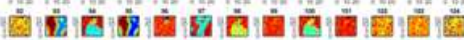

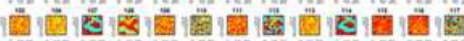

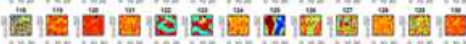

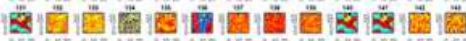

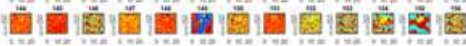

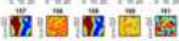

(a) Male

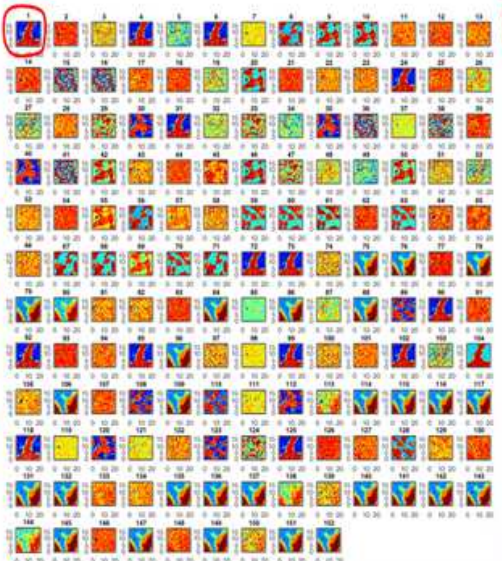

(b) Female

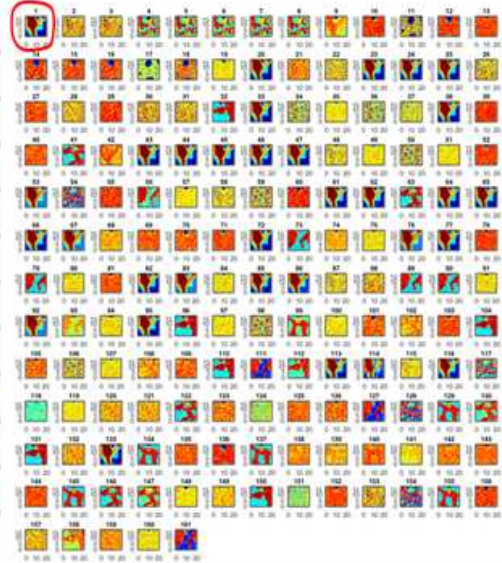

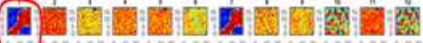

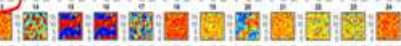

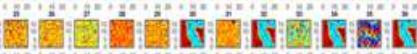

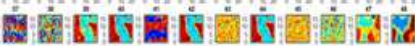

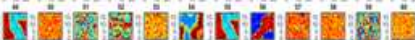

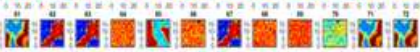 a vivi

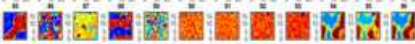

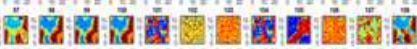

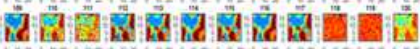

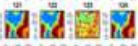

\section{Figure 6}

SOM component planes visualization for European isolates. Component planes 1 (encircled) represent the SARS-CoV-2 reference genome. The male and female isolates have 2 SOM maps each with country and (component plane map position(s)) distributed as follows: Male - (a) Map 1: Switzerland (2), Faroe Island (3-7), Belgium (8-9), Poland (10-23), Greece (14-29), Romania (30-43), Spain (44-102), Georgia (103-105), Italy (106-161). Map 2: Italy (2-59), Russia (60-73), France (74-112), Slovakia (113), Hungary (114-118), Cyprus (119), Ukraine (120-125), Sweden (126), Austria (127), Croatia (128-129), Bosnia and Herzegovina (130), Czech Republic (131-152). Female - (b) Map 1: Switzerland (2), Faroe Islands (3-6), Belgium (7-8), Greece (9-19), Germany (20-26), Romania (27-47), Spain (48-95), Georgia (96), Italy (97161). Map 2: Italy (2-28), Russia (29-55). France (56-87), Slovakia (88-90), Moldovia (91-93), Hungary (94100), Ukraine (101-104), Austria (105), Finland (106), Bosnia and Herzegovina (107), Czech Republic (107-123).

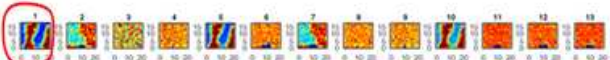

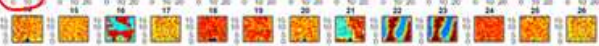

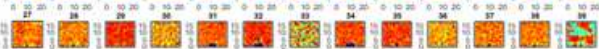

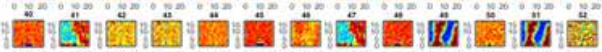

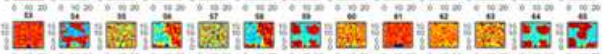

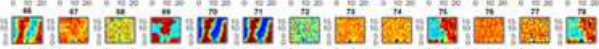

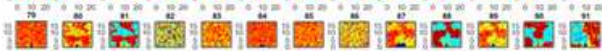

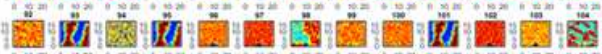

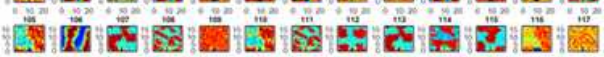
洞

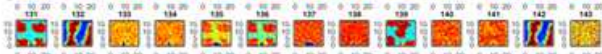

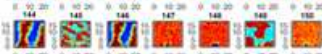

(a) Male

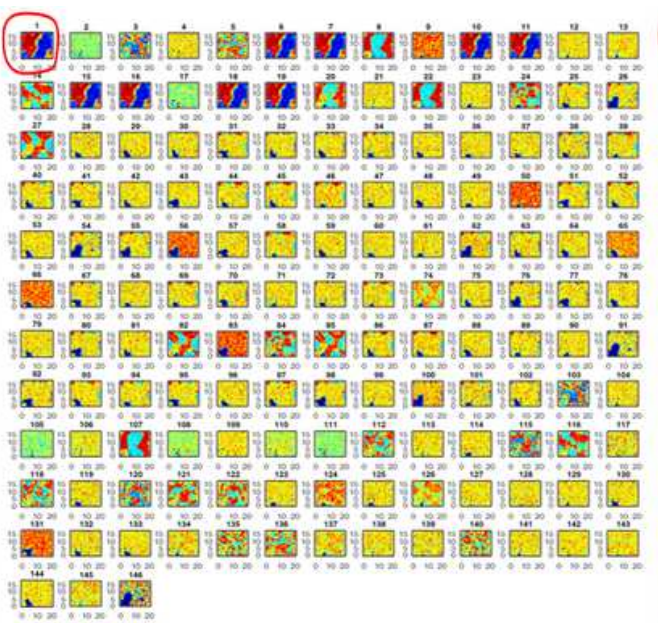

(4⿻)丨

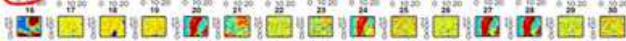

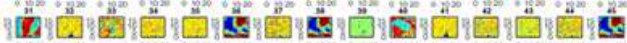

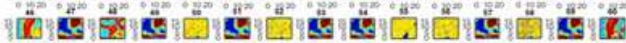

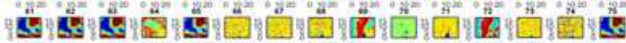

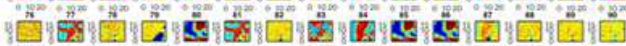

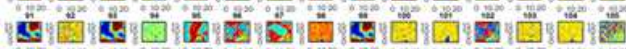
ง W

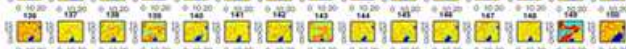

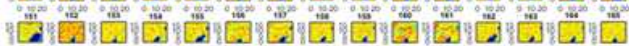

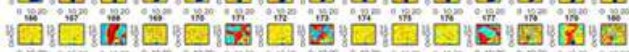

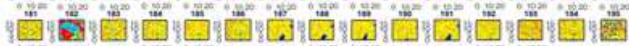
3ำ

(b) Female

Figure 7 
SOM component planes visualization for North American isolates. Component planes 1 (encircled) represent the SARS-CoV-2 reference genome. The male isolates have 2 SOM maps while the female isolates have 1 map, each with country and (component plane map position(s)) distributed as follows: Male - (a) Map 1: Mexico (2-46), USA (47-150). Map 2: USA (2-23), Panama (25-102), Saint Martin (103105), Guadeloupe (106-109), Canada (110-112), Costa Rica (113-145), Dominican Republic (146). Female - (b) Map 1: Mexico (2-34), USA (35-106), Panama (107-165), Saint Martin (166-168), Guadeloupe (169176), Canada (177-182), Costa Rica (183-196), Dominican Republic (197-200).

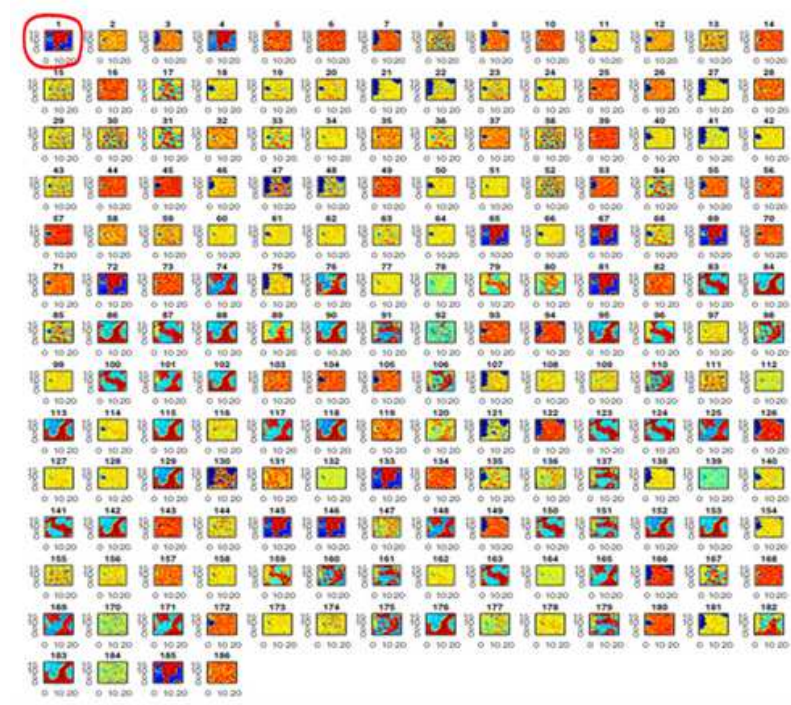

(a) Male

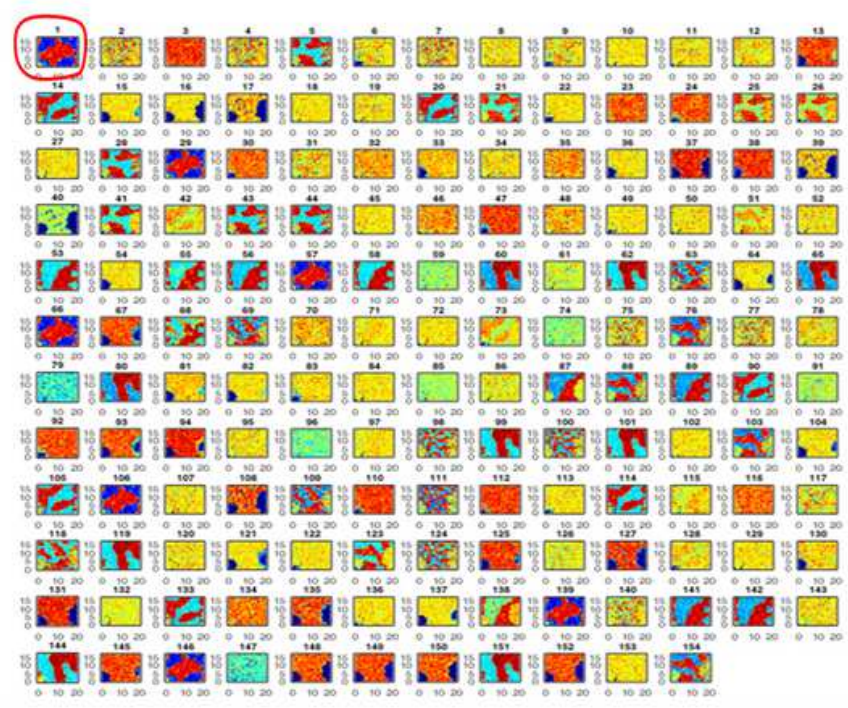

(b) Female

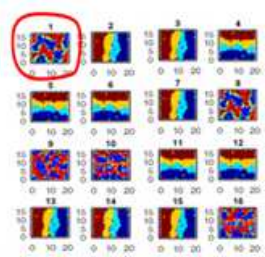

(c) Male and female

\section{Figure 8}

SOM component planes visualization for South American and Oceanian isolates. Component planes 1 (encircled) represent the SARS-CoV-2 reference genome. For South American isolates, the male isolates (a) and female isolates (b) have $1 \mathrm{SOM}$ map each. For Oceanian isolates, the male and female isolates (c) are condensed into 1 map, each with country and (component plane map position(s)) distributed as follows: Male - (a) Map 1: Venezuela (2-3), Chile (4), Argentina (5), Colombia (6-62), Ecuador (63-72), Peru (73), Brazil (74-186). Female - (b) Venezuela (2), Argentina (3), Colombia (4-47), Ecuador (48-50), Brazil (51-154). Male and female - (c) Map 1: Male - Australia (2-7), Guam (8-9), New Zealand (10). Female - Australia (11-15), New Zealand (16).

\section{Supplementary Files}

This is a list of supplementary files associated with this preprint. Click to download.

- SupplData1.xlsb

- SuppIData3.xlsb

- SupplData2.xIsx

- SuppIData4.xlsx 
- SupplData5.xlsx

- SuppIData6.xlsx

- SuppIData7.xlsx

- SuppIData8.xlsx

- ScientificReportSupplInfo.docx 